University of South Florida

DIGITAL COMMONS

Digital Commons @ University of

@ UNIVERSITY OF SOUTH FLORIDA

South Florida

USF Tampa Graduate Theses and Dissertations

USF Graduate Theses and Dissertations

$2-1-2010$

\title{
Refinement of a Chemistry Attitude Measure for College Students
}

Xiaoying Xu

University of South Florida

Follow this and additional works at: https://digitalcommons.usf.edu/etd

Part of the American Studies Commons

\section{Scholar Commons Citation}

Xu, Xiaoying, "Refinement of a Chemistry Attitude Measure for College Students" (2010). USF Tampa Graduate Theses and Dissertations.

https://digitalcommons.usf.edu/etd/1816

This Thesis is brought to you for free and open access by the USF Graduate Theses and Dissertations at Digital Commons @ University of South Florida. It has been accepted for inclusion in USF Tampa Graduate Theses and Dissertations by an authorized administrator of Digital Commons @ University of South Florida. For more information, please contact digitalcommons@usf.edu. 
Refinement of a Chemistry Attitude Measure for College Students

by

Xiaoying $\mathrm{Xu}$

A thesis submitted in partial fulfillment

of the requirements for the degree of

Master of Science

Department of Chemistry

College of Arts and Sciences

University of South Florida

Major Professor: Jennifer E. Lewis, Ph.D.

Xiao Li, Ph.D.

Robert F. Dedrick, Ph.D.

Santiago Sandi-Urena, Ph.D.

Date of Approval:

February 1, 2010

Keywords: scale development, reliability, validity, factor analysis, higher education

(C) Copyright 2010, Xiaoying Xu 


\section{Acknowledgements}

I would like to thank Dr. Lewis, my major advisor, for her support, guidance and encouragement during the study. Her enthusiastic, patient and persistent attitudes in chemical education program are extremely valuable to overcome possible difficulties. This project could not be done without her.

I need to thank my committee, Drs. Sheryl Li, Robert Dedrick and Santiago Sandi-Urena for their essential contribution in many ways. I also thank Drs. Kromrey and Ferron for conversation on data analysis. I am in gratitude to all group members, Alicia, Bo, Janelle, Karla, Keily, Sachel, Teresa and Ushiri for their friendship and academic advice. I appreciate the instrumental role the chemistry department office staffs, instructors, peerleaders, test proctors, lab TAs and students played, and the data services the scanning office provided. Special acknowledgement is for Dr. Rick Moog for helpful suggestions on the manuscript.

Finally I would like to acknowledge the steadfast love, inspiration and support from my family: Charley and Feng Cheng. 
Table of Contents

List of Tables $\quad$ iii

List of Figures $\quad$ vi

Abstract vii

Chapter One: Introduction $\quad 1$

Why Attitude? 3

Attitude Concept in Social Psychology 5

Attitude Concept in Science Education $\quad 9$

Attitude Concept in This Study 12

Chapter Two: Literature Review

Typical Attitude Measurement Scales 15

Quality Evaluation for Existing Science Attitude Instruments 16

Quality Evaluation for Existing Chemistry Attitude Instruments 21

Research questions $\quad 25$

Question $1 \quad 25$

Question 2

Question 3

Chapter Three: Methodological Background 26

Proposed Instrument Development Processes 26

Reliability $\quad 27$

$\begin{array}{ll}\text { Validity } & 29\end{array}$

Factor Analysis $\quad 35$

Sample Size $\quad 35$

EFA or PCA

EFA or CFA $\quad 37$

The Number of Factors $\quad 38$

$\begin{array}{ll}\text { Summary } & 39\end{array}$

Chapter Four: Method $\quad 40$

General Research Methods $\quad 40$

Instruments $\quad 40$

Participants and Data Collection 41

Data Analysis Strategy 42

Scale Reconstruction Based on ASCI V1 44

Validity Estimate for ASCI V2 Score 46 
Nomological Network among Attitude, Aptitude and Chemistry Achievement

Predictive Validity for ASCI V2 score $\quad 47$

Chi-Square Analysis for V3.1 Participants 48

Chapter Five: Quality Evaluation for Original ASCI (V1) 49

Results and Discussion $\quad 49$

Proposal for Possible Revisions of ASCI 55

$\begin{array}{ll}\text { Summary } & 57\end{array}$

Chapter Six: Quality Evaluation for Revised ASCI 58

Quality Evaluation for Revised ASCI V2, Peer-Led classes 58

Results and Discussion $\quad 58$

Nomological Network among Attitude, Aptitude and Chemistry Achievement 63 Results and Discussion 64

Predictive Validity to Predict Chemistry Achievement 65

Results and Discussion $\quad 66$

Evaluation of ASCI V3 for Chemistry Class at University MW 68

Results and Discussion $\quad 68$

Evaluation of ASCI V3.1 for Attitudes toward Calculus $\quad 72$

Results and Discussion $\quad 72$

Evaluation of ASCI V2 for Biochemistry Class $\quad 79$

Results and Discussion $\quad 79$

$\begin{array}{ll}\text { Summary } & 82\end{array}$

Chapter Seven: Summary and Concluding Discussion 83

Summary and Implication for Chemical Education $\quad 83$

Limitations of the Study and Recommendations for Future Research 85

$\begin{array}{ll}\text { References } & 87\end{array}$

Appendices $\quad 98$

Appendix A: Commonly Used Acronyms $\quad 99$

Appendix B: ASCI V1 100

Appendix C: ASCI V2 101

Appendix D: ASCI V3 102

Appendix E: ASCI V3.1 103 


\section{List of Tables}

Table 1.1.1 Definition of attitude-related concepts with possible items

Table 1.1.2 Definition of science attitude and related concepts with possible items

Table 2.1 Description of four typical attitude measurement scales

Table 2.2 Score for chemistry attitude instruments on JCE according to Blalock

Table 4.1 Summary of administrations for different versions of ASCI

Table 5.1 Descriptive statistics for ASCI V1, General Chemistry labs I and II

Table 5.2 Internal consistency and test-retest reliability for ASCI, General Chemistry labs

Table 5.3 The item loadings for V1, General Chemistry labs

Table 5.4.1 Subscale scores and Pearson correlations for V1

Table 5.4.2 Subscale scores and Pearson correlations by Bauer

Table 5.5 Fit statistics of V1 for four-factor CFA

Table 5.6 Factor correlation for V1 from CFA

Table 5.7 CFA results for Scale Reconstruction based on ASCI V1 56

Table 6.1 Descriptive statistics for ASCI V2, PL classes 59

Table 6.2 Subscale scores and Pearson correlations for V2, PL classes, $\quad 60$ along with I labs 
Table 6.3 Internal consistency for V2, PL classes, along with I Lab I and literature results

Table 6.4 The item loadings for V2, PL classes

Table 6.5 Fit statistics of V2 results for 1- and 2-factor CFA

Table 6.6 Descriptive analysis for attitude, aptitude score and final score on ACS

Table 6.7 Pearson correlation among attitude, aptitude and achievement

Table 6.8 Descriptive statistics for ASCI V3, MW chemistry

Table 6.9 Internal consistency for V3, MW chemistry

Table 6.10 The item loadings for V3 at MW and V2 from PL classes at SE

Table 6.11 Factor scores and Pearson correlations for V3, MW and PL

Table 6.12 Fit statistics of V3 at MW from two-factor CFA

Table 6.13 Descriptive statistics of ASCI V3.1 for calculus attitude

Table 6.14 Internal consistency by Cronbach's alpha for V3.1 calculus

Table 6.15 The item loadings for V3.1 Calculus sections

Table 6.16 Factor score for V3.1, calculus sections

Table 6.17 The frequency of most declared majors for students at each

Table 6.18 Fit statistics of V3.1 calculus results from two-factor CFA, along with MW

Table 6.19 Descriptive statistics of ASCI V2 for Biochemistry class

Table 6.20 Internal consistency for V2 in Biochemistry class 
Table 6.22 Factor score and Pearson correlations for PL and Biochemistry class

Table 6.23 Fit statistics of V2 results from two-factor CFA 


\section{List of Figures}

$\begin{array}{lll}\text { Figure 1.1 Conceptual framework for attitude } & 6\end{array}$

Figure 3.1 Instrument Development Processes 27

Figure 3.2 Internal consistency and unidimensionality 30

Figure 3.3 PCA and EFA Model 36

Figure $3.4 \quad$ EFA and CFA model $\quad 38$

Figure 4.1 Framework for Scale Development 45

Figure 6.1 Parameter estimate for one-factor and two-factor model 62 


\title{
Refinement of a Chemistry Attitude Measure for College Students
}

\author{
Xiaoying $\mathrm{Xu}$
}

\begin{abstract}
This work presents the evaluation and refinement of a chemistry attitude measure, Attitude toward the Subject of Chemistry Inventory (ASCI), for college students. The original 20-item and revised eight-item versions of ASCI (V1, V2, V3 and V3.1) were administered to different samples. The evaluation for ASCI had two main foci on the psychometric properties: reliability and validity. Both psychological theory and factor analysis techniques were applied to guide instrument refinement. Evidence for good reliability and validity was established for ASCI V2 score interpretation. The two-factor correlated structure was supported by confirmatory factor analysis. The two subscales, intellectual accessibility and emotional satisfaction, are indicators of cognition and affect components of attitude, and thus we can make good connection with tripartite attitude framework (cognition, affect and behavior) in psychology. As regards to attitudeachievement relationship, other than the well-known aptitude test score, students' attitude played a significant role in predicting final achievement in General Chemistry I course. This work represents the first time in the area of chemical education that a benchmark for scale development was successfully implemented to reconstruct an existing instrument. In addition to showcasing a method for examining validity, a second important result of
\end{abstract}


this work is to recommend refinements that lead to greater ease of administration while improving validity: this eight item instrument now takes very little time to administer. 


\section{Chapter One}

\section{Introduction}

Assessment is an essential component in education. Results from assessments serve diverse functions for diagnosis, placement, and prediction. Course teachers rely on diverse tests to obtain information of student's mastery of content and other contextual variables such as problem solving and creativity. Although assessment itself is not able to suggest proper instruction, it provides evidence for teachers to judge how effective or ineffective the teaching has worked to accomplish their expected course objectives. Nation-wide exams are mostly used for screening of large candidate pool. For example, most colleges use SAT or ACT scores for college admissions, and GRE scores for graduate admissions. The critical role of educational assessment has produced a burgeoning testing industry with a market growing from $\$ 7$ million in 1955 (adjusted to 1998 dollars) to $\$ 263$ million in 1997 , to somewhere between $\$ 400$ million to $\$ 700$ million in 2002 (WGBH Educational Foundation, 2002).

There has been a long and vigorous debate among education stakeholders in terms of how to interpret test scores and create education policy (Sedlacek, 2004). The debate has developed into a national concern since the implementation of the No-Child-Left-Behind (NCLB) Act in 2001. Under this influential education reform, all participating states and school districts receiving Title I funds are subject to biennial National Assessment of Educational Progress (NAEP) testing in reading and math for the $4^{\text {th }}$ and $8^{\text {th }}$ grades since 2003 and state testing. All schools need to make adequate yearly progress (AYP) so that 
all students can meet the proscribed proficient level by the 2013-2014 school year. Supporters of NCLB believe the mandated performance standards and emphasis on test scores can improve the quality of public education for all students. Critics focus on the limitations of the tests, potential misinterpretations of test scores, and the unintended consequences of a testing program. For example, is the NAEP measuring the most important aspects of the curriculum? Unfortunately, the love of learning and creativity is not included in the accountability system. Does the testing system motivate teachers to teach students only how to fill in exam bubbles or even to cheat? How does one match up individual state test to NAEP and performance standards? Is it meaningful to compare two groups of students to measure educational progress and AYP? Is it fair to label the schools that didn't meet annual progress in all items as "failures" and penalize them, regardless of the effort those schools have made to improve? Overall, does the testing program result in help for disadvantaged students? These issues, and others, are still debated so frequently in the political arena that it is hard to find a discussion of the relevant issues that moves beyond "sound bites."

While questions such as these will always be difficult to address, a better understanding of educational measurement theory can provide a more nuanced approach to discussions of education policy. The full assortment of measurement theories and practices is beyond the scope of this paper, but the basics are pertinent for all of us who teach chemistry and are aware of the need to improve STEM education outcomes at the national level. For the purpose of assessing both academic achievement and non-cognitive variables such as attitude, the first and most important thing is to find "good" assessments. This study will present one way to proceed with this task. 


\section{Why Attitude?}

The term "attitude" falls within the purview of "scientific literacy", which is a central goal of science education. Usually, scientific literacy focuses on the cognitive knowledge dimension, as highlighted by the proposition "the scientifically literate person accurately applies appropriate science concepts, principles, laws, and theories in interacting with his [sic] universe" (Rubba \& Anderson, 1978). However, many science educators emphasize that non-cognitive factors such as values and attitudes are important component of science literacy. According to the American Association for the Advancement of Science (AAAS, 1989), "spelling out the knowledge, skills, and attitudes all students should acquire as a consequence of their total school experience" is a requirement for a curriculum to be considered as promoting scientific literacy. AAAS places attitudes on an equal footing with knowledge and skills.

Appropriately, there have been many research studies investigating students' attitudes toward learning science (Custers \& Ten Cate, 2002; Dahle, Forsberg, Svanberg-Hard, Wyon, \& Hammar, 1997; Gouveiaoliveira, Rodrigues, \& Demelo, 1994; Hren et al., 2004;

Parke \& Coble, 1997). Educational practitioners have developed quality science curricula informed by attitude-related learning theories. Rather than indoctrination, great effort has been taken to develop various innovative programs, which put more emphasis on the problem solving, inquiry-based learning, hand-on activities and computer aided instruction (Ault, 1998; Freedman, 1997; Laws, Rosborough, \& Poodry, 1999; Ozmen, 2008; Paris, Yambor, \& Packard, 1998; Romance \& Vitale, 1992; Shymansky, Yore, \& Anderson, 2004; Steele, Medder, \& Turner, 2000). The ideal is a curriculum that supports both gains in content knowledge and positive attitudes toward science. 
While most practitioners are comfortable creating their own measures of content knowledge, and can recognize a "bad test" or a "bad question" if necessary, fewer are likely to have the necessary skills and comfort level to create and evaluate a measure of attitude. They may turn to existing instruments, and either use them directly or with slight adaptations to fit a particular course. Unfortunately, most existing studies of attitude fail to scrutinize the validity of the instruments they have chosen to use, which can raise questions about study results. Conflicting results, in particular, highlight the importance of using well-characterized instruments, so that the instrument itself can be ruled out as a major source of disagreement. For example, an examination of literature on attitude and chemistry achievement reveals conflicting results (Fowler, 1980; Gutwill, 1998; Lindsay, 2001; Pribyl, Adams, Hoganmiller, \& Stevens, 1991; Shibley, Milakofsky, Bender, \& Patterson, 2003; Turner \& Lindsay, 2003). While some claim a low correlation between attitude and achievement, others claim the two are strongly positively correlated. Is this disagreement an artifact of the way attitude was measured (differently in each case!), or a real difference stemming from the diverse contexts of the studies?

What if, as in the example above, there is no readily available high-quality instrument that has a long history of working well in the relevant context? With much science education research focused on the $\mathrm{K} 12$ environment, it is often difficult to find high quality instruments that are appropriate for use in the college science classroom. Creating a high quality instrument is a research project in itself, and one that many faculty would not be interested in undertaking. However, it is possible to take an existing instrument, test it in the desired setting, and quickly optimize it for use. This study seeks to offer an example of carefully modifying an existing attitude instrument to achieve better quality, 
while reviewing appropriate strategies for any instrument development process:

reliability, validity, factor analysis, and the alignment of any sub-scales with a theoretical framework. These issues must be addressed in deciding whether an assessment can be considered "good."

The remainder of this chapter will introduce the central concept of attitude in psychology and science education, and create a conceptual framework for this study.

\section{Attitude Concept in Social Psychology}

Attitude is one of the most important concepts in social psychology, dating back to the ancient philosophers (Zanna \& Rempel, 1988). Attitude has been extensively investigated the literature. From a behavioral view, attitude is defined as "mental and neural state of readiness to respond, organized through experience, exerting a directive and/or dynamic influence upon the individual's response to all objects and situations with which it is related" (Allport, 1935, p. 810). In other words, attitudes are considered as tendencies or predispositions to respond to certain stimuli, and the traditional tripartite model comprises three major types of responses: cognitive, affective, and behavioral as illustrated in Fig. 2.1 (Rosenberg \& Hovland, 1960, p. 3). Given a particular object about which an attitude exists, "cognition" refers to how people think about the object, i.e. knowledge and beliefs about properties of the object (including both favorable and unfavorable judgments). "Affect" pertains to how people feel about the object (both good and bad feelings), as expressed via physiological activity or overt communication. "Behavior" is overt actions with respect to the object as well as intentions to act (again, both positive and negative actions and intentions). The object of attitude can be something material, such as the game of baseball, or something abstract, such as romantic 
love. The research and application of attitude theory from this view highlights the responses to stimuli (such as punishments or rewards), and reinforcement of positive behaviors.

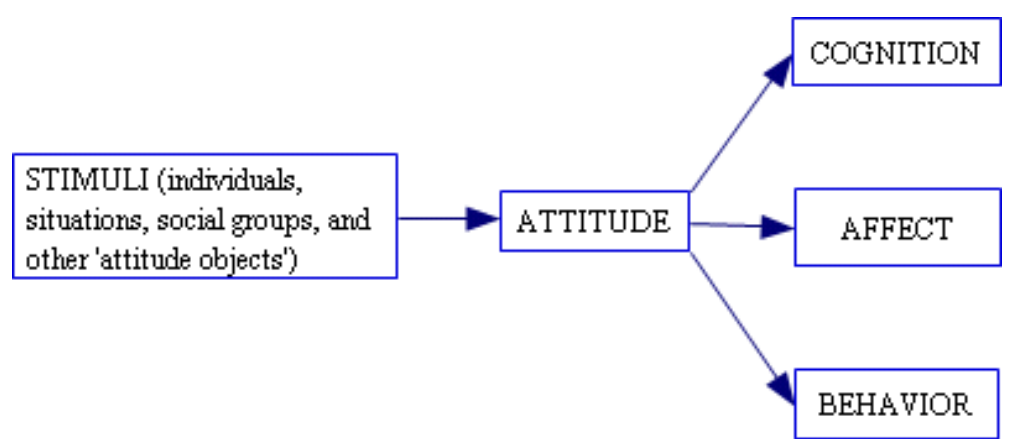

Figure 1.1 Conceptual frameworks for attitude

Since the later era of last century, scholars of cognitive system have competed with the behaviorists, and argued that influence of environmental stimuli on attitude was overemphasized. Instead, attitude is regarded as a node in a dynamic network, as elaborated in theory of cognitive dissonance, self-perception, value-expectancy, selfefficacy, and dissonance-reduction. For example, Bandura believed that attitude concept is used in conjunction with motivation to achieve is self-efficacy in his social cognitive theory (Bandura, 1977). He emphasized the interaction between people, behavior and environments, and that people have the capacity to regulate their motivation, affect and behavior. The theory of cognitive dissonance assumes that a person knows "about himself, about his behavior, and about his surroundings" (Festinger, 1957, p. 9). For example, John knows that he likes smoking, that Mary doesn't like smoking, and that Mary is his mother. The theory proposes that people have a motivational drive to "reduce dissonance by changing their attitudes, beliefs, and behaviors..." (Festinger, 1957). Possibly, John will change his attitude and stop smoking. Self-perception theory posits 
that when people don't have enough internal cues of their own attitude, they may infer their attitude based on external cues and their own previous behaviors (Bem, 1967; Bem \& McConnell, 1970).

Eagly \& Chaiken reviewed the attitude related theory from different perspective and proposed a working definition. They considered that attitude is "a psychological tendency that is expressed by evaluating a particular entity with some degree of favor or disfavor" (Eagly \& Chaiken, 1993) p. 1. This definition lies in the root of cognitive theories, because the nature of attitude is evaluation, which is more subjective. In behaviorism system, the nature of attitude is the tendency to respond to environmental stimuli. Eagly \& Chaiken further conceptualized the evaluation of attitude as "all classes of evaluative responding, whether overt or covert, or cognitive, affective, or behavioral. Evaluation thus encompasses the evaluative aspects of beliefs and thoughts, feelings and emotions, and intentions and overt behavior" (Eagly \& Chaiken, 2007, p. 583). This conceptualization has three necessary components in the tripartite model: cognition, affect, and behavior as in Fig. 1.1, therefore, they called it a neo-tripartite model. By this approach, the neo-tripartite framework may provide a useful link with the previous attitude research and further theory development.

The three-component structure of attitude has been supported by many empirical studies (Bagozzi \& Burnkrant, 1979; Breckler, 1984; Eagly \& Chaiken, 2007). However, the dimensionality of attitude has been challenged. Some studies apply a unitary model. Petty et al. defined attitude as "evaluation of objects along a dimension from positive to negative" (1997). Attitude here is considered unitary rather than multi-dimensional. This hypothesis is supported in some studies because high correlations were observed among 
the three components (Ostrom, 1969). Zanna disagreed with the unitary model. He (1988) emphasized that cognitive and affect are two different components of attitude. The twocomponent model has been proposed, which does not include the behavior component. The behavior component is often questioned because of the weak prediction power of attitude for prescribed behaviors (Biddle \& Mutrie, 2001; Hagger, Chatzisarantis, \& Biddle, 2002). Furthermore, it is very hard to create specific behavior items when complicated patterns of behaviors are involved with the objects. The question arises, which model is more appropriate, unitary, two or three-component (McGuire, 1985)? One focus of attitude literature has been on the attitude-behavior relationship and crosssituation behavior consistency issues. Most of the results are suggesting weak relationship and inconsistent behavior pattern (Berg, 1966; Bray, 1950; Kutner, Wllkins, \& Yarrow, 1952; Lapiere, 1934; Palmer, Burwitz, Dyer, \& Spray, 2005; Perlman, Bobak, Steptoe, Rose, \& Marmot, 2003). Meta-analysis of 30 attitude-behavior studies yielded no or weak relationships between them (Wicker, 1969). The theory of planned behavior (TPB) is proposed to approach the problem for a better prediction (Fishbein \& Ajzen, 1975). In TPB theory, the behavior component is excluded from attitude and considered as another distinct concept; the intention link is added to mediate attitude and behavior. He used attitude and other factors to account for intention, and intention to explain behavior. The TPB theory has been applied in current literatures and the strong correlation between intention and behavior has been supported (Randall \& Wolff, 1994; Rivis \& Sheeran, 2003). The relationships among various concepts are not the major research purpose in this study but can provide insight for estimation of attitude-related nomological network. 


\section{Attitude Concept in Science Education}

Historically, learning outcomes are predominantly measured in terms of cognitive factors by standard aptitude test, grade point average (GPA), logical thinking ability and spatial ability (Sedlacek, 2004). However, some researchers argue that the common exams may have little predictive validity for the potential of students from various backgrounds and cultures (Sedlacek, 2004; Sternberg \& Williams, 1997; Tracey \& Sedlacek, 1984, 1987). Noncognitive factors have been considered as an important learning outcome as early as the Socratic era. Assessment of noncognitive properties, including attitude, motivation, self-efficacy, and learning strategy, can provide unique information to account for students’ academic achievement.

Science education is influenced by attitude related theory in various ways. The behavioral theories have been applied to learning and instruction, such as the application of TPB in SER literature (Fishbein \& Ajzen, 1975). One teaching approach is called operant conditioning, which focuses on the effect of reinforcement to desirable learning behaviors. One teaching approach from a social cognitive perspective is self-regulation learning (SRL) (Corno \& Mandinach, 1983). Since SRL was proposed in the 1980s, it has gained broad popularity in field of science education research and practice. It emphasizes the interactions of cognitive, motivational, and contextual factors and focuses on the effect of environments to help students to become self-regulated learners. SRL has been referred to as the theoretical base in many SER articles (Bong, 2001; Bong \& Clark, 1999; Cunningham \& Mahoney, 2004; Franko et al., 2008; Gao, Lee, \& Harrison, 2008; Hsieh \& Schallert, 2008; Margolis \& McCabe, 2006; Mills, Pajares, \& Herron, 2007; Pajares \& 
Graham, 1999; Schunk, 1991; Sins, van Joolingen, Savelsbergh, \& van Hout-Wolters, 2008; Walker, Greene, \& Mansell, 2006).

The science attitude concept is rarely defined clearly and operationalized consistently, possibly due to the diverse theory sources. Researchers started to use attitude in a vague way that will "involve instincts, appetites, habits, emotions, sentiments, opinion, and wishes" (Park \& Burgress, 1924). Attitudes toward science (or science attitude) has been defined and dimensionalized in different ways. It may be defined as "the emotional reactions of students towards science... interest, satisfaction, and enjoyment" (Gardner, 1975), which puts emphasis on the affective aspect of attitude. Influenced by TPB, attitude is viewed as "a learned, positive, or negative feeling about science that serves as a convenient summary of a wide variety of beliefs about science" (Koballa \& Crawley, 1985), which is more cognitive. These definitions viewed attitude as a unitary concept, whether affective or cognitive component.

In education research literature, science attitude has a more broad meaning. It can include non-cognitive factors, such as self-concept and scientific attitude. Scientific attitude is another different concept which is about "critical mindedness, respect for evidence, objectivity, open-mindedness, and questioning attitude” (Mayer \& Richmond, 1982) p. 56. Attitude can be used exchangeable with other terms. For example, the concept of "motivation" is extensively investigated in learning theory and sometimes used as another name of attitude. Motivation is defined as "the internal state that arouses, directs, and sustains goal-related behavior" (Brophy, 2004). Jurisevic et al. used the threecomponents for the intrinsic motivation, including emotional component of interest, cognitive component of interest and challenge component of internal motivation 
(Jurisevic, Glazar, Pucko, \& Devetak, 2008). The components of motivation are partially overlapped with the cognitive and affective aspects of attitude. Since the motivation estimate in science learning is more dependent on specific science course and institution, it will not be framework in this study.

It is worth mentioning that the attitude cognitive component is different from the cognitive concept. In education, cognitive test usually means knowledge tests to measure students' mastery of content knowledge or thinking skills. On the contrary, attitude cognitive component is the belief about the knowledge, value and habits of thinking ways, which is the major issue in this study. More attitude-related terms mostly used in SER and sample test items are listed in Table 1.1. In sum, there is an overlapping part using various terms. The same name could be used to describe different things, and different names could be used for the same thing. Research findings would be more insightful when major concepts are clearly defined and distinguished from other concepts. It is hard to generalize results across studies using instruments based on vague definition and different conceptualization.

Table 1.1.1 Definition of attitude-related concepts with possible test items

\begin{tabular}{|c|c|c|}
\hline Concept & Definition and reference & Possible item \\
\hline Motivation & $\begin{array}{l}\text { "The internal state that arouses, directs, and sustains goal-related } \\
\text { behavior". (Brophy, 2004) }\end{array}$ & $\begin{array}{l}\text { "I feel most fulfilled when I am able } \\
\text { to solve a difficult problem." (Tuan, } \\
\text { Chin, \& Shieh, 2005) }\end{array}$ \\
\hline Meta-cognition & $\begin{array}{l}\text { "the knowledge and regulation of one's own cognitive system" (Brown, } \\
\text { 1987) }\end{array}$ & $\begin{array}{l}\text { "I check to see that it (result) agrees } \\
\text { with what I expected." (Melanie M. } \\
\text { Cooper \& Santiago Sandi-Urena, } \\
\text { 2009) }\end{array}$ \\
\hline Self-efficacy & $\begin{array}{l}\text { "Belief in capacity to achieve in a specific domain or task" (Martin \& } \\
\text { Dowson, 2009)or "judgments of how well one can execute courses of } \\
\text { action requires to deal with prospective situations" (Bandura, 1982) }\end{array}$ & $\begin{array}{l}\text { "How well can you interpret } \\
\text { chemical equations?" (Uzuntiryaki } \\
\text { \& Aydin, 2009) }\end{array}$ \\
\hline Self-concept & $\begin{array}{l}\text { "A cognitive evaluation of one's ability in a domain" } \\
\text { (Pintrich \& Schunk, 1996) (Bauer, 2005) }\end{array}$ & $\begin{array}{l}\text { "I participate confidently in } \\
\text { discussions with school friends about } \\
\text { chemical topics." }\end{array}$ \\
\hline
\end{tabular}


Table 1.1.2 Definition of science attitude and related concepts with possible test items

\begin{tabular}{|c|c|c|}
\hline Concept & Definition and reference & Possible item \\
\hline $\begin{array}{l}\text { Attitudes } \\
\text { toward } \\
\text { science }\end{array}$ & $\begin{array}{l}\text { "The emotional reactions of students towards science... Interest, satisfaction, and } \\
\text { enjoyment" (Bauer, 2005) (Gardner, 1975) }\end{array}$ & $\begin{array}{l}\text { Science is fascinating and } \\
\text { challenging }\end{array}$ \\
\hline $\begin{array}{l}\text { Scientific } \\
\text { attitudes }\end{array}$ & $\begin{array}{l}\text { "critical mindedness, respect for evidence, objectivity, open-mindedness, and } \\
\text { questioning attitude" (Mayer \& Richmond, 1982)p. } 56\end{array}$ & $\begin{array}{l}\text { I believe my calculation } \\
\text { results whatever it makes } \\
\text { sense or not. }\end{array}$ \\
\hline $\begin{array}{l}\text { Value of } \\
\text { science }\end{array}$ & $\begin{array}{l}\text { "Problem-solving, science inquiry, thinking, and the relevance of science } \\
\text { knowledge in students' daily lives" (American Association for the Advancement of } \\
\text { Science 1993, NRC 1996) }\end{array}$ & $\begin{array}{l}\text { "Learning science is } \\
\text { important because I can use it } \\
\text { in my daily life." (Tuan et al., } \\
2005 \text { ) }\end{array}$ \\
\hline $\begin{array}{l}\text { Nature of } \\
\text { science }\end{array}$ & $\begin{array}{l}\text { "the aims of science, its epistemology, its tactics, its values, its institutional } \\
\text { functions, its interactions with society, and its human needs" (Aikenhead, 1973) }\end{array}$ & $\begin{array}{l}\text { Science can provide absolute } \\
\text { truth for everything. }\end{array}$ \\
\hline
\end{tabular}

\section{Attitude Concept in This Study}

This study is focused on the concept of attitude towards the science subject, chemistry. The investigator is interested to develop an easy-to-use and high quality chemistry attitude instrument for college students. In order to accomplish the goal, it is important to establish the theoretical framework for the instrument design. Moreover, instrument should be able to stand up for empirical evaluation. If the assessment people used to collect data is not based on the proposed theory and there is no evidence in the follow-up studies in terms of reliability and validity, it is hard to compare the results based on different attitude assessments. Just as Doran and colleagues pointed out:

... [T]hat ambiguity of terms and quality of instruments are two serious problems facing those interested in assessing attitudes to science. The lack of a theoretical base has been cited in nearly all cases as a hindrance to assessment. Furthermore, the lack of empirical support for most of the existing instruments has exacerbated the situation (Doran, Lawrenz, \& Helgeson, 1994, p. 428). 
This study does not have a specific theory to base on. Instead, the investigator agrees with Eagly et al in the use of the cognitive perspective of attitude concept, because learning is a complicated and interactive process. Derived from Eagly's working definition, science attitude is defined as the psychological tendency through evaluating the subject of science in general with some degree of favor or disfavor.

From this definition, the investigator is creating a pragmatic model including two attitude components from the neo-tripartite model: cognition and affect. Although definitions by Gardner and Petty view attitude as a unitary concept, the investigator would argue for the retaining a two-component framework in the area of science education. First, educators typically care about both cognitive and affective issues. Just as a person's attitude toward ice cream has a cognitive component (unhealthy, not a part of a balanced diet) and an affective component (yummy!), students often say science is challenging (cognitive) yet interesting (affective). The affective and cognitive components of attitude remain conceptually distinct. It is helpful to know students' answers to both kinds of questions, rather than lumping them together to get a single attitude score or simply gathering information regarding one or the other.

The investigator would also argue that, when the science subject in general is the object of attitude, instruments that exclude the behavior component are the best for many research purposes. Although attitude can be inferred from behavior, behavior is not at the same level of abstraction as cognition and emotion. In that sense, concrete items about behavior on an instrument can actually make it harder for respondents to focus on accurate reporting for more abstract items relating to emotions or beliefs. Also, since desirable behavior patterns can vary dramatically for instructional settings, it is hard to 
create behavioral items suitable for different situations in order to estimate attitudinal differences. Furthermore, when attitude is to be treated as an indicator of future behavior, as the Theory of Planned Behavior recommends, excluding behavior from the attitude study is meaningful (Fishbein \& Ajzen, 1975). Therefore, the investigator decided to use the two-component framework.

The two-component model including the cognitive and affective aspects has been supported by confirmatory factor analysis (CFA) in the SER literature (Gonzàlez, 1992; Mohsin, 1990; Oppenheim, 1992). In the instrument which was developed in 2000 to assess student attitude toward physical education with reliability and validity evidence, the authors found two primary factors, enjoyment and perceived usefulness, which are congruent with the affective and cognitive aspects of the two component framework (Subramaniam \& Silverman, 2000, 2007). In sum, the two component (cognition and affect) attitude model will be used as a framework to guide this instrument development process. In the following thesis, Chapter Two summarizes existing attitude measurements; Chapter Three introduces technique background about psychometric quality, including reliability and validity estimate; Chapter Four is the method section for this study; Chapters Five and Six are results and discussion from the administration of original and revised ASCI; at last, Chapter Seven summarizes the whole study. 


\section{Chapter Two}

\section{Literature Review}

This chapter starts with literature review of the typical attitude scales. Then the previous attempts to measure attitude towards science and chemistry are discussed.

\section{Typical Attitude Measurement Scales}

Appropriate assessments of science attitude are important for diverse research purpose, such as evaluation of course effect and attitude theory development. The concept of "attitude toward science" is elusive and cannot be measured directly, at least not as directly as the way to measure speed using a stopwatch. Indicators from responses to carefully designed statements are often used to measure abstract constructs indirectly. Qualitative and quantitative methods have been used to measure students' attitudes toward science. Because qualitative approaches including observations and interviews are time consuming and not applicable to classroom use, this study focuses on the quantitative methods using psychometric survey. Single indicator attitude survey is often used, for example, how do you describe your liking of science on a 1-10 scale? Critiques of single indicator survey are the lack of reliability estimate (Straus \& Wauchope, 1992). A composite score based on multiple indicators is better than a single indicator in terms of reliability and validity evidence from a psychometric perspective. According to the organization of test items, there are four typical different attitudes scales, including Thurstone, Likert, Guttman, and semantic differential (Table 2.1). Thurstone and Guttman scales call for answers of agree or disagree, so the responses are dichotomous. 
Likert and Semantic differential scales ask participants to choose the position they locate usually on a five or seven-point scale.

Table 2.1 Description of four typical attitude measurement scales

\begin{tabular}{|c|c|c|}
\hline Scale & Description & Sample test item \\
\hline $\begin{array}{l}\text { Guttman scale } \\
\text { (DeVellis, 2003) }\end{array}$ & $\begin{array}{l}\text { "a subset of the survey items having binary answers scale if } \\
\text { they can be ranked in some order so that, for a rational } \\
\text { respondent, the response pattern can be captured by a single } \\
\text { index on that ordered scale." Agreement with item } 3 \text { implies } \\
\text { agreement with items of lower rank order: } 1 \text { and } 2 \text {. }\end{array}$ & $\begin{array}{l}\text { To what level the attitude is toward } \\
\text { immigrants: Are you willing to permit } \\
\text { immigrants to live } \\
\text { (Least extreme) } 1 \text { in your country? 2. in } \\
\text { your community? 3. in your neighborhoods? } \\
\text { 4. next door to you? (Most extreme) 5. in your } \\
\text { family (marry your child)? ( answer Y/N to } \\
\text { each one) }\end{array}$ \\
\hline $\begin{array}{l}\text { Thurstone Scale } \\
\text { (Thurstone, 1928) }\end{array}$ & $\begin{array}{l}\text { The statements followed by binary answer (e.g. agree or } \\
\text { disagree) should constitute nearly an evenly graduated series } \\
\text { of scale values (e.g. from very necessary to useless). }\end{array}$ & $\begin{array}{l}\text { Happiness has ------ to do with achieving } \\
\text { educational or material goal. } \\
1 \text { nothing } 2 \text { something } 3 \text {. a lot ( answer Y/N to } \\
\text { each one) }\end{array}$ \\
\hline $\begin{array}{l}\text { Likert Scale } \\
\text { (Likert, 1932) }\end{array}$ & $\begin{array}{l}\text { respondents specify their level of agreement to a declarative } \\
\text { statement. (could range from strongly disagree to strongly } \\
\text { agree in a } 5 \text { likert) }\end{array}$ & $\begin{array}{l}\text { Science knowledge is important in my daily } \\
\text { life. } \\
1 \text { strongly disagree } 2 \text { disagree } 3 \text { Neutral 4agree } \\
5 \text { strongly agree (pick one from the five } \\
\text { options) }\end{array}$ \\
\hline $\begin{array}{l}\text { Semantic } \\
\text { differential Scale } \\
\text { (Snider \& Osgood, } \\
\text { 1969) }\end{array}$ & $\begin{array}{l}\text { The respondent is asked to choose where his or her position } \\
\text { lies, on a scale between bipolar adjectives }\end{array}$ & $\begin{array}{l}\text { Learning chemistry is: } \\
\text { Valuable- - - - - Worthless. } \\
\text { (pick one from the seven positions) }\end{array}$ \\
\hline
\end{tabular}

\section{Quality Evaluation for Existing Science Attitude Instruments}

Many science attitude instruments exist. Fortunately, meta-analysis can be utilized to systematically evaluate the quality of these instruments, and, when published metaanalyses exist, they are a tremendous help for instrument selection. For example, Munby reviewed 56 instruments for their psychometric and conceptual evidence (1983), and recommended seven instruments. However, his selection criteria did not put much weight on validity and item content issues. More recently, Blalock developed a scoring rubric to rate the 66 instruments published in 150 peer-reviewed articles during $1935 \sim 2003$

(Blalock et al., 2008). The rating rubric includes five major categories:

1) Theoretical background for instrument development (3 pts) 
2) Reliability: internal consistency, test-retest, and standard error of measurement (9 pts)

3) Validity: content, discriminant, congruent, contrasting groups, and factor analyses (9 pts)

4) Dimensionality (6 pts)

5) Development and usage (1 pt)

This rubric covered most aspects of psychometric properties. A high-quality instrument should hold to current measurement standards, and score high on a rubric like this. However, a high score on this rubric does not necessarily guarantee a high quality instrument, because Blalock's rubric is not harsh but relatively lenient. Some important issues were not accounted for in his rating rubric, such as the influence of missing data, descriptive analysis and normality check to perform factor analysis. Moreover, there are different factor analysis techniques which serve different research purposes and should be used consistently. At this time, the investigator use Blalock's rubric for estimate the existing attitude instruments.

The average score for the 66 instruments was reported to be 9.5 out of 28 . Scores ranged from 0 to 22, with a standard deviation of 4.9. Twenty-four instruments scored 7 or below. At the higher end, only two instruments scored higher than 20 points. Blalock's conclusion is that the general quality of instruments is quite low. Most of them lack the psychometric aspects, including the use of explicit theory base, report of reliability and validity evidence. Researchers have created and are still continuing to create new attitude instruments on their own resulting in the overall poor psychometric quality instead of revising and improving an existing one. Most instruments have never been used in follow-up studies. When an old one is used, very little attention was paid about its quality. Even the most extensively used one, Scientific Attitude Inventory (only scored 10 out of 
28), which was even criticized for the revised form (Lichtenstein et al., 2008). Although psychometrics property has long been well honored, science attitude instruments did not exhibit an obvious pattern of quality improvement with years.

There are various reasons to possibly account for this unsatisfactory situation. One is that test validation is a long and complicated process, which always involves mixed research methods and crosses multiple disciplines like psychology, psychometrics, learning theory, inferential statistics, pedagogy, and subject content knowledge. Another reason is that in most graduate programs students are poorly trained in measurement-related fields and there is a shortage of measurement professionals to take the responsibility of test score validation. As Pedhazur and Schmelkin (1991) observed, "most programs in sociobehavioral sciences, especially doctoral programs, require a modicum of exposure to statistics and research design, few seem to require the same where measurement is concerned" (p. 2).

Proper description and reference of theory background is the first and important step in guiding instrument development, because it is the starting point to clearly define what kind of attitude concept the instrument is really intended to measure and the dimensionality of the concept. The developers tended to bring more related constructs to an attitude questionnaire without careful definition and discrimination, such as selfconcept, self-efficacy, interest, learning strategy, motivation, behavior of effort, and learning goals, value of science and so on. So the survey itself is a network of related constructs rather than components of one major construct (more descriptions about these terms are in Table 1.1). The intension and dimensionality of the concept should be consistently applied to create pilot item pool. If an instrument has more than one 
dimension, it is problematic to use it as if it is one-dimensional by using a single composite score(Neuberg, West, Judice, \& Thompson, 1997).

Review of literature revealed more instrument develop problems. It is desirable to have items designed to load on one thing conceptually not the others (Netemeyer, Bearden, \& Sharma). If concepts are not discriminated from one another, it is hard to create items and make interpretations using sum scores. For example, the item "I feel proud of my ability" could be an indicator of constructs like self confidence, self-concept, self-efficacy, selfesteem or self-respect on different instruments. However, an item like this is not appropriate to be used for different concepts on one instrument.

Moreover, it is improper to add items representing different objects together to create one composite score. For example, it doesn't make sense to have the factor score for items "I like the banana" and "I like computer". Science attitudes surveys tend to have items representing various attitude objects including classroom environment, labs, test anxiety, teachers and scientists, which seem inclusive and comprehensive. In this case, it is hard to compare the composite score across situations with different backgrounds because students may have different understanding of specific objects like labs or teachers. The importance of a single attitude object is illustrated as follows:

An attitude instrument yields a score. If this score is to be meaningful, it should faithfully reflect the respondent's position on some well-defined continuum. For this to happen, the items within the scale must all be related to a single attitude object. A disparate collection of items, reflecting attitude towards a wide variety of attitude object, does not constitute a scale, and cannot yield a meaningful score (Gardner, 1975: 12). 
Psychometric evidence should be reported when using instruments, and the strategies to perform statistics analysis should be carefully selected to serve the research purpose. Unfortunately that is very rare. Methodological problems have been found in the science or chemistry attitude measurements. Most articles never justify their strategies and just report the "best" evidence after trying different strategies, or overuse the default option provided by the statistical software, hence cannot stand against the critics (Cronkhite \& Liska, 1980). For example, test-retest reliability requires two administrations of the same instrument for the same people after a period of time, and should not be used for the different test forms or different samples. Another issue is, the internal consistency measured by Cronbach's alpha for the whole instrument doesn't lend support to unidimensionality and the use of the total score (Gardner, 1995). This means, Cronbach's alpha and factor score should be reported for each scale rather than overall instrument. For construct validity, many researchers didn't justify why they used CFA rather than EFA, why PCA, why oblique rotation rather than orthogonal rotation, how the number of factors was decided to extract and so on. Furthermore, when factor analysis yields a model of different item loading patterns from the proposed model, usually no explanations or suggestions were given.

Because of various reasons, the average score for the overall instrument is so low. To make the findings based on instruments more acceptable and generalizable for other scientists and practitioners, it is important to establish evidence for the responses each time when using the instrument. In depth discussions about the techniques to evaluate psychometric quality such as factor analysis will be discussed in Chapter Three. 


\section{Quality Evaluation for Existing Chemistry Attitude Instruments}

The question arises, is the situation of science attitude instruments similar to chemistryspecific instruments? Several chemistry attitude instruments have been developed and reported specifically (Barbera, Adams, Wieman, \& Perkins, 2008; Bauer, 2005, 2008; Leavers, 1975; S. E. Lewis, Shaw, Heitz, \& Webster, 2009; Walczak \& Walczak, 2009). They are asking students to answer questions on different attitude related construct, such as attitude towards science, self-concept, metacognition, cognitive expectations toward chemistry. When Blalock's rubric is applied to these reports (Table 2.2), overall the psychometric quality is better than for the science attitude measurements but still unsatisfactory. The only two instruments for which detailed factor analysis and factor scores were reported were the Attitude toward the Subject of Chemistry Inventory (ASCI) (Bauer, 2008) and the Chemistry Self-concept Inventory (SCI) (Bauer, 2005). SCI has excellent evidence for reliability and validity, scoring the highest of all the instruments, but it is aligned with a particular sub-construct of attitude rather than with the general attitude concept discussed above as our target. ASCI, which is more aligned with the general attitude concept, scored the second highest, with 18 out of 28 points, significantly higher than the average of the 66 science attitude instruments but still lower than desirable. In addition, the ASCI subscales were not captured well via factor analysis, indicating a potential problem with the underlying fit between the instrument and its theoretical framework. 
Table 2.2 Score for chemistry attitude instruments on JCE according to Blalock's rubric

\begin{tabular}{|c|c|c|c|c|c|c|c|}
\hline Survey & Study population & $\begin{array}{l}\text { Theoretic } \\
\text { base }\end{array}$ & Reliability & Validity & Dimensionality & $\begin{array}{l}\text { Development } \\
\text { and usage }\end{array}$ & Score \\
\hline Highest possible & points & 3 & $9^{a}$ & $9^{b}$ & 6 & 1 & 28 \\
\hline $\begin{array}{l}\text { Opinion survey } \\
\text { (Leavers, 1975) }\end{array}$ & $\begin{array}{l}\mathrm{n}=130 \text {, college } \\
\text { chemistry class } \\
\text { students (for } \\
\text { nonscientist) }\end{array}$ & 0 & 0 & 0 & 0 & 0 & 0 \\
\hline $\begin{array}{l}\text { Attitudes toward } \\
\text { Laboratories } \\
\text { (Chatterjee, } \\
\text { Williamson, McCann, } \\
\text { \& Peck, 2009) }\end{array}$ & $\begin{array}{l}\mathrm{n}=703 \text {, college } \\
\text { chemistry laboratory } \\
\text { students }\end{array}$ & 3 & 0 & 3 & 0 & 0 & 6 \\
\hline $\begin{array}{l}\text { VOSTS (Walczak \& } \\
\text { Walczak, 2009) }\end{array}$ & $\begin{array}{l}\mathrm{n}=37 \text {, college } \\
\text { chemistry students in } \\
\text { a non-science } \\
\text { major's course }\end{array}$ & 3 & 0 & 6 & 0 & 1 & 10 \\
\hline $\begin{array}{l}\text { CHEMX (Grove \& } \\
\text { Bretz, 2007) }\end{array}$ & $\begin{array}{l}\mathrm{n}=157, \text { college } \\
\text { chemistry faculty }\end{array}$ & 3 & 3 & 9 & 0 & 1 & 16 \\
\hline $\begin{array}{l}\text { ClASS (Barbera et al., } \\
\text { 2008) }\end{array}$ & $\begin{array}{l}\mathrm{n}>500 \text {, college } \\
\text { student in general } \\
\text { chemistry }\end{array}$ & 3 & 3 & 9 & 0 & 1 & 16 \\
\hline $\begin{array}{l}\text { MCAI (M. M. Cooper } \\
\text { \& S. Sandi-Urena, } \\
\text { 2009) }\end{array}$ & $\begin{array}{l}\mathrm{N}=537 \text {, college } \\
\text { students, intact class } \\
\text { in chemistry lab }\end{array}$ & 3 & 3 & 9 & 0 & 1 & 16 \\
\hline $\begin{array}{l}\text { ASCI } \\
\text { (Bauer, 2008) }\end{array}$ & $\begin{array}{l}\mathrm{n}=379, \text { college } \\
\text { chemistry lab }\end{array}$ & 3 & 2 & 9 & 3 & 1 & 18 \\
\hline $\begin{array}{l}\text { Self-Concept Inventory } \\
\text { (Bauer, 2005) }\end{array}$ & $\begin{array}{l}\mathrm{N}=379, \text { students in a } \\
\text { non-science major's } \\
\text { college chemistry } \\
\text { course }\end{array}$ & 3 & 5 & 9 & 6 & 1 & 24 \\
\hline
\end{tabular}

${ }^{\mathrm{a}}$ Internal consistency, test-re-test and standard error of measurement

${ }^{\mathrm{b}}$ Content, discriminant, congruent, contrasting groups, FA

The investigator found that the Attitude toward the Subject of Chemistry Inventory (ASCI) (Bauer, 2008) was a good candidate to for this study for several reasons. Overall the ASCI is a high-quality instrument, and it is informative for other teachers' implementation in chemistry classroom. Firstly, the test purpose is clearly stated, to measure the attitude towards chemistry in general, not the specific course or instructor. The attitude concept was properly defined and distinguished with other variables like belief, self-concept and scientific habits. Secondly, it is designed in the 7-point semantic differential format: "Students position themselves on a seven-point scale between two polar adjectives, in reference to how they feel about the attitude object 'chemistry'." One sample item asks students to rate their position from "exciting" to "boring". It is the 
easiest format to answer and intuitive to interpret. Twenty pairs of objectives are carefully selected to tap students' attitudinal status towards a single object of chemistry in general after a cognitive interview. Furthermore, ASCI provided an acceptable internal consistency and test-retest reliability. Construct validity was supported by correlation of attitude scores with other concepts, contrasting groups, discriminate and factor analysis. The items were grouped into five subscales: interest and utility (including five items), fear (one item), emotional satisfaction (four items), intellectual accessibility (five items), and anxiety producing (four items) according to factor analysis results. Finally, ASCI comes with guidelines for administration, scoring, and score interpretation for instructors and other researchers.

However, there is space for improvement. The factors emerging from factor analysis based on the 379 responses from the first semester of general chemistry laboratories did not reflect the subscales the authors claimed. Actually, only three factors emerged from factor analysis. The Fear subscale only has one item, which did not load well on other factors, so it cannot be considered as a factor. The Emotional Satisfaction items loads on multiple factors, so the authors used the word "Set" rather than a "Factor". Moreover, the Interest and Utility subscale possibly contains two different concepts. Because procedures like confirmatory factory analysis (CFA) was not performed, there is no report of measurement error.

Another reason for choosing ASCI is the attitude object for ASCI is chemistry in general, rather than specific curriculum or lab. This study is interested in developing an attitude measurement which can yield reliable and valid scores for the college students toward chemistry in general in order to fit the different universities or curriculums. If items are 
about specific contexts like cooperative learning for college chemistry, students could have different understanding dependent on their course settings, which will lead to different item loading pattern for different populations. By using chemistry in general, the investigator expected that assessment would hold valid for diverse college chemistry course situations.

The study of the Attitude Toward Science in School Assessment (ATSSA) (Germann, 1988), which scored the highest of all the science attitude instruments on Blalock's rubric, inspired us to use factor analysis to refine an instrument. In its pilot test, ATSSA included 24 items which loaded on 5 factors from exploratory factor analysis (EFA). The developer concluded that the first factor, comprising 14 items, was consistent with the desired construct but the other 10 items dealt with more specific objects like testing and labs. In a follow-up administration of a shortened version of the instrument, the onecomponent structure was supported, and this became the final version of the instrument. In addition to proposing and administering a revised version of ASCI, we will be able to utilize confirmatory factor analysis to obtain an estimate of the model fit and information about sources of measurement error, which was not easy to do at the time ATSSA was developed.

In this study, because the investigator wanted to capture two subscales (to align with two components of the general theory of the attitude concept), the original and revised ASCI (V2), comprising items from the original 20-item ASCI, were proposed for college chemistry students. It is expected that the revised ASCI would yield responses with twocomponent structure and map into our two-component theoretical framework, and thus improve the construct validity. The technique backgrounds for scale reconstruction and 
quality evaluation, however, deserves further comment and will be discussed in the next chapter.

This study will attempt to address three specific research questions.

\section{Research questions}

\section{Question 1}

How is psychometric quality evaluation for the responses from ASCI in terms of reliability and validity?

\section{Question 2}

How can ASCI be modified based on factor analysis and theoretical framework?

\section{Question 3}

How is psychometric quality evaluation for the responses from revised ASCI versions in terms of reliability and validity? 


\section{Chapter Three}

\section{Methodological Background}

This chapter presents the methodological background about psychometric quality which is necessary to understand what is coming in the next chapters. It starts with the proposed instrument development processes, and then elaborates the two major issues for instrument development: reliability and validity. Then several factor analysis techniques are discussed.

\section{Proposed Instrument Development Processes}

The development of a "good" instrument from scratch involves a long, cyclic process. The overall instrument development process is illustrated in Fig. 3.1. The first stage (left part) involves the qualitative process. It includes the identification of test purpose: what is the concept the test is designed to measure? The construct should be clearly defined along with content domain and dimensionality. After the test blueprint or table of specification is created, it is good to generate initial item pool. Ask an expert and layperson to review items to identify and discuss any content issues related to these items: What is the scale of measurement for these items? What is your reaction to the analyses using this scale in terms of content validity and face validity? Revision will be made to make the pilot test items according to the feedback. The second stage (the right part) mainly involves the quantitative psychometric process. Pilot test is given to the representative samples to examine the responses in terms of reliability, validity, utility and practicality. Revise or delete the items associated with responses of poor psychometric quality. Continue to conduct studies until the revised test is functioning well. The last step is to develop 
guidelines for administration, scoring, and interpreting the scores for further study and other researchers.

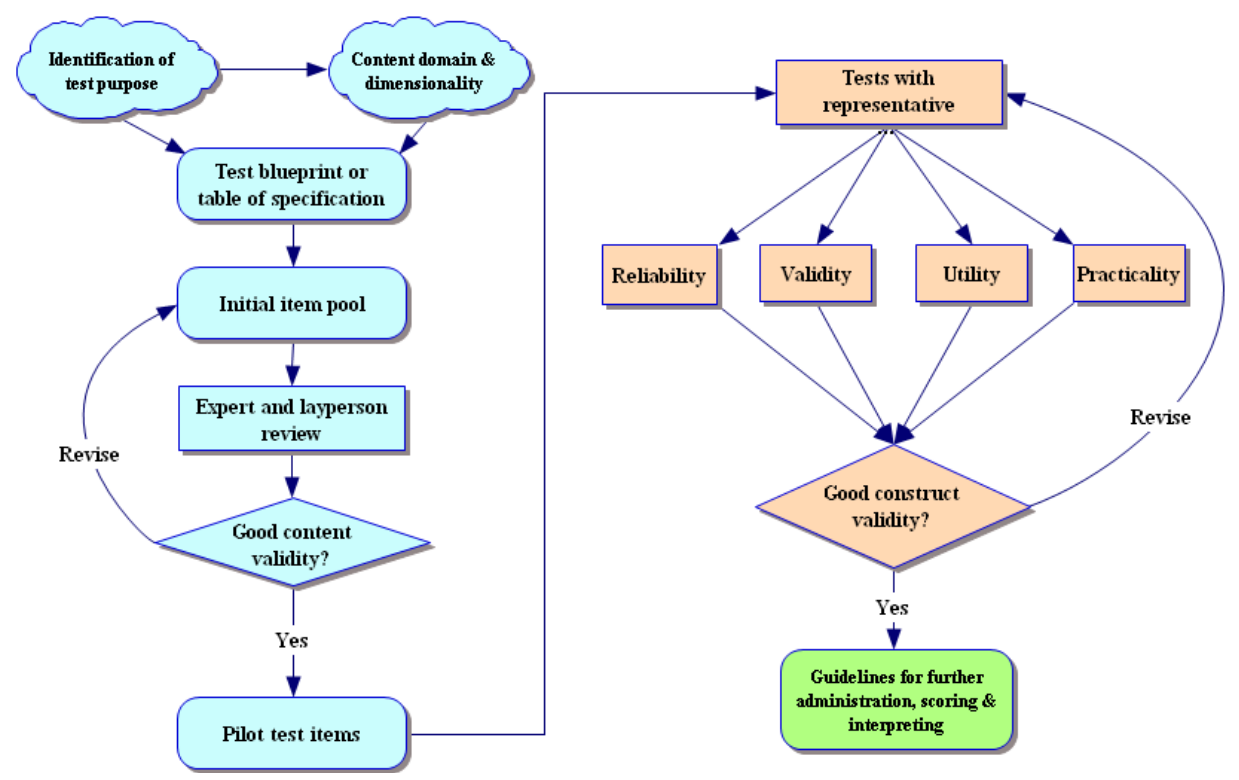

Figure 3.1 Instrument development processes (from Dedrick's class note)

As is discussed in the previous chapter, ASCI did a good job in term of qualitative part. Starting from ASCI has the advantage of skipping the most time-consuming part of the first stage. The second stage, the quantitative part especially on reliability and validity, is the key point for this study and will be discussed in more details below.

\section{Reliability}

The most important issues for a "good" instrument pertain to the reliability of the scores (Is it providing consistent results?) and validity (Is it measuring what the developer intended to measure?). The conception of reliability dates back to 1904 (Spearman, 1904). Spearman first proposed the concept and the ways to evaluate the degree of score reliability. Reliability is important because no score can be perfectly reliable even in the natural science area. As stated by Pedhazur, "the presence of measurement errors in behavioral research is the rule rather than the exception" and "reliabilities of many 
measures used in the behavioral sciences are, at best, moderate" (Pedhazur, 1997, p. 172). If a measurement yields totally random scores, the scores are not reliable and cannot measure anything. The scores with poor reliability cannot be valid. And the findings based on the unreliable measured scores are questionable. Wilkinson and the APA Task Force on Statistical Inference emphasized the importance of reporting the reliability estimate:

It is important to remember that a test is not reliable or unreliable... Thus, authors should provide reliability coefficients of the scores for the data being analyzed even when the focus of their research is not psychometric. .. Interpreting the size of observed effects requires an assessment of the reliability of the scores. (Wilkinson, 1999, p. 596)

Reliability estimate has different angles such as test-retest reliability and internal consistency. Test-retest reliability means that the same individual should score similarly on one instrument at different times if other environmental factors are controlled. However, people usually only take the instrument once, therefore test-retest reliability is hard to estimate. Another aspect of reliability is internal consistency, which can be measured by Cronbach's alpha to estimate the level that all items hold together and consistently measure one construct. Cronbach's alpha is the mostly frequently reported reliability estimate because of its convenience of single administration. It is calculated using Equation 3.1:

$\propto=\left[\frac{K}{K-1}\right] *\left[1-\left(\sum \delta_{\mathrm{k}}^{2}\right) / \delta_{\text {total }}^{2}\right] \quad$ Equation 3.1

Where $K$ is the number of items, $\sum \delta_{\mathrm{k}}{ }^{2}$ is the sum of the $K$ individual item score variance and $\delta_{\text {total }}{ }^{2}$ is the variance in the total score. Cronbach's alpha can range from negative 
infinity to +1 mathematically. The closer it is to +1 , the more reliable the total score is. When it is close to +1 , the item scores are positively linearly correlated with each other and the total score. Being greater than .7 is considered to be acceptable reliability (Nunnally, 1978). If the alpha is significantly less than 0, the items may be perfectly correlated with each other but with mixed signs (positive or negative relation mixed), and thus makes Crohbach' alpha horribly low. If the alpha is close to 0 , the items scores are uncorrelated.

\section{Validity}

Reliability is only one part of the instrument validity but not sufficient (Moss, 1994). If the scores are not reliable, they cannot be considered to be valid unless the instrument is designed to measure nothing (Bruce Thompson, 2003). An instance of validity is, if I step on a scale three times in a day, and it reads 0, 100 and 200, then I am really not sure what is to measure. Even when good internal consistency estimate is achieved, it is not sufficient for validity of one construct and use of total score. A good example was presented by Gardner (1995) as shown in Fig 3.2. Assume we have nine items in the instrument. For situation 1, items produce random and not correlated results, suggesting poor internal consistency and poor dimensionality. For situation 3, all items are highly correlated with each other, which indicate good internal consistency and one dimension. In situation 2, nine items are divided into 3 distinct groups. In this situation, overall internal consistency is good, items within groups are correlated. Since three factors are distinct and uncorrelated mathematically, it is better to report factor score on each scale rather than a total score. It is not meaningful to add an apple, a hotdog and a notebook together. When the test has three dimensions like in situation 2, validity of using a single 
composite score is not established. Instead, internal consistency and factor score should also be reported for each scale rather than for the whole instrument.

\begin{tabular}{|c|c|c|c|}
\hline Internally consistent? & No & Yes & Yes \\
\hline Unidimensional? & No & No & Yes \\
\hline Item variances & $\begin{array}{l}\text { Items share no } \\
\text { variance. }\end{array}$ & $\begin{array}{l}\text { Each item shares } \\
\text { variance with some } \\
\text { others. }\end{array}$ & $\begin{array}{l}\text { All items share } \\
\text { common variance. }\end{array}$ \\
\hline
\end{tabular}

Figure 3.2 Internal consistency and unidimensionality (Gardner, 1995) Validity is about the degree to which scores from a measurement measure what it purports to measure. Score interpretation will affect the following decision and action, which is also a validity concern. For example, if I stand on the scale and it reads 200 , does that mean I am IQ 200? Does that mean I am a smart student? Shall I celebrate for that? Here is a list of representative selection of more elaborate definitions and standards for validity.

[Validity is] the degree to which inferences from the results of the assessment of the knowledge, skills, attitudes, and behaviors of the evaluatee are trustworthy. (The joint committee on standards for educational evaluation, 2007, p. 179) The key validity issues in future assessment are the same as they have always been, ... Validity is an integrated evaluative judgment of the degree to which empirical evidence and theoretical rationale supports the adequacy and 
appropriateness of inference and actions based on test scores or other models of assessment (S. Messick, 1989).

[Validity refers to] "the degree to which evidence and theory support the interpretations of test scores entailed by proposed uses of tests. Validity is, therefore, the most fundamental consideration in developing and evaluating tests. The process of validation involves accumulating evidence to provide a sound scientific basis for the proposed score interpretations. It is the interpretations of test scores required by proposed uses that are evaluated, not the test itself. When test scores are used or interpreted in more than one way, each intended interpretation must be validated" (AERA, APA, \& NCME, 1999, p. 9). Validation speaks to a diverse and potentially critical audience; the arguments must link concepts, evidence, social and personal consequences, and values... Strong construct validation is best guided by the phrase "plausible rival hypotheses'... The bottom line is that validators have the obligation to review whether a practice has appropriate consequences for individuals and institutions, an especially to guard against adverse consequences. (L. J. Cronbach, 1988) There are common features running through these validity definitions. Validity is a property of test scores rather than the test itself (AERA, APA, \& NCME, 1999, p. 9). Both empirical evidence and theoretical rationale need to be considered in terms of validity (S. Messick, 1989). Psychometric evaluation of an instrument score can verify the theory related to the construct. They suggest modification for the theory underlying the construct when necessary. They indicate modification of the instrument for better psychometric quality. It is worthy to mention that test scores can be valid for one purpose 
but not for another. Validity is also the process to justify the inference based on the test scores. Cronbach further emphasizes the plausibility against rival hypotheses (L. J. Cronbach, 1988).

There are various aspects of validity discussed in literature, such as content validity, factorial validity, convergent validity, and criterion-related validity etc. Content validity involves the process of developing and reviewing the content of the instrument by the panel of subject-matter experts about clarity and representative of construct domain. This is a fundamental property of a test, but it is arbitrary and not dependent on the test scores. Factorial validity refers to the loadings of test item scores on the assumed factors from internal structure analysis, and thus provides strong evidence of validity. Convergent validity means the results of one specific construct from different methods should be similar. Discriminant validity means the results of different constructs should be different. Criterion-related validity includes predictive (purpose of measurement, predict later performance) and concurrent validity (correlation with other related constructs measured at the same time). Nomological network pertains to empirical evidence to build "lawful" sets of relationships between the measured construct and other theoretical concepts or observable properties in order to make a case for the existence of the construct (Lee $\mathrm{J}$. Cronbach \& Meehl, 1955). They used the word "law" to describe the expected relationship among observable properties or theoretical constructs. They proposed that "to make something is" scientifically means to set forth the laws in which it occurs. My understanding is, a robust nomological network grounds a measured construct in a web of proposed relationships, the strengths and directions of which, as determined empirically, 
match theoretical predictions. Accordingly, correlational and experimental analyses are the most-used techniques to support nomological network building.

All aspects of validity can fall under one overarching category: construct validity. Construct validity is considered as "a mutual verification of the measuring instrument and the theory of the construct it is meant to measure. More accurately, it reflects a verification of the inferences and interpretations to be drawn from the test scores and a corresponding modification (if so indicated) of the instrument and/or the theory underlying the construct" (Angoff, 1988). Similarly, construct validity is defined as "the unifying concept of validity that integrates criterion and content considerations into a common framework for testing rational hypotheses about theoretically relevant relationships" (Samuel Messick, 1980). Cronbach and Meehl first proposed the factor analysis as a useful computational tool since "a matrix of intercorrelations often points out profitable ways of dividing the construct into more meaningful part" (Lee J. Cronbach \& Meehl, 1955).

The Standards for Educational and Psychological Tests (SEPT) recommended the report of internal structure from a test score, and dimensionality, which is supported by statistical technique like factor analysis.

If the rationale for a test use or interpretation depends on premises about the relationships among parts of the test, evidence concerning the internal structure of the test should be provided.... It might be claimed, for example, that a test is essentially unidimensional. Such a claim could be supported by a multivariate statistical analysis, such as factor analysis, showing that the score variability 
attributable to one major dimension was much greater than score variability attributable to any other identified dimension. When a test provides more than one score, the interrelationships of those scores should be shown to be consistent with the construct(s) being assessed. (Standard 1.11)

Regardless of the endorsements from the most eminent scientists like Cronbach and SEPT standard mentioned above, factor analysis has encountered critics, as Cronkhite and Liska noted:

Apparently, it is so easy to find semantic scales which seem relevant to [information] source, so easy to name or describe potential/hypothetical sources, so easy to capture college students to use the scales to relate the sources, so easy to submit those ratings to factor analysis, so much fun to name the factors when one's research assistant returns with the computer printout, and so rewarding to have a guaranteed publication with no fear of nonsignificant results that researchers, once exposed to the pleasures of the factor analytic approach, rapidly become addicted to it. (Cronkhite \& Liska, 1980, p. 102)

It is important to keep these critics in mind when factor analysis is used for data analysis and interpretation. Factor analytic approach should not be misused as an advantage over other statistics approaches. It should not have any privilege for publication purpose without careful judgment. To make good use of factor analysis, the research design and analysis strategy should be carefully selected and justified, rather than just trying different strategies and reporting the best-wanted results. Several methodological problems have been mentioned in previous chapter. In the following sections, the factor analysis approach will be discussed in more details. 


\section{Factor Analysis}

Factor analysis is widely used to analyze scores from an instrument. It seeks to discover the simple pattern in the relationship among the observed variables. For example, if an instrument has 20 items grouped into 2 scales and items within each scale are highly correlated, it is reasonable to report 2 factor scores summing the grouping items, rather than report all the 20 items. It makes the interpretation simple and easy!

\section{Sample Size}

Usually factor analysis requires a large sample size. However, it is not clear how large is enough. Some rules of thumb can be used at hand (Hogarty, Hines, Kromrey, Ferron, \& Mumford, 2005; MacCallum, Widaman, Preacher, \& Hong, 2001; Marsh \& Balla, 1994; Marsh, Balla, \& McDonald, 1988; Shevlin \& Miles, 1998). Unfortunately, there are serious drawbacks to such guidelines. One problem is that these recommendations vary dramatically. For instance, Gorsuch (1983) suggested a ratio of five participants per measured variable and that the sample size never be less than 100. In contrast, Nunnally (1978) and Everitt (1975) proposed ratios of 10 to 1. More importantly, recent research has suggested that such guidelines are not sufficiently sensitive to a variety of important characteristics of the data (MacCallum et al., 1999; Velicer \& Fava, 1998). The primary limitation of such guidelines is that adequate sample size is not a function of the number of measured variables per se but is instead influenced by the extent to which factors are overdetermined and the level of the communalities of the measured variables. When each common factor is overdetermined (i.e., at least three or four measured variables represent each common factor) and the communalities are high (i.e., an average of .70 or higher), accurate estimates of population parameters can be obtained with samples as small as 100 
(MacCallum et al., 1999). However, under more moderate conditions a sample size of at least 200 might be needed; when these conditions are poor it is possible that samples as large as 400 to 800 might not be sufficient (Fabrigar, Wegener, MacCallum, \& Strahan, 1999).

EFA or PCA

EFA and PCA (principal component analysis) are similar eigenvector-based multivariate analysis methods with the only difference in the regression direction. The different model of EFA and PCA is illustrated in Fig. 3.3 (from Ferron Statistics classnote). EFA is used when a researcher wishes to identify a set of latent constructs underlying a battery of measured variables. The primary purpose of EFA is to arrive at a more parsimonious conceptual understanding of a set of measured variables. Before using EFA, a researcher should carefully consider if this is a goal of the research project (Fabrigar et al., 1999). In PCA, the component variables are combinative of all items, and they don't reflect latent variables as in EFA. Therefore, there are clear conceptual distinctions between PCA and EFA. Although these approaches often produce similar results, this is not true in certain contexts. When the goal of the analysis is to identify latent constructs underlying measured variables, it is more sensible to use EFA than PCA (Cattell, 1978; Gorsuch, 1983; McDonald, 1985; Mulaik, 1972; (Fabrigar et al., 1999). 


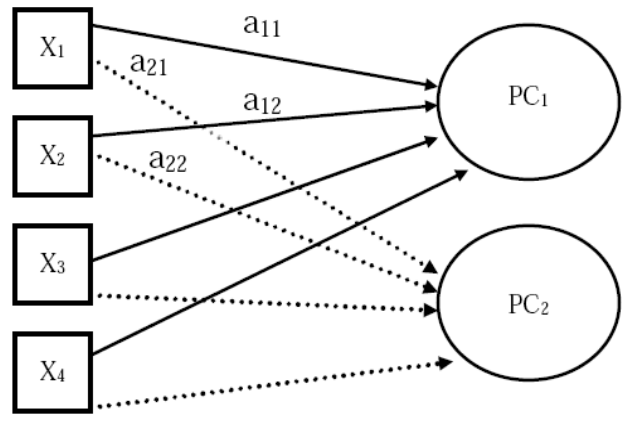

PCA Model

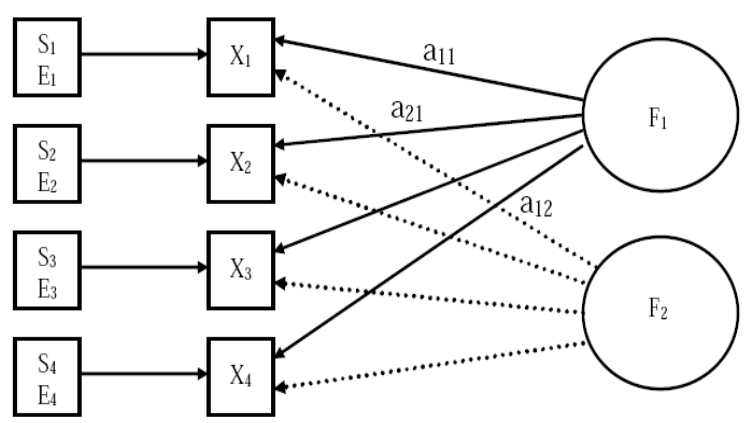

EFA model

Figure 3.3 PCA and EFA model

\section{EFA or CFA}

While both EFA and CFA provide parameter estimate including item loadings, CFA offers more advantages over EFA at the instrument validation stage. It is even more appropriate when the instrument is designed based on a theoretical and conceptual model. In this situation, the CFA preference is endorsed by measurement professionals, which is embodied in statements, that "current think[ing] on construct validation argues that the most rigorous test of factorial structure is through CFA techniques" (Greenbaum \& Dedrick, 1998), and that "CFA is a commonly accepted method to test/confirm dimensionality" (Netemeyer et al., 2003). CFA can provide fit indexes to examine the overall goodness of fit of a model which EFA cannot. Also it offers information about the source of measurement error and how the model fit can be improved by modifying the model.

EFA and CFA models are illustrated in Fig. 3.4. For the EFA, all items are allowed to load on all the factors. The term "factor pattern coefficient" is consistently used for the weight (or standard regression coefficient) of each item on its factors. It is given in the factor pattern coefficient (matrix P). The single correlation coefficient between the item and the factor score is presented in the "factor structure coefficient" (matrix S). The two 
sets of coefficients are identical in number for orthogonal rotation when factor correlation is 0 (so factor correlation matrix $\mathrm{R}$ is identity matrix), but different for oblique rotation. Both the matrix P and S are expected for EPM (Educational and Psychological Measurement) manuscripts (B. Thompson \& Daniel, 1996). For CFA, the term "loading" is used to refer to either matrix P or S, since in CFA items are set to load on one factor only, and there is only one set of coefficient matrix. When we use the term item loading, we always mean the correlation coefficient for the item on its specific factor.

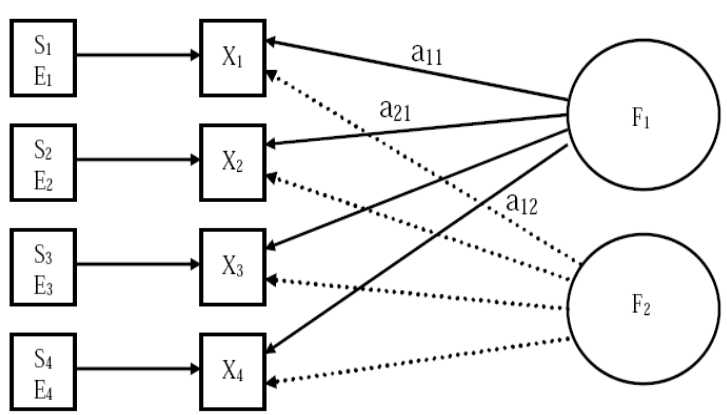

EFA model

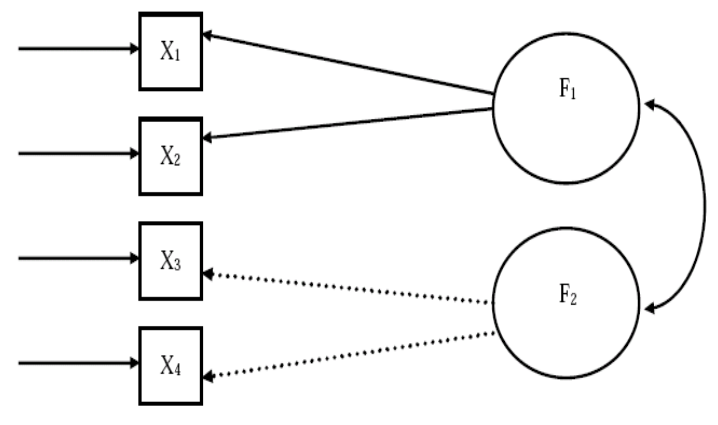

CFA model

Figure 3.4 EFA and CFA model

\section{The Number of Factors}

As to how many factors should be extracted in the EFA, there are many rules of thumbs.

The most used rule is to examine the number of eigenvalue greater than one because it is the default option in most statistics packages like Mplus (Muthe'n \& Muthe'n, 2007). However, it is far from perfect because it is hard to defend, especially to decide a factor when eigenvalue is 1.01 and not a factor when eigenvalue is .99. Other approaches, such as bootstrap (Thompson, 1994) and parallel analysis, have more considerable merit but are underused. It is safe to check from different ways leading to the same solution. 


\section{Summary}

It is clear that reliability and validity estimates are necessary to support the statistical inference based on test scores. However, report on reliability and establishment of validity is not frequently seen in literature. The mostly used strategies for factor analysis for the instrument development in science education are PCA or EFA, even when the instrument has a clear design of subscales and CFA is the most appropriate. CFA has never been reported in the attitude-related instruments published on JCE at present. Chapter Four will report the methods part for all administrations for different versions of ASCI. 


\section{Chapter Four}

\section{Method}

The different versions of ASCI were administered for five times in this study during the semester of spring and summer of 2009. Firstly, original ASCI (V1) was administered. Then three revised versions of ASCI were created and given to four different populations. The responses from all administrations were evaluated in terms of psychometric properties and compared with literature results where appropriate. The evaluations had two main foci: reliability and validity.

This method chapter is organized in four parts. The first is the summary of general research methods that are common to all administrations. The second is the scale reconstruction, i.e., using results from ASCI V1 to create meaningful subscales aligned with the general theory of the attitude concept. The third is the gathering of additional validity evidence for ASCI V2 scores, including the discussion of a nomological network and of predictive validity. The last is analysis specific for calculus course such as Chisquare test.

\section{General Research Methods}

\section{Instruments}

For the first administration, ASCI V1 (Bauer, 2008) was used. As discussed previously, it has twenty pairs of objectives grouped into five subscales to tap students' attitudinal status towards chemistry in general. For the second administration, the revised ASCI (V2) was used. ASCI V2 (Appendix) is a short form of V1. It has eight pairs of objectives 
organized in two subscales. ASCI V3 has the same eight items as those in V2, with the only difference in item order of \#2 (simple vs complicated) and \#8 (chaotic vs organized). V3.1 is the same as V3, except that the word "Chemistry" is changed to "Calculus" in order to measure students' attitude towards calculus.

\section{Participants and Data Collection}

The participants for the five administrations are summarized in Table 4.1 organized on time and version order. ASCI V1 was given in all lab rooms of General Chemistry I \& II labs at a large Southeastern Public Research University (SE) during the $4^{\text {th }}$ week of the Spring 09 semester. ASCI V2 was given to all the General Chemistry I Peer-led (PL) sessions on Mar. 27 (two days after the third term exam and after the course drop date) at SE. ASCI V3 was given to chemistry students during the last week of Spring 09 at a large Middle West Public Research University (MW). ASCI V3.1 was given to students in seven calculus classrooms during the last week at SE. Later in the first week of Summer 09 semester, V2 was given to all the Biochemistry students at SE.

Table 4.1 Summary of administrations for different versions of ASCI

\begin{tabular}{llllll}
\hline ASCI & \# of & \# of & Administration time & participants & \\
version & item & scale & & & Major changes \\
\hline V1 & 20 & 5 & Near the end of semester & General Chemistry lab at UNH $^{\text {a }}$ & Original, or V1 (Bauer, 2008) \\
V1 & 20 & 5 & $2 / 2 \sim 2 / 6,4^{\text {th }}$ week, Sp09 & General Chemistry lab I, II, at SE & Replication of V1 \\
V2 & 8 & 2 & $3 / 27,11$ week, Sp09 & General Chemistry class at SE & Short from V1 \\
V3 & 8 & 2 & $4 / 27 \sim 5 / 1$, last week, Sp09 & Chemistry class at MW & Change item order from V2 \\
V3.1 & 8 & 2 & $4 / 20 \sim 4 / 24$, last week, Sp09 & Calculus class at SE & Chemistry inV3, calculus in V3.1 \\
V2 & 8 & 2 & $5 / 18,1^{\text {st }}$ week, Summer 09 & Biochemistry class at SE & Replication of V2 \\
\hline
\end{tabular}

Note: administrations are organized by time.

${ }^{a}$ UNH: University of New Hampshire

${ }^{\mathrm{b}} \mathrm{SE}$ : a large Southeastern Public Research University

${ }^{c}$ MW: a large Middle West Public Research University

For each administration, the instrument was given to each intact class as a paper-andpencil test, most at the beginning of the class. Ten students in one lab section were asked 
to take the survey twice, before and after the lab experiment, to calculate test-retest reliability. Students were verbally instructed to answer with their feelings toward chemistry in general, rather than to a specific teacher or course. The10-choice scantron (marked from A through J or from 0 through 9) was used to collect the data. Students were asked to bubble in the name, UID, and their answer to each item on the scantron. Any response with multiple answers, missing data, missing UID or wrong response beyond the supposed range (each response should range from 1 to 7 ) was excluded for all the analysis below. The same data cleaning process was applied for all the analysis throughout the study. Pattern of missing data was checked for whether the missing data may bias the findings.

\section{Data Analysis Strategy}

To accomplish research goals, data from each administration was analyzed for reliability and validity evidence. Various statistics were performed including descriptive statistics, reliability, effect size of group difference, correlation among different concepts, multiple regression to predict chemistry achievement, and factor analysis (exploratory \& confirmatory).

All descriptive statistics were performed in SPSS 17.0 for each item score after the negatively stated items were reversely coded. Good normality of the item score distribution was examined by skewness and kurtosis. Internal consistencies were calculated by Cronbach's alpha for each subscale. Test-retest reliability was obtained for ASCI V1. Factor score was created by adding scores of all the items associated with the factor. Difference in factor scores of student groups at various course levels was quantified using Cohen's $d$ effect size (Cohen, 1988). The guidelines 
$(\mathrm{d}>.2$, small; $\mathrm{d}>.5$, medium, $\mathrm{d}>.8$, large) are used to interpret the $\mathrm{d}$ effect size based on Cohen's standards (1988). Cohen's $d$ reveals how many standard deviation units apart the two groups are on the factor score.

Factor correlation values were measured in two ways. In the traditional way, factor correlations are based on the factor score as the sum of all grouping items. Due to the existence of measurement error, these correlations can be underestimated. Factor correlations obtained via confirmatory factor analysis are corrected for measurement error. Both values are reported to support discussion of how well students discriminate the different scales.

EFA was performed on the correlation matrix of all the item data in SPSS 17.0 to better understand the internal structure of the results each time. To decide the number of factors to extract, the eigenvalue-greater-than-one rule was carefully used, and comprehensive approaches such as scree plot, parallel analysis, and interpretability were used. Bauer performed FA using principal components analysis (PCA) and Varimax rotation, which will be referred to as strategy A. Strategy A was occasionally used to make easy comparison with literature results. However, PCA is appropriate for the research interest of prediction, which is not the major concern here. Because the research interest is the measure of latent variable and components which are correlated, principal axis factor analysis methods (EFA) and Promax to allow factors to correlate (strategy B). Strategy $\mathbf{B}$ was applied consistently throughout all the FA report if not stated explicitly. CFA was performed in Mplus 5.2 to estimate how theoretical model fits the data. It was run on a first-order (4-factor solution for ASCI V1, 2-factor for V2, V3 and V3.1), where the latent factors were set to correlate with each other. Using the variance-covariance 
matrix of all the item data as indicated by Cudeck (1989), a maximum-likelihood method was employed. All items were set to load on their assumed factors only. Model is identified by fixing the first item on its factor at 1 . In general, models based on a large number of scores are likely to have an inflated Chi-square value for the model fit, so it is a good idea to examine three additional fit statistics: if the Comparative Fit Index (CFI) is greater than .95 (some may use CFI less than.90, (Cheng \& Chan, 2003)), and the Root Mean Square Error of Estimation (RMSEA) and the Standard Root Mean Square Residue (SRMR) are both less than .08, the model can be considered a good fit to the data (Hu \& Bentler, 1999). This criterion will be used consistently for the estimate of model fit. For the CFA, it is important to falsify the plausible rival hypotheses since untested models may fit the same data even better. For the ASCI V1, we tested many possible model options based on responses of reduced number of items, in order to create conceptual meaningful scales for the revised version. For the ASCI V2, when the twofactor model fit was supported by CFA, we further tested the plausible rival hypotheses of one-factor model for the most parsimonious solution.

\section{Scale Reconstruction Based on ASCI VI}

A framework for scale reconstruction was created (Fig. 4.1) and the major steps were implemented to refine ASCI. Step 1 is the obtainment of pilot test information, which was ASCI (V1) from literature; Step 2 is the administration of the instrument; Step 3 is the descriptive analysis of mean, standard deviation, pattern of missing data, reliability, and item-total correlations; Step 4 is EFA for the internal structure and comparison with literature; Step 5 is CFA for alternate model fit and revealing aspects of measurement error; and Step 6 is to propose conceptually meaningful scales when there is a lack of 
psychometric evidence for existing scales, and to run CFA on the possible revised versions based on the scores of remaining items and reconstructed models. The proposed revised version is then administered to a different population and the process is repeated. Step 7, which we are currently working on in collaboration with others, is extensive administration to independent populations within a similar context. Step 8 (not shown) would involve evaluation in different contexts.

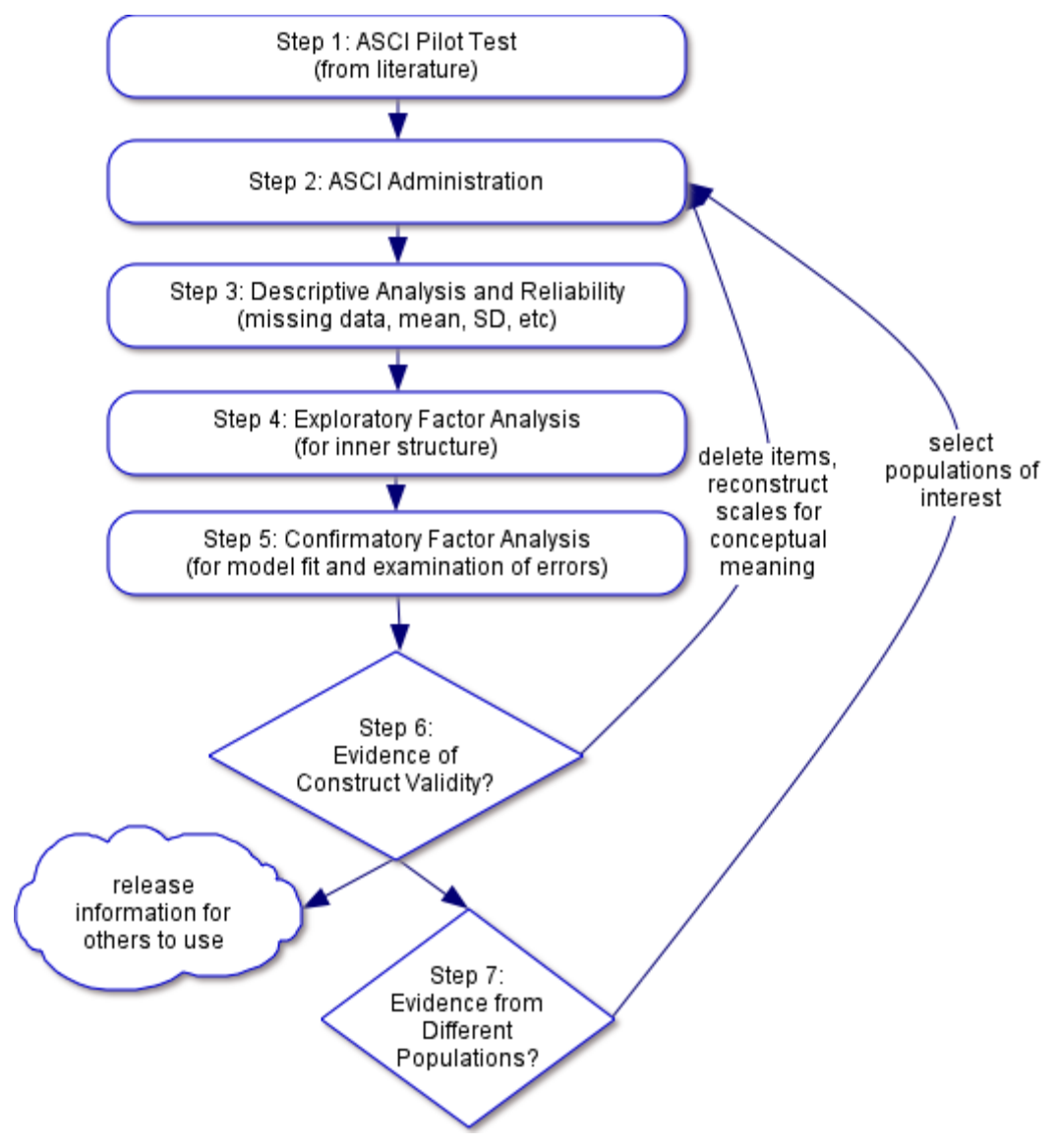

Figure 4.1 Framework for scale development

The ideal candidates for removal from an instrument are items with poor psychometric quality, including those with highly skewed or unbalanced distributions, low variabilities, low item-total correlations, weak loadings on the hypothetical factor (below .35 from EFA), or heavy loadings on multiple factors. Additionally, CFA can reveal items or 
scales with correlated errors, which indicates that only one of the correlated items/scales is needed to capture the information. This scale development strategy has been successfully applied to create new scales emerging from factor analysis of test responses in literature (Germann, 1988).

\section{Validity Estimate for ASCI V2 Score}

\section{Nomological Network among Attitude, Aptitude and Chemistry Achievement}

Correlational analysis among attitude, ability and achievement was performed in SAS 9.13 to support attitude nomological network. Data were obtained from the same general chemistry population as ASCI V2 data. ASCI V2 score (emotion and cognition components) was used to measure students' chemistry attitude. Student demographic information and their ability scores were collected via the registrar's office. Previous ability was measured by the quantitative portion of the Scholastic Aptitude Test (SATM), which has been used to predict the first year chemistry achievement (Scott E. Lewis \& Lewis, 2007). . At the end of the semester, students' scores on the First Term General Chemistry Blended Examination from the Examinations Institute of the ACS Division of Chemical Education (40 items) (www4.uwm.edu/chemexams/contact). Due to confidentiality requirements for using the ACS Exam, no test item can be shown here. The distribution for each variable was examined. Scatterplots of each pair of variables were also examined. Consequently, the relationships among variables were summarized using correlation coefficients. The following values (.10 small, .30 medium, .50 large) (51) were used to interpret the magnitude of coefficients. 
The distribution for each variable was examined. Scatterplots of each pair of variables were then visually examined. Consequently, these relationships were summarized using correlations coefficients. The following values ( .10 small, .30 medium, .50 large) in social science study (Cohen, 1977) was used to interpret the magnitude of coefficients $r$.

\section{Predictive Validity for ASCI V2 score}

Multiple regression analysis was performed in SAS 9.13 to predict student achievement in general chemistry based on scores from ASCI V2 and SATM. The score on the ACS exam was the dependent variable (the variable we want to predict, or D.V.). Three different regression models were tested using combination of predictor variables (the variables we use to make prediction, or independent variable, I.V.). The possible violation of assumptions to run correlation multiple regression include normality, linearity, outliers and homoscedasticity, which may greatly affect the results when violated (Osborne \& Waters, 2002). Normality assumption means all the predictor variables (emotion, cognition and SATM), dependent variable (ACS) and prediction error should be normally distributed. Linearity assumption means that there a linear correlation between the I.V. and the P.V. Homoscedasticity assumption means that the error should distribute equally on the both sides of the regression line at any point of the predicted value. Data were checked for possible violations of assumptions, including assumptions of normality, linearity, and homoscedasticity. Influential outliers were examined by studentized residuals and Cook's D. The prediction equation and semi-partial correlations are reported for the best and most parsimonious model. 


\section{Chi-square Analysis for V3.1 Participants}

In the study of ASCI V3.1 given to calculus students, 7 sections of calculus class instructors agreed to participate. In order to examine the representative of the student sample in the whole college calculus student population, the frequency of surveyed students on declared major was compared with those all the enrolled students without survey by Chi-square analysis and Fisher exact test (Fisher, 1922). For Chi-square analysis, when the cells in the contingency table have less than 5 counts, the test assumption of large sample size may be violated. Fisher exact test is a better estimate when cells have small sample size. In this study, most students belonged to a few majors such as biomedical sciences and engineering major, while many other majors like social science have zero count. Therefore, Fisher exact test was performed along with the traditional Chi-square analysis.

In the next two chapters, results from the original and revised ASCI will be presented, each started with a brief method description and followed by analysis and discussion. 


\section{Chapter Five}

\section{Quality Evaluation for Original ASCI (V1)}

This chapter presents results from quality evaluation of ASCI V1. ASCI V1 was given to each intact class of General Chemistry I and II labs during the 6th week of the Spring 09 semester (from Feb. 2 through Feb 6) at a large Southeastern Public Research University (SE). The data analysis process described by the ASCI developer was applied to this study here. New versions of ASCI based on ASCI V1 results will be proposed.

\section{Results and Discussion}

There were 405 complete and correct responses for General Chemistry I labs and 509 responses for General Chemistry II labs. No pattern was found in those missing data. Descriptive statistics are shown in Table 5.1 for each item organized by each subscale described in Bauer's study with all 14 negatively stated items recoded (2008). According to the literature, the "interest and utility" subscale has five items, which are items $15,2,6$, 12 and 3. The "anxiety" subscale has five items, which are items 19, 16, 8, 20 and 13. The "intellectual accessibility" subscale has five items (4, 5, 1, 10 and 9). The "emotional satisfaction" subscale has four items $(11,14,17$ and 7$)$. The average item scores ranged from 2.31 to 5.82 , and standard deviations ranged from 1.27 to 1.71 . No item was found to have skewness or kurtosis greater than 1.2 , which suggests good normality of the item score. For the General Chemistry I labs, the mean scores for the five items in "interest and utility" subscale were 4.86, 5.13, 4.54, 4.68 and 4.00, which are all above the middle point, suggesting average students feel chemistry is interesting and useful. The item mean scores for the "Anxiety" subscale were 5.1, 5.82, 3.95, 4.14 and 3.95, which suggests 
students think chemistry is anxiety producing. For the "intellectual accessibility" subscale, the item means were $2.80,3.22,2.6,2.31$ and 4.02, which indicates they normally think chemistry is not intellectually accessible. For the "emotional satisfaction" subscale, the item means were $3.63,3.76,4.03$ and 3.26 , which means they are not emotionally satisfied.

Table 5.1 Descriptive statistics for ASCI V1, General Chemistry labs I and II

\begin{tabular}{|c|c|c|c|c|c|c|}
\hline \multirow[b]{2}{*}{ Item in each subscale } & & & Mean & SD & Mean & SD \\
\hline & & & \multicolumn{2}{|c|}{ Lab I $(\mathrm{N}=405)$, } & \multicolumn{2}{|c|}{ Lab II $(\mathrm{N}=509)$} \\
\hline \multicolumn{7}{|l|}{ Interest \& utility } \\
\hline $15 \mathrm{r}^{\mathrm{a}}$ & worthwhile & useless & 4.86 & 1.57 & 4.92 & 1.48 \\
\hline 2 & worthless & beneficial & 5.13 & 1.58 & 5.14 & 1.48 \\
\hline $6 r$ & good & bad & 4.54 & 1.6 & 4.56 & 1.53 \\
\hline $12 \mathrm{r}$ & interesting & dull & 4.68 & 1.6 & 4.56 & 1.61 \\
\hline $3 r$ & exciting & boring & 4.00 & 1.54 & 4.05 & 1.61 \\
\hline \multicolumn{7}{|l|}{ Anxiety } \\
\hline $19 \mathrm{r}$ & tense & relaxed & 5.1 & 1.36 & 4.94 & 1.38 \\
\hline $16 r$ & work & play & 5.82 & 1.36 & 5.65 & 1.46 \\
\hline $8 \mathrm{r}$ & scary & fun & 3.95 & 1.41 & 4.06 & 1.44 \\
\hline $20 \mathrm{r}$ & insecure & secure & 4.14 & 1.4 & 4.16 & 1.36 \\
\hline $13 r$ & disgusting & attractive & 3.95 & 1.3 & 3.92 & 1.44 \\
\hline \multicolumn{7}{|c|}{ Intellectual accessibility } \\
\hline 4 & complicated & simple & 2.80 & 1.52 & 2.91 & 1.51 \\
\hline 5 & confusing & clear & 3.22 & 1.5 & 3.38 & 1.51 \\
\hline $1 \mathrm{r}$ & easy & hard & 2.6 & 1.27 & 2.98 & 1.45 \\
\hline 10 & challenging & unchallenging & 2.31 & 1.35 & 2.57 & 1.47 \\
\hline $9 \mathrm{r}$ & comprehensible & incomprehensible & 4.02 & 1.5 & 4.26 & 1.52 \\
\hline \multicolumn{7}{|l|}{ Fear } \\
\hline 18 & safe & dangerous & 3.88 & 1.39 & 3.78 & 1.44 \\
\hline \multicolumn{7}{|l|}{ Emotional satisfaction } \\
\hline $11 \mathrm{r}$ & pleasant & unpleasant & 3.63 & 1.51 & 3.69 & 1.53 \\
\hline $14 \mathrm{r}$ & comfortable & uncomfortable & 3.76 & 1.39 & 3.91 & 1.39 \\
\hline 17 & chaotic & organized & 4.03 & 1.62 & 3.97 & 1.54 \\
\hline $7 \mathrm{r}$ & satisfying & frustrating & 3.26 & 1.71 & 3.44 & 1.71 \\
\hline
\end{tabular}

Note: Each score should range from 1 to 7 , and 4 is in the middle point. Items are organized by each subscale in the same order as in the literature. Higher score means students feel chemistry is interesting and useful, anxiety producing, intellectually accessible, dangerous and emotional satisfying. Item 16 has the highest mean, and item 10 has the lowest mean, which indicates they feel chemistry is work rather than play, and is challenging. $\mathrm{r}^{\mathrm{a}}$ : item score is reversed before averaging. 
The internal consistencies for each subscale using the listwise deletion are in Table 5.2. Cranbach's alpha was $.82, .71, .79$ and .74 for the General Chemistry I labs for each subscale, and $.85, .79, .82$ and .78 for General Chemistry II labs, which are all above satisfactory level .70, and comparable to the literature results. The test-retest (before and after the lab) reliability was above .9 and better than literature report. From these analyses, our instrument data has a very good reliability.

Table 5.2 Internal consistency and test-retest reliability for V1, General Chemistry labs

\begin{tabular}{llll|ll}
\hline Scale (Items) & \multicolumn{2}{l}{$\begin{array}{l}\text { Internal consistency by Cronbach's } \\
\text { alpha }\end{array}$} & \multicolumn{2}{l}{ Test-retest reliability by Pearson correlation } \\
& $\begin{array}{l}\text { Lab I } \\
(\mathrm{N}=405)\end{array}$ & $\begin{array}{l}\text { Lab II } \\
(\mathrm{N}=509)\end{array}$ & $\begin{array}{l}\text { Bauer's } \\
\text { study }\end{array}$ & $\begin{array}{l}\text { for our sample } \\
(\mathrm{N}=10)\end{array}$ & Bauer's study \\
& & .85 & .83 & .91 & .74 \\
\hline Interest\&Utility $(15,2,6,12,3)$ & .82 & .79 & .77 & .96 & .64 \\
Anxiety (19,16,8,20,13) & .71 & .82 & .78 & .96 & .71 \\
Accessibility (4,5,1,10,9) & .79 & .78 & .79 & .96 & .72 \\
Emotional satisfaction (11, & .74 & & & & \\
$14,17,7)$ & & & &
\end{tabular}

Item loadings from EFA are listed in Table 5.3 along with the loading Bauer reported.

For the two subscales, "Interest and utility" and "Intellectual accessibility", all items are loaded well on the assumed factors in the literature. For the subscales "anxiety" and “emotional satisfaction", some items are loaded on more than two subscales. For example, item 8 , which is about "scary" vs "fun", has the item loading of -..38, .26, .53 and -.15 on the four subscales ( "interest and utility", "anxiety, "intellectual accessibility" and “emotional satisfaction") for General Chemistry I labs and has the loading of $.49, .33, .40$ and -.20 for General Chemistry II labs. It is hard to tell since this item should be loaded on "Interest and utility", however sometimes it can load on "intellectual accessibility". Similar loading patterns for the three data sets indicate that different 
student samples from different institutions and different levels may respond to survey

items in a similar way.

Table 5.3 The item loadings for V1, General Chemistry labs

\begin{tabular}{|c|c|c|c|c|c|c|c|c|c|c|c|c|c|c|}
\hline & \multirow[t]{2}{*}{ Item } & & \multicolumn{4}{|c|}{ General Chemistry I labs } & \multicolumn{4}{|c|}{ General Chemistry II labs } & \multicolumn{4}{|c|}{ Literature } \\
\hline & & & f1 & $\mathrm{f} 2$ & $\mathrm{f} 3$ & $\mathrm{f} 4$ & $\mathrm{f} 1$ & $\mathrm{f} 2$ & f3 & f4 & f1 & $\mathrm{f} 2$ & $\mathrm{f} 3$ & f4 \\
\hline & Interest and & utility & use & anx & accs & emot & use & anx & accs & emot & use & anx & accs & emot \\
\hline $15^{\mathrm{a}}$ & worthwhile & useless & .75 & -.22 & .01 & .06 & .85 & .05 & -.08 & .06 & .85 & .01 & -.06 & -.11 \\
\hline 2 & worthless & beneficial & -.68 & .21 & .05 & .04 & -.79 & -.01 & .09 & -.06 & -.79 & -.1 & .03 & -.04 \\
\hline $6^{\mathrm{a}}$ & good & bad & .68 & -.20 & -.16 & .13 & .72 & -.22 & -.12 & .17 & .71 & .05 & -.2 & -.04 \\
\hline $12^{\mathrm{a}}$ & interesting & dull & .80 & -.17 & -.13 & -.01 & .77 & -.31 & .00 & .05 & .67 & .32 & .02 & -.15 \\
\hline \multirow[t]{2}{*}{$3^{\mathrm{a}}$} & exciting & boring & .69 & .08 & -.24 & -.08 & .57 & -.48 & -.03 & .02 & .58 & .38 & -.05 & -.09 \\
\hline & Anxiety & & & & & & & & & & & & & \\
\hline $19^{\mathrm{a}}$ & tense & relaxed & -.17 & .55 & .45 & .31 & -.23 & .65 & .39 & -.11 & -.14 & -.75 & .32 & .02 \\
\hline $16^{\mathrm{a}}$ & work & play & -.14 & .23 & .36 & .71 & -.05 & .71 & .39 & -.03 & .06 & -.74 & .23 & -.15 \\
\hline $8^{\mathrm{a}}$ & scary & fun & -.38 & .26 & $\underline{.53}$ & -.15 &.- .49 & .33 & .40 & -.20 & -.35 & -.6 & .18 & .16 \\
\hline $20^{\mathrm{a}}$ & insecure & secure & -.20 & .64 & .37 & -.17 & -.35 & .46 & .16 & -.43 & -.34 & -.53 & .23 & .29 \\
\hline \multirow[t]{2}{*}{$13^{\mathrm{a}}$} & disgusting & attractive & $\underline{-.55}$ & .44 & .08 & .16 & -.58 & .45 & .12 & -.12 & -.42 & -.53 & -.01 & .11 \\
\hline & Intellectual & $\begin{array}{l}\text { Accessibil } \\
\text { ity }\end{array}$ & & & & & & & & & & & & \\
\hline 4 & complicated & simple & -.05 & .17 & .72 & .05 & -.06 & .22 & .76 & -.02 & -.03 & -.13 & .8 & -.13 \\
\hline 5 & confusing & clear & -.10 & .04 & .78 & -.06 & -.25 & .18 & .77 & -.13 & -.24 & -.33 & .75 & .06 \\
\hline $1^{\mathrm{a}}$ & easy & hard & .19 & -.24 & -.70 & -.07 & .29 & -.07 & -.71 & .18 & .13 & .18 & -.73 & -.34 \\
\hline 10 & challenging & $\begin{array}{l}\text { unchallen } \\
\text { ging }\end{array}$ & .08 & .09 & .69 & .36 & .20 & .25 & .74 & -.03 & .29 & -.36 & .54 & -.01 \\
\hline \multirow[t]{2}{*}{$9^{\mathrm{a}}$} & $\begin{array}{l}\text { comprehens } \\
\text { ible }\end{array}$ & $\begin{array}{l}\text { incompre } \\
\text { hensible }\end{array}$ & .49 & -.12 & -.52 & .20 & .54 & -.11 & -.51 & .32 & .38 & -.03 & -.52 & -.41 \\
\hline & Fear & & & & & & & & & & & & & \\
\hline \multirow[t]{2}{*}{18} & safe & dangerous & .09 & -.29 & -.18 & .68 & -.01 & -.03 & .00 & .87 & .03 & .05 & -.05 & -.85 \\
\hline & Emotional & $\begin{array}{l}\text { Satisfactio } \\
\mathrm{n}\end{array}$ & & & & & & & & & & & & \\
\hline $11^{\mathrm{a}}$ & pleasant & $\begin{array}{l}\text { unpleasan } \\
\mathrm{t}\end{array}$ & .60 & -.13 & -.50 & -.10 & .55 & -.47 & -.32 & .18 & .5 & .44 & -.35 & -.27 \\
\hline $14^{\mathrm{a}}$ & comfortable & $\begin{array}{l}\text { uncomfort } \\
\text { able }\end{array}$ & .46 & -.42 &. .48 & .03 & .52 & -.35 & -.31 & .37 & .48 & .43 & -.35 & -.28 \\
\hline 17 & chaotic & organized & -.25 & .73 & .08 & -.07 & $\underline{-.25}$ & .11 & .28 & $\underline{. .55}$ & -.44 & -.34 & .32 & -.15 \\
\hline $7^{\mathrm{a}}$ & satisfying & frustrating & .49 & -.07 & -.67 & .03 & .56 & -.32 & -.43 & .18 & .41 & .3 & -.46 & -.28 \\
\hline
\end{tabular}

Note: EFA is performed in SPSS 17.0. Same parameters were used including principal components methods and Varimax (orthogonal) rotation using the covariance matrix. Four factors are extracted for comparison. Item loadings on the assumed factors are highlighted in bold along with the literature loading. The item loadings with different loading pattern are italic.

${ }^{a}$ negatively stated

Factor scores (created by adding scores of all the items associated with the factor) and factor correlation values are listed in Table 5.4.1. General Chemistry II lab students score 
slightly higher than General Chemistry I lab students in the "intellectual accessibility" subscale. There is no significant difference in other subscales for these two populations. Compared with the literature, our data are lower in the "intellectual accessibility" subscale and higher in the "fear" subscale. Our chemistry major students score relative higher in the "anxiety" and "emotional satisfaction" than the non-major students. They experienced strong feelings but we don't know for sure due to the small sample size.

Factor correlation pattern is very similar, which indicates the instrument function similarly across different populations.

Table 5.4.1 Factor score and Pearson correlations for V1

\begin{tabular}{|c|c|c|c|c|c|c|c|c|c|c|}
\hline & Interest\&use & Anxiety & Access & Fear & Emotion & Interest\&use & Anxiety & Access & Fear & Emotion \\
\hline & $\begin{array}{l}\text { General Chem } \\
(n=405)\end{array}$ & \multicolumn{4}{|c|}{ General Chemistry I lab } & $\begin{array}{l}\text { General Chem } \\
(\mathrm{n}=509)\end{array}$ & stry II lab & & & \\
\hline Mean $^{a}$ & 54.9 & 59.9 & 33.2 & 47.9 & 44.5 & 54.6 & 59.1 & 37.0 & 46.3 & 45.9 \\
\hline \multirow[t]{2}{*}{ SD } & 13.3 & 15.7 & 17.6 & 23.2 & 19.8 & 13.7 & 17.4 & 19.0 & 24.0 & 20.1 \\
\hline & \multicolumn{5}{|c|}{ Chemistry major students in lab I $(\mathrm{N}=12)$} & \multicolumn{5}{|c|}{ Chemistry major students in lab II $(\mathrm{N}=12)$} \\
\hline Mean & 62.6 & 64.5 & 42.8 & 54.1 & 46.4 & 61.4 & 66.7 & 45.2 & 50.6 & 53.6 \\
\hline Factor & correlation & & & & & & & & & \\
\hline Interest\&Use & & -0.55 & 0.40 & -0.18 & 0.63 & & -0.63 & 0.38 & -0.15 & 0.64 \\
\hline Anxiety & & & -0.64 & 0.17 & -0.75 & & & -0.66 & 0.19 & -0.79 \\
\hline Access & & & & -0.17 & 0.68 & & & & -0.18 & 0.67 \\
\hline Fear & & & & & -0.25 & & & & & -0.28 \\
\hline
\end{tabular}

Table 5.4.2 Subscale scores and Pearson correlations reported by Bauer (2008)

\begin{tabular}{llllll}
\hline From literature & Interest \& use & anxiety & access & fear & emotion \\
\hline Mean $^{\text {a }}$ & 56 & 60 & 44 & 38 & 45 \\
Mean of chemistry major & 82 & 43 & 46 & 41 & 70 \\
& & & & & \\
\hline Factor & correlation & & & & \\
\hline Interest \& use & & -0.51 & 0.32 & -0.15 & 0.64 \\
anxiety & & & 58 & .15 & -0.72 \\
access & & & & -0.19 & 0.62 \\
fear & & & & -0.22
\end{tabular}


* Subscale scores in percentage for comparison (scale value $1=0 \%, 7=100 \%$ ).

CFA was performed to estimate goodness of the 4-factor solution. The five items, which are items 15, 2, 6, 12 and 3, were set to load on the factor "interest and utility" only. The items 19, 16, 8, 20 and 13, were set to load on factor "anxiety" only; and so on for the factors "intellectual accessibility" and "emotional satisfaction". The estimation of the 4factor model fit for General Chemistry I lab is (Table 5.5): $\chi^{2}(\mathrm{~N}=405, \mathrm{df}=146, \mathrm{p}=.00)$ $=618.5, \mathrm{CFI}=\mathbf{. 8 6}, \mathrm{RMSEA}=0.089, \mathrm{SRMR}=.076$. For General Chemistry II lab is: $\chi^{2}$ $(\mathrm{N}=509, \mathrm{df}=146, \mathrm{p}=.00)=692.9, \mathrm{CFI}=.89, \mathrm{RMSEA}=0.086, \mathrm{SRMR}=.079$. Since CFI was less than .95 and RMSEA was greater than .08 , the overall model doesn't fit the data reasonably well.

Table 5.5 Fit statistics of V1 for four-factor CFA

\begin{tabular}{lll}
\hline Fit Statistic & Lab I & Lab II \\
\hline$\chi^{2}$ & 618.5 & 692.9 \\
$\mathrm{df}$ & 146 & 146 \\
$\mathrm{p}$ & .00 & .00 \\
$\mathrm{~N}$ & 405 & 509 \\
$\mathrm{CFI}$ & .86 & .89 \\
RMSEA & .089 & .086 \\
SRMR & .076 & .079 \\
\hline
\end{tabular}

Note: $\chi^{2}=$ Chi-square, $\mathrm{df}=$ degree of freedom, $\mathrm{N}=$ sample size, $\mathrm{CFI}=$ Comparative Fit Index, RMSEA = Root Mean Square Error of Approximation, SRMR = Standardized Root Mean Square Residual

Factor correlation from CFA is shown in Table 5.6. The correlation between the "anxiety" and "emotional satisfaction" constructs is about -.97, which means these two subscales are strongly correlated and redundant. 
Table 5.6 Factor correlation for V1 from CFA

\begin{tabular}{lcccccc}
\hline & Anxiety & Access & Emotional satisfaction & Anxiety & Access & Emotional satisfaction \\
\hline & & Lab I & & & Lab II & \\
\hline Interest \& utility & -.72 & -.46 & .80 & -.77 & -.49 & .84 \\
Anxiety & & .83 & -.98 & & .82 & -.97 \\
Intellectual Accessibity & & & -.85 & & & -.82 \\
& & & & & & \\
\hline
\end{tabular}

\section{Proposal for Possible Revisions of ASCI}

Because no item exhibited an unexpected distribution or contributed negatively to internal consistency, the descriptive analysis did not indicate any item candidates for removal. This result reflected the relatively high quality of ASCI VI. EFA results revealed the item loading pattern to be similar to the literature report, which yielded a smaller number of factors than intended. CFA results indicated that the proposed factors did not produce an acceptable model fit and contained redundancies, revealing the need to refine the instrument by reconsidering its intended scale structure.

Given the existing items, there are various possible combinations for creating scales for a new version. Our first step was simply to look at the scales individually. Table 5.7

presents the model fit results from CFA for six one-scale versions. For the single scale of "intellectual accessibility", CFA was performed with all its items $(1,4,5,9$, and 10) loaded on one factor, with poor fit statistics (Option 1-A). Because Item 9 loaded on multiple factors from the EFA of the whole instrument (Table 5.3), we excluded it and ran CFA again based on the remaining four items. Both fit statistics are improved: CFI $=.99$ and SRMR $=.02$, which supports the one-factor structure (Option 1-B). 
Table 5.7 CFA results for Scale Reconstruction based on ASCI (V1) subscales

\begin{tabular}{|c|c|c|c|c|c|c|}
\hline \multirow[t]{2}{*}{ Option } & \multirow{2}{*}{$\begin{array}{l}\text { \# Of } \\
\text { Scale }\end{array}$} & \multirow[t]{2}{*}{ Items } & \multicolumn{3}{|c|}{ Model Fit Statistics } & \multirow[t]{2}{*}{ Comments } \\
\hline & & & CFI & RMSEA & SRMR & \\
\hline $1-\mathrm{A}$ & 1 & $\begin{array}{l}1,4,5,9, \\
10\end{array}$ & 0.94 & 0.15 & 0.08 & 9 harms the validity of intellectual accessibility scale; removing it \\
\hline $1-\mathrm{B}$ & 1 & $1,4,5,10$ & 0.99 & 0.08 & 0.02 & \multirow{3}{*}{$\begin{array}{l}\text { removing } 15 \text { (redundant with } 2 \text { ) produces a better fit; regardless, the } \\
\text { scale is conceptually problematic }\end{array}$} \\
\hline $2-\mathrm{A}$ & 1 & $\begin{array}{l}2,3,6,12 \\
15\end{array}$ & 0.95 & 0.14 & 0.04 & \\
\hline $2-\mathrm{B}$ & 1 & $2,3,6,12$ & 0.99 & 0.09 & 0.02 & \\
\hline 3 & 1 & $\begin{array}{l}8,13,16 \\
19,20\end{array}$ & 0.97 & 0.09 & 0.04 & good fit for the anxiety scale \\
\hline 4 & 1 & $\begin{array}{l}7,11,14, \\
17\end{array}$ & 0.99 & 0.07 & 0.02 & $\begin{array}{l}\text { good fit for this emotional satisfaction set, also a good match with } \\
\text { attitude theory }\end{array}$ \\
\hline $\mathrm{V} 2$ & 2 & $\begin{array}{l}1,4,5,10 \\
7,11,14, \\
17\end{array}$ & 0.96 & 0.08 & 0.04 & $\begin{array}{l}\text { final version captures both intellectual accessibility and emotional } \\
\text { satisfaction, congruent with two-component attitude theory }\end{array}$ \\
\hline
\end{tabular}

For the scale of "interest and utility", when all items $(2,3,6,12,15)$ are set to load on one factor for CFA (Option 2-A), the fit statistics are: $\chi^{2}(\mathrm{~N}=509, \mathrm{df}=10, \mathrm{p}=.00)=$ $54.2, \mathrm{CFI}=.95, \mathrm{RMSEA}=.14$. Based on model modification indices, the $\chi 2$ value would decrease by 42.5 if the correlation between error terms of Items 2 and 15 was added to the model. One of these two items was therefore a good candidate for deletion. A CFA model was run without Item 15 (Option 2-B). The fit statistics are: $\chi^{2}(\mathrm{~N}=509, \mathrm{df}=6, \mathrm{p}$ $=.00)=9.7, \mathrm{CFI}=.99, \mathrm{SRMR}=.02$, which supports the one-factor model. However, since the scale actually has two concepts (interest and utility), and it is not desirable for one subscale to have more than one concept, it was not included in the revised version. The CFA model fits are acceptable for the subscales of "anxiety producing" and “emotional satisfaction” with all the grouping items (Options 3 and 4). Since "anxiety producing" and "emotional satisfaction" scores are linearly related and redundant, only one scale was chosen for the revised version for administration. "Emotional satisfaction" fits better with the affect component of the attitude framework.

In order to capture both scales, cognition and affect, we propose the ASCI V2. It consists of four items from "intellectual accessibility" about the difficulty of chemistry, and four 
items from "emotional satisfaction" about how good students feel about chemistry. The model fit of two-factor structures based on the eight item scores was tenable (Table 5.7). The next step is to determine whether students discriminate these two factors in an instrument that contains only the relevant eight items, which requires the administration of ASCI V2 to another student sample.

\section{Summary}

Based on above analysis, ASCI V1 functions similarly across our population and those described by Bauer. It did not provide meaningful interpretation for all these 20 items, and did not reflect the underpinning theoretical framework, because the way to group the items is not stable and inconsistent with factor analysis results. The analysis of this administration leads to the modification of a new version. ASCI V2 was proposed and hopefully can be more conceptually meaningful. It has eight items across two subscales. One is intellectual accessibility and the other is emotional satisfaction, therefore, it was congruent with the cognitive and affective components of attitude theory. ASCI V2 and two more derivative versions (V3 and V3.1) were further given to different student populations and will be discussed in the next chapter. 


\section{Chapter Six}

\section{Quality Evaluation for Revised ASCI}

This chapter describes quality evaluation results from four administrations of the modified ASCI. All of these modified versions (V2, V3, V3.1) have eight items grouped across two subscales. The following presentation of results is organized based on each administration in the same order as in Table 4.1.

ASCI V2 was given to the General Chemistry I Peer-Led (PL) classes on March 27 at the beginning of the class at a large Southeastern Public Research University, two days after the third term exam and after the drop date. ASCI V3 and V3.1 were created on the basis of V2 to examine if changed item order could lead to better validity evidence. V3.1 was modified from V3 to assess the effectiveness in a calculus context to measure students' attitude toward calculus. At last, ASCI V2 was given to another student group enrolled in Biochemistry course.

\section{Quality Evaluation for Revised ASCI V2, Peer-Led classes}

\section{Results and Discussion}

From 375 set of data returned, 354 respondents with the complete set were used for data analysis. Descriptive statistics were performed for each item score after all four negatively stated items were recoded. Average scores for each item from the 354 respondents ranged from 2.50 to 4.26 , and standard deviation ranged from 1.28 to 1.70 (Table 6.1). No item was found to have skewness or kurtosis greater than .7, which suggests good normality of the scores. The item scores on V2 are comparable to the same 
item scores in V1. The mean scores for General Chemistry I lab students are comparable to the scores constructed for a similar sample of students who took ASCI V1 in the General Chemistry I Laboratory (Table 6.1).

Table 6.1 Descriptive statistics for ASCI V2, PL classes

\begin{tabular}{|c|c|c|c|c|c|c|c|}
\hline \multicolumn{4}{|c|}{ Item \# } & \multicolumn{2}{|c|}{ Lab I, n=405, V1 } & \multicolumn{2}{|c|}{$\mathrm{PL}, \mathrm{n}=354, \mathrm{~V} 2$} \\
\hline V1 & $\mathrm{V} 2$ & & & Mean & SD & Mean & SD \\
\hline 1 & $1 \mathrm{r}$ & easy & hard & 2.60 & 1.27 & 2.81 & 1.28 \\
\hline 4 & 2 & complicated & simple & 2.80 & 1.52 & 2.95 & 1.43 \\
\hline 5 & 3 & confusing & clear & 3.22 & 1.50 & 3.36 & 1.40 \\
\hline 14 & $4 r$ & comfortable & uncomfortable & 3.76 & 1.39 & 3.64 & 1.36 \\
\hline 7 & $5 r$ & satisfying & frustrating & 3.26 & 1.71 & 3.24 & 1.70 \\
\hline 10 & 6 & challenging & unchallenging & 2.31 & 1.35 & 2.50 & 1.50 \\
\hline 11 & $7 \mathrm{r}$ & pleasant & unpleasant & 3.63 & 1.51 & 3.38 & 1.41 \\
\hline 17 & 8 & chaotic & organized & 4.03 & 1.62 & 4.26 & 1.66 \\
\hline
\end{tabular}

Note: Item score is reversed before averaging.

Each item score should range from 1 to 7 , while 4 is in the middle point. Higher score means students feel chemistry is intellectually accessible, emotional satisfying. Item 8 has the highest mean of 4.26, and item 6 has the lowest mean of 2.50 , which indicates they feel chemistry is organized, and is challenging.

Internal consistency reliability was measured by Cronbach's alpha for each subscale. Cronbach's alpha was .82 and .79 for the "intellectual accessibility" and "emotional satisfaction" subscales, respectively. Both values are above the rule-of-thumb satisfactory level of .7, and comparable to ASCI (V1) and the literature results.

Factor scores were created by summing the items within each subscale: 2.91 (31.8\% if converted to a percentage) for intellectual accessibility and $3.63(43.8 \%)$ for emotional satisfaction, with a correlation of .64 between the two factors. Factor scores and correlation for this administration of ACSI V2 were very similar to those calculated from ASCI V1 data for a similar sample of students, which indicate these eight items function similarly even when the other 12 items are removed from the instrument. 
Table 6.2 Subscale scores and Pearson correlations for ASCI V2, PL classes, along with results from General Chemistry I labs

\begin{tabular}{|c|c|c|c|c|c|c|c|}
\hline \multicolumn{3}{|c|}{ PL ( $n=354), V 2$} & \multicolumn{5}{|c|}{ Gen. Chemistry I lab $(n=405)$, ASCI V1 } \\
\hline & Access & Emotion & Interest\&Use & Anxiety & Access & Fear & Emotion \\
\hline Mean & $2.91\left(31.8^{\mathrm{a}}\right)$ & $3.62\left(43.8^{\mathrm{a}}\right)$ & 54.9 & 59.9 & 33.2 & 47.9 & 44.5 \\
\hline SD & 1.13 & 1.20 & 13.3 & 15.7 & 17.6 & 23.2 & 19.8 \\
\hline Factor & & & correlation & & & & \\
\hline Interest \& Use & & & & -0.55 & 0.40 & -0.18 & 0.63 \\
\hline Anxiety & & & & & -0.64 & 0.17 & -0.75 \\
\hline Access & & .64 & & & & -0.17 & 0.68 \\
\hline Fear & & & & & & & -0.25 \\
\hline
\end{tabular}

${ }^{a}$ Subscale scores in percentage for comparison (scale value 1=0\%, 7=100\%).

Table 6.3 Internal consistency for PL classes, along with General Chemistry I Lab I and Bauer's results

\begin{tabular}{|c|c|c|c|}
\hline & Internal consistency by & Cronbach's alpha & \\
\hline & $\mathrm{PL}(\mathrm{N}=354), \mathrm{V} 2$ & lab I $(\mathrm{N}=405), \mathrm{V} 1$ & Bauer's result (2008), V1 \\
\hline Intellectual Accessibility $^{\text {a }}$ & .82 & .79 & .78 \\
\hline Emotional satisfaction & .79 & .74 & .79 \\
\hline
\end{tabular}

${ }^{a}$ The ASCI V1, Intellectual accessibility has five items $(4,5,1,10,9), \mathrm{V} 2$ has its four without item 9.

An exploratory factor analysis for V2 was performed using strategy A including principal components methods and Varimax rotation as in the literature. Two factors were extracted. Item loadings are listed in Table 6.4. All items were loaded well (all loadings were greater than .6 here) on the assumed factors in the literature. The loading pattern for the short version was exactly what we expected for the revised version. 
Table 6.4 The item loadings for V2, PL classes

\begin{tabular}{cllll}
\hline Item \# in each scale & V2 & & loading \\
& & & F1 & F2 \\
\hline Intellectual & Accessibility & & & \\
$1 \mathrm{r}^{\mathrm{a}}$ & easy & hard & 0.41 & $\mathbf{0 . 6 6}$ \\
2 & complicated & simple & 0.34 & $\mathbf{0 . 7 5}$ \\
3 & confusing & clear & 0.45 & $\mathbf{0 . 6 8}$ \\
6 & challenging & unchallenging & 0.00 & $\mathbf{0 . 8 6}$ \\
\hline Emotional & Satisfaction & & & \\
$4 \mathrm{r}$ & comfortable & uncomfortable & $\mathbf{0 . 7 4}$ & 0.29 \\
$5 \mathrm{r}$ & satisfying & frustrating & $\mathbf{0 . 7 2}$ & 0.36 \\
$7 \mathrm{r}$ & pleasant & unpleasant & $\mathbf{0 . 7 5}$ & 0.38 \\
8 & chaotic & organized & $\mathbf{0 . 7 1}$ & 0.02 \\
\hline
\end{tabular}

Note: EFA is performed in SPSS 17.0. Strategy A was used including principal components methods and Varimax (orthogonal) rotation using the covariance matrix. 2 factors are extracted for comparison. Item loadings on the assumed factors are highlighted in bold.

$r^{a}$ : negatively stated

CFA was performed to estimate goodness of fit for the 2-factor model. Items 1, 2, 3 and 6 were set to load on factor "intellectual accessibility" only; items 4, 5, 7 and 8 were set to load on factor "emotional satisfaction" only, and the two factors were allowed to correlate. In order to investigate a more parsimonious model, the alternate 1-factor model solution was also sought. Models were identified by fixing the first item on its factor at 1 .

Fig. 6.1 presents the standardized parameter estimates for both models. 


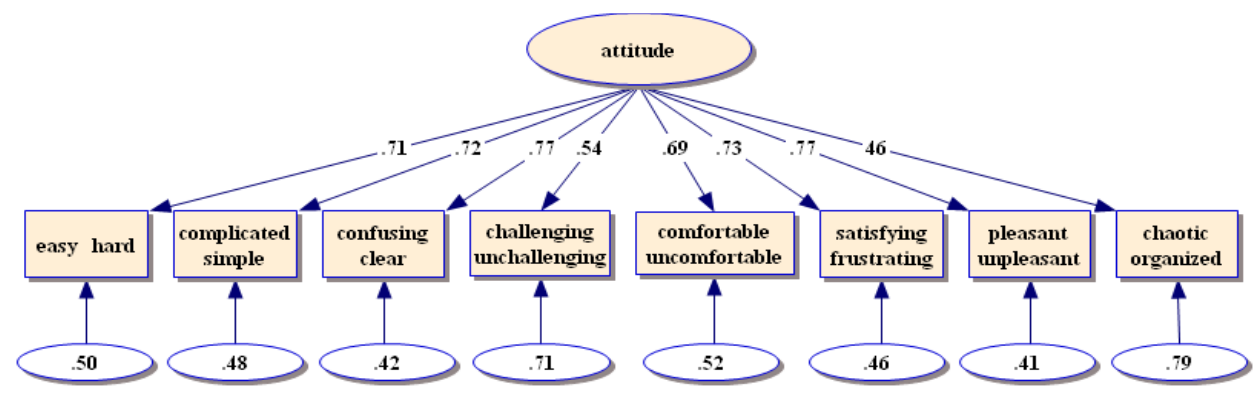

Parameter estimate for one-factor model

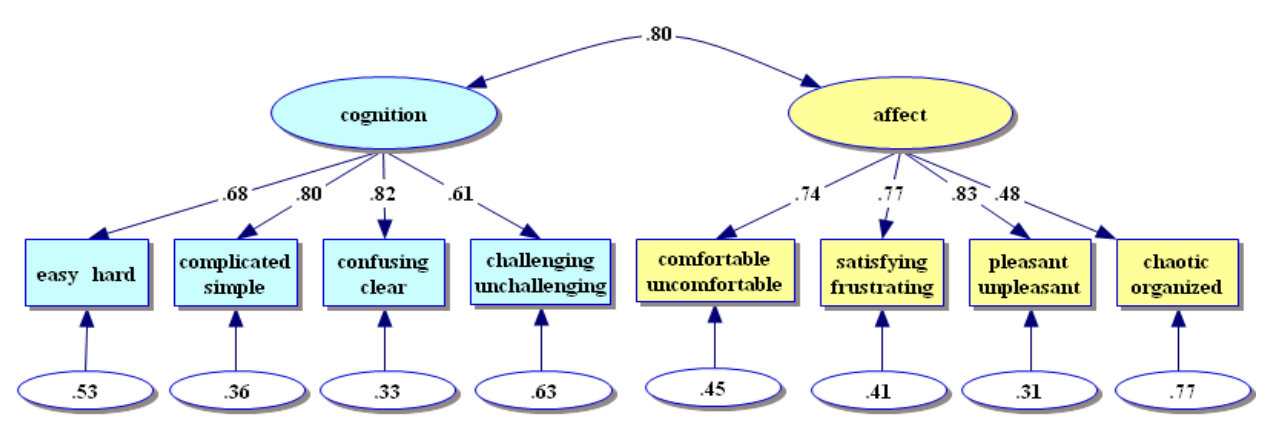

Parameter estimate for two-factor model

Figure 6.1 Standardized parameter estimate for one-factor and two-factor model ( $\mathrm{N}=354)$. The large ovals designate the latent variables, the small circles are the residual variances, and the rectangles indicate the observed variables. Items were set to load on their assigned factors only. All item loadings are significantly different from $0(\mathrm{p}<.01)$.

The estimation of the 2-factor model fit (Table 6.5) test was: $\chi^{2}(\mathrm{~N}=354, \mathrm{df}=19, \mathrm{p}=.00)$ $=77.0, \mathrm{CFI}=.95, \mathrm{RMSEA}=0.093, \mathrm{SRMR}=.042$. Since CFI was.95, and RMSEA was close to .08 , SRMR was less than .08 , the overall model fits the data reasonably well. The estimation of the 1 -factor model fit was: $\chi^{2}(\mathrm{~N}=354, \mathrm{df}=19, \mathrm{p}=.00)=156.1, \mathrm{CFI}=.89$, RMSEA $=0.14$, SRMR $=.056$. Since CFI was less than .95 , and RMSEA was greater than .08, the overall 1-factor model does not fit the data. Therefore, the 2-factor model is more tenable. 
Table 6.5 Fit statistics of V2 results for 1- and 2-factor CFA

\begin{tabular}{lll}
\hline Fit Statistic & \multicolumn{2}{c}{ Value } \\
\hline Model & one-factor & two-factor \\
\hline$\chi^{2}$ & 156.1 & 77.0 \\
$\mathrm{df}$ & 19 & 19 \\
$\mathrm{p}$ & .00 & .00 \\
$\mathrm{~N}$ & 354 & 354 \\
$\mathrm{CFI}$ & .89 & .95 \\
RMSEA & .14 & .093 \\
SRMR & .056 & .042 \\
\hline
\end{tabular}

Note: $\chi^{2}=$ Chi-square, $\mathrm{df}=$ degree of freedom, $\mathrm{N}=$ sample size, $\mathrm{CFI}=$ Comparative Fit Index, RMSEA = Root Mean Square Error of Approximation, SRMR $=$ Standardized Root Mean Square Residual

The two aspects of attitude measured by ASCI V2 are expected to be related, though not redundant, which is supported by the 2-factor CFA: the correlation between the "intellectual accessibility" and "emotional satisfaction" constructs is .80.

From the above results, the results of V2 exhibit better psychometric quality to measure and discriminate meaningful component for attitude construct.

\section{Nomological Network among Attitude, Aptitude and Chemistry Achievement}

Previous aptitude score such as SATM is often used for college admission in the United States due to its predictive power of their performance in college science courses (Scott E. Lewis \& Lewis, 2007). In this study ACS score was used as part of the final exam for the General Chemistry I course and expected to correlate with SATM and ACTM. In previous studies, low to moderate attitude-achievement correlation was found. Here ASCI score is expected to correlate with ACS. Since cognition part (intellectual accessibility) is asking students' opinion about the difficulty of the chemistry, cognition score may be correlated with SATM. 


\section{Results and Discussion}

There were 456 students enrolled in the discussion sections of the General Chemistry I course and had ACS score, 383 had SATM scores, 292 had ACTM scores, and 354 had ASCI V2 score. The entire population was included in the correlation analysis.

First, we examined the distribution for each variable. The mean, standard deviation, skewness and kurtosis values are presented in Table 6.6. All the skewness and kurtosis values are less than .32 , which indicates normal distribution. Scatterplots of each pair of variables were then examined. No bivariate outliers or nonlinear relationships were found. Attitude scores for SAT and ACT test takers were not significantly different.

Table 6.6 Descriptive analysis for attitude, aptitude score and final score on ACS

\begin{tabular}{llllll}
\hline Variable & $\mathrm{N}$ & Mean & Std Dev & Skewness & Kurtosis \\
\hline access & 354 & 2.91 & 1.13 & 0.32 & -0.25 \\
emotion & 354 & 3.63 & 1.2 & -0.03 & -0.08 \\
SATM & 383 & 548.5 & 67.1 & 0.19 & 0.23 \\
ACTM & 292 & 23.19 & 3.66 & 0.19 & -0.22 \\
ACS & 456 & 23.17 & 6.2 & 0.02 & -0.07 \\
\hline
\end{tabular}

The relationships among these variables were summarized with correlation coefficient, as presented in Table 6.7, which in essence allows examination of a small nomological network. All relationships were positive as anticipated, significant at the .05 level. The correlation between ACS and other four variables is classified as moderate, based on the guideline for interpreting the magnitude of coefficient $\mathrm{r}$ (.10 small, .30 moderate, .50 
large) in social science study (Cohen, 1977). The attitude-achievement correlation (coefficients: .30 and .34) is consistent with extensive studies (Germann, 1988; Reynolds \& Walberg, 1992; Salta \& Tzougraki, 2004) and not as strong as the ability-achievement correlation (.45 and .46). Since attitude towards chemistry and mathematical ability are conceptually distinct, it is reassuring that low correlations between constructs related to those different concepts are observed (coefficients: .19, .14, .13 and .15). Since two components of the attitude concept, cognition and emotion, should be related but not identical, the high correlation between these two variables from ASCI V2 (coefficient: .64) is also reassuring. Finally, as expected, SATM and ACTM, both intended to measure the mathematics ability, reveal the highest correlation of all (coefficient: .74).

Table 6.7 Pearson correlation among attitude, aptitude and achievement, $\mathrm{N}=456$, Prob > $|\mathrm{r}|$ under $\mathrm{H} 0:$ Rho $=0$

\begin{tabular}{lllll}
\hline & Emotion & SATM & ACTM & ACS \\
\hline Cognition (Intellectual accessibility part of ASCI) & .64 & .19 & .14 & $\mathbf{. 3 0}$ \\
Affect (Emotional satisfaction part of ASCI) & & .13 & .15 & $\mathbf{. 3 4}$ \\
SATM & & & .74 & $\mathbf{. 4 5}$ \\
ACTM & & & $\mathbf{. 4 6}$ \\
\hline P $<0.05$ for all the correlation, correlation coefficients with ACS (dependent variable) are in bold.
\end{tabular}

In sum, all five variables correlate with each other as expected, and thus provide evidence for a small but reasonable nomological network.

\section{Predictive Validity to Predict Chemistry Achievement}

Multiple regression analysis was performed to predict the students' achievement in general chemistry measured by ACS from three predictor variables: ASCI V2 cognition, emotion and SATM. For the 456 students in the above correlation analysis, 297 of them 
have complete data for SATM, ASCI V2 and ACS score. All 297 students were used in the following regression analysis. We expect that the attitude can account for the different portion from SATM in the variance of chemistry achievement.

\section{Results and Discussion}

All three predictors were entered into an initial regression model: emotional satisfaction (ASCI V2), intellectual accessibility (ASCI V2), and mathematics ability (SATM). The maximum values of studentized residuals and Cook's D were 3.3 and .048, respectively. These small values led us to believe that none of the cases were exerting undue influence on the regression analysis. An examination of a scatterplot of the residuals with the predicted values revealed no violations of the linearity or homescedasicity assumptions, and the distribution of the residuals was found to be approximately normal (skewness $=.098$, kurtosis $=-.025)$. Based on the screening of the data it appeared appropriate to proceed with the result analysis.

The obtained $\mathrm{R}^{2}$ value was .286 , suggesting about $28.6 \%$ of the variance in ACS Exam score was accounted for by the three predictors. From squared semipartial correlation of the predictors, SATM uniquely accounted for $17.7 \%$ of the variability in ACS score, emotional satisfaction uniquely $2.4 \%$ and intellectual accessibility $.3 \%$. The regression coefficient for the intellectual accessibility was found to not be significantly different from zero. Although intellectual accessibility and SATM both correlate moderately with ACS score, SATM partially overlaps with the intellectual accessibility. This is a reasonable result, since intellectual accessibility of chemistry as perceived by General Chemistry I and II students is expected to be highly influenced by mathematical ability. 
Therefore, a more parsimonious second model was run with only emotional satisfaction and SATM as predictors.

For the two-predictor model, the obtained $\mathrm{R}^{2}$ value was .283 , suggesting about $28.3 \%$ of the variance in ACS Exam score was accounted for by the two predictors. The adjusted $\mathrm{R}^{2}$ was .278. It appears that the model accounted for an acceptable proportion of the variability in ACS Exam scores. Cohen's effect size $\mathrm{f}^{2}=\mathrm{R}^{2} /\left(1-\mathrm{R}^{2}\right)$ was computed to be .40 , which can be interpreted as a large effect. The root mean square error was 4.95 , which indicated that predictions of ACS Exam scores from this model tend to be off by about 5 points and cannot be regarded as exact predictions.

The obtained prediction equation was:

Predicted ACS score $=-2.29+1.24 *$ Emotion $+0.038 *$ SATM $($ Equation 6.1$)$

The regression coefficients were statistically significant. Since the magnitudes for each variable are different, the regression coefficients should be standardized for better comparison of their contributions to ACS Exam score prediction. Values of .25 and .44 were obtained for emotion and SATM, respectively. The intercept with mean-centered predictors was 23.5, so the predicted ACS score for a student with an average emotional satisfaction score and average SATM score is 23.5. SATM scores uniquely account for $18.8 \%$ of the variability in ACS Exam scores, while emotional satisfaction uniquely accounted for $6.16 \%$.

A two-predictor model using intellectual accessibility and SATM was also examined. SATM uniquely accounted for $18.0 \%$ of the variability in ACS score, while intellectual accessibility uniquely accounted for $4.05 \%$. The obtained $\mathrm{R}^{2}$ value was .262 , suggesting 
about $26 \%$ of the variance in ACS test was accounted by the two predictors, which is lower than the two-predictor model with emotional satisfaction and SATM.

Comparisons of the three regression models suggest that a two-predictor model based on emotional satisfaction and SATM represents the best model to predict ACS Exam score for this data. In terms of predictive validity, the emotional satisfaction score from ASCI V2 can be used to improve predictions of chemistry achievement that would result from the use of a predictor of mathematical ability alone, which supports the idea that emotional satisfaction is a distinct measured construct.

\section{Evaluation of ASCI V3 for Chemistry Class at University MW}

In ASCI V2, items 1, 2 and 3 were all about the intellectual accessibility. I am interested to see how the survey works when the items from two scales are more mixed. For this purpose, the item order of items 2 and 8 was swapped, and thus the new version V3 was created. Hopefully it might reduce possible measurement error and achieve better quality for V3. ASCI V3 was given to chemistry students at a large Middle West Public Research University (MW) during the week of April 27, 2009. There were 309 responses returned, 305 of which with complete sets of data were used for the following analysis. The results of ASCI V1 from PL classes are also listed for comparison.

\section{Results and Discussion}

Descriptive statistics were performed for each item score after all four negatively stated items were recoded (Table 6.8). The average scores for each item ranged from 3.07 to 4.44, and standard deviation ranged from 1.29 to 1.58 . No item was found to have skewness or kurtosis greater than .93 , which suggests good normality of the scores. Each 
item mean score was higher than that in the V2 version for PL students, which suggests a more positive attitude for the MW students.

Table 6.8 Descriptive statistics for ASCI V3, MW chemistry

\begin{tabular}{lllllll}
\hline Item \# & & & MW, n=305, & V3 & PL, n=354, & V2 \\
\hline & & & Mean & SD & Mean & SD \\
\hline 1r & easy & hard & $\mathbf{3 . 6 4}$ & 1.48 & $\mathbf{2 . 8 1}$ & 1.28 \\
2 (in PL, \#8) & chaotic & organized & $\mathbf{4 . 4 4}$ & 1.29 & $\mathbf{4 . 2 6}$ & 1.66 \\
3 & confusing & clear & $\mathbf{4 . 2 6}$ & 1.40 & $\mathbf{3 . 3 6}$ & 1.40 \\
$4 \mathrm{r}$ & comfortable & uncomfortable & $\mathbf{4 . 4 1}$ & 1.35 & $\mathbf{3 . 6 4}$ & 1.36 \\
$5 \mathrm{r}$ & satisfying & frustrating & $\mathbf{4 . 2 9}$ & 1.58 & $\mathbf{3 . 2 4}$ & 1.70 \\
6 & challenging & unchallenging & $\mathbf{3 . 0 7}$ & 1.29 & $\mathbf{2 . 5 0}$ & 1.50 \\
$7 \mathrm{r}$ & pleasant & unpleasant & $\mathbf{4 . 1 3}$ & 1.35 & $\mathbf{3 . 3 8}$ & 1.41 \\
8 (in PL, \#2) & complicated & simple & $\mathbf{3 . 4 6}$ & 1.33 & $\mathbf{2 . 9 5}$ & 1.43 \\
\hline
\end{tabular}

Note: Item score is reversed before averaging.

Each score should range from 1 to 7 , and 4 is in the middle point. Higher score means students feel chemistry is intellectually accessible, emotional satisfying. Item 2 has the highest mean of 4.44, and item 6 has the lowest mean of 3.07, which indicates they feel chemistry is organized, and is challenging.

Internal consistencies were calculated for each subscale using the listwise deletion (Table 6.9). According to instrument design, the "intellectual accessibility" subscale has four items, which are items 1, 8, 3 and 6. The "emotional satisfaction" subscale has four items, which are items 4, 5, 7 and 2. Cranbach's alpha was .77 and .78 for the 2 subscales, which are all above satisfactory level .70, and comparable to the Bauer's results. Table 6.9 Internal consistency for V3, MW chemistry

\begin{tabular}{llll}
\hline \multicolumn{4}{c}{ Internal consistency by Cronbach's alpha } \\
\hline & MW (N=305), V3 & PL (N=354), V2 & Literature (Bauer, 2008) V1 \\
\hline Intellectual accessibility & $\mathbf{. 7 7}$ & .82 & $.78^{\text {a }}$ \\
Emotional satisfaction & $\mathbf{. 7 8}$ & $\mathbf{. 7 9}$ & .79 \\
\hline
\end{tabular}

\footnotetext{
${ }^{\mathrm{a}}$ The ASCI V1, intellectual accessibility scale has five items.
} 
An exploratory factor analysis was performed using strategy B (principal axis factor analysis methods and Promax). Two factors are extracted. Item loadings are listed in Table 6.10. All items were loaded well on the assumed factors except items 1 and 3. Table 6.10 The item loadings for V3 at MW and V2 from PL sessions at SE

\begin{tabular}{lllllll}
\hline Item \# in each scale & & & Loading & MW, V3 & Loading & PL, V2 \\
& & & F1 & F2 & F1 & F2 \\
Intellectual accessibility & & & $\mathrm{N}=305$ & & $\mathrm{n}=354$ & \\
$1 \mathrm{r}^{\mathrm{a}}$ & & hard & 0.35 & $\mathbf{0 . 4 9}$ & 0.38 & $\mathbf{0 . 3 8}$ \\
8 (in V2, \#2) & complicated & simple & 0.02 & $\mathbf{0 . 7 6}$ & 0.01 & $\mathbf{0 . 8 1}$ \\
3 & confusing & clear & $\mathbf{0 . 4 5}$ & 0.37 & 0.19 & $\mathbf{0 . 6 6}$ \\
6 & challenging & unchallenging & -0.19 & $\mathbf{0 . 8 1}$ & -0.11 & $\mathbf{0 . 7 3}$ \\
Emotional satisfaction & & & & & & \\
$4 \mathrm{r}$ & comfortable & uncomfortable & $\mathbf{0 . 7 4}$ & 0.00 & $\mathbf{0 . 8 0}$ & -0.06 \\
$5 \mathrm{r}$ & satisfying & frustrating & $\mathbf{0 . 8 9}$ & -0.13 & $\mathbf{0 . 7 9}$ & -0.01 \\
$7 \mathrm{r}$ & pleasant & unpleasant & $\mathbf{0 . 7 6}$ & -0.08 & $\mathbf{0 . 8 0}$ & 0.03 \\
2 (in V2, \#8) & chaotic & organized & $\mathbf{0 . 3 9}$ & 0.08 & $\mathbf{0 . 4 2}$ & 0.06 \\
\hline
\end{tabular}

Note: EFA is performed in SPSS 17.0. Strategy $\mathbf{B}$ was used including principal axis factor analysis methods and Promax rotation using the covariance matrix. 2 factors are extracted for comparison. Item loadings on the assumed factors are highlighted in bold. Items not loaded on the assumed factors in the literature are in italic.

${ }^{a}$ : negatively stated

Factor scores created by summing item scores and factor correlation value are listed in Table 6.11. Factor score is 3.61 for intellectual accessibility and 4.31 for emotional satisfaction, with a correlation of .51 between them. Factor correlation was similar with that from V2 of for peer-led classes, which indicated the factor function similarly across different versions. Factor score for MW students is higher in both scales, which indicates they feel chemistry is more intellectually accessible and satisfying. 
Table 6.11 Factor scores and Pearson correlations for V3, MW and PL classes at SE

\begin{tabular}{lcccc}
\hline & \multicolumn{2}{c}{ MW, V3 (n=305) } & \multicolumn{2}{c}{ PL, V2 (n=354) } \\
& Intellectual access & Emotion & Intellectual access & Emotion \\
\hline Mean & 3.61 & 4.31 & 2.91 & 3.63 \\
SD & 1.07 & 1.08 & 1.13 & 1.20 \\
\hline Factor correlation & & & & 0.64 \\
\hline Intellectual accessibility & & 0.51 & \\
\hline
\end{tabular}

Confirmatory factor analysis (CFA) was performed to estimate the influence of the measure error and the fit of 2-factor model. The estimation of the 2-factor model fit for the MW chemistry class is (Table 6.12): $\chi^{2}(\mathrm{~N}=305, \mathrm{df}=19, \mathrm{p}=.00)=113.2, \mathrm{CFI}=.89$, RMSEA $=0.13$, SRMR $=.07$. Since CFI was less to .95 , and RMSEA was greater than .08 , the overall model does not fit the data well. The source of misfit is the relatedness for the error term of items 6 and 8. The $\chi^{2}$ would decrease 45.0 if this association is added to the model.

Table 6.12 Fit statistics of V3 at MW from two-factor CFA

\begin{tabular}{ll}
\hline Fit Statistic & Value \\
\hline$\chi^{2}$ & 113.2 \\
$\mathrm{df}$ & 19 \\
$\mathrm{p}$ & .00 \\
$\mathrm{~N}$ & 305 \\
$\mathrm{CFI}$ & .89 \\
RMSEA & .13 \\
SRMR & .07 \\
\hline
\end{tabular}

Note: $\chi^{2}=$ Chi-square, $\mathrm{df}=$ degree of freedom, $\mathrm{N}=$ sample size, $\mathrm{CFI}=$ Comparative Fit Index, RMSEA = Root Mean Square Error of Approximation, SRMR = Standardized Root Mean Square Residual

Factor correlation from CFA between the "intellectual accessibility" and "emotional satisfaction" constructs is .66 , which is consistent with previous findings. 
From the above analysis, the construct validity of ASCI V3 results is not supported by two-factor CFA.

\section{Evaluation of ASCI V3.1 for Attitudes toward Calculus}

All versions of ASCI discussed so far are for chemistry attitude. In order to examine how the survey works for the calculus course, the word "chemistry" was changed to "Calculus" to makes the Version 3.1. At the similar time of ASCI V3 administration, ASCI V3.1 was given to 7 sections of the calculus course during the first 15 minutes of class ( 3 from Engineering Calculus II, 1 from Engineering Calculus I, 1 from Engineering Calculus III, 1 from life science Calculus II, and 1 from Calculus I) during the week of April 20th through April 24th. There were 190 responses returned, 187 with complete sets of data and correct UID without multiple answers, which were used for the following analysis.

\section{Results and Discussion}

Descriptive statistics were performed for each item score after all four negatively stated items were recoded (Table 6.13). It shows the average scores for each item range from 2.66 to 4.68 , and standard deviations range from 1.41 to 1.76 . No item was found to have skewness or kurtosis greater than 1, which suggests good normality of the scores. 
Table 6.13 Descriptive statistics of ASCI V3.1 for calculus attitude

\begin{tabular}{lllll}
\hline Item \# & Calculus, V3.1 & $(\mathrm{N}=187)$ & Mean & SD \\
\hline $1 \mathrm{r}$ & easy & hard & $\mathbf{3 . 2 9}$ & 1.59 \\
2 & chaotic & organized & $\mathbf{4 . 6 8}$ & 1.47 \\
3 & confusing & clear & $\mathbf{4 . 0 9}$ & 1.65 \\
$4 \mathrm{r}$ & comfortable & uncomfortable & $\mathbf{4 . 0 7}$ & 1.55 \\
$5 \mathrm{r}$ & satisfying & frustrating & $\mathbf{3 . 8 6}$ & 1.76 \\
6 & challenging & unchallenging & $\mathbf{2 . 6 6}$ & 1.45 \\
$7 \mathrm{r}$ & pleasant & unpleasant & $\mathbf{3 . 9 4}$ & 1.49 \\
8 & complicated & simple & $\mathbf{3 . 1 6}$ & 1.41 \\
\hline
\end{tabular}

Note: item score is reversed before averaging.

Each score should range from 1 to 7 , and 4 is in the middle point. Higher score means students feel calculus is intellectually accessible, emotional satisfying. Item 2 has the highest mean of 4.68 , and item 6 has the lowest mean of 2.66 (italic), which indicates they feel calculus is organized, and is challenging.

The internal consistencies were calculated for each subscale using the listwise deletion (Table 6.14). The "intellectual accessibility" subscale has four items, which are items 1, 3, 6 and 8. The "emotional satisfaction" subscale has four items, which are items 2, 4, 5 and 7. Cranbach's alpha was .83 and .78 for the 2 subscales, which is above satisfactory level .70, and comparable to the literature results.

Table 6.14 Internal consistency by Cronbach's alpha for V3.1 calculus sections

\begin{tabular}{lll}
\hline Cronbach's alpha & Calculus V3.1 (N=187) & $\begin{array}{l}\text { Literature V1 (Bauer, } \\
2008)\end{array}$ \\
\hline Intellectual accessibility $(1,8,3,6)$ & $\mathbf{. 8 3}$ & $.78^{\text {a }}$ \\
Emotional satisfaction $(4,5,7,2)$ & $\mathbf{. 7 8}$ & .79 \\
\hline
\end{tabular}

${ }^{\mathrm{a}}$ The original version for the literature, Intellectual accessibility has five items.

An exploratory factor analysis was performed using strategy $\mathbf{B}$ (principal axis factor analysis methods and Promax). Two factors were extracted. Item loadings are listed in Table 6.15. All items were loaded well on the assumed factors except items 5 and 2. It is not clear why items 5 and 2 loaded on the "Intellectual accessibility" scale, instead of the 
"satisfaction" scale. Further analysis and cognitive interview need to be done to examine the possible reason for this different data pattern.

Table 6.15 The item loadings for V3.1 Calculus sections from EFA

\begin{tabular}{lllllll}
\hline Item \# in each scale & & & Loading & Calculus, 3.1 & Loading & MW,V3 \\
& & & F1 & F2 & F1 & F2 \\
\hline Intellectual accessibility & & & $\mathrm{N}=187$ & & $\mathrm{~N}=305$ & \\
$1 \mathrm{r}^{\mathrm{a}}$ & easy & hard & $\mathbf{0 . 5 3}$ & 0.29 & 0.35 & $\mathbf{0 . 4 9}$ \\
8 & complicated & simple & $\mathbf{0 . 6 5}$ & -0.07 & 0.02 & $\mathbf{0 . 7 6}$ \\
3 & confusing & clear & $\mathbf{0 . 6 1}$ & 0.20 & $\mathbf{0 . 4 5}$ & 0.37 \\
6 & challenging & unchallenging & $\mathbf{0 . 8 1}$ & -0.02 & -0.19 & $\mathbf{0 . 8 1}$ \\
\hline Emotional satisfaction & & & & & & \\
4r & comfortable & uncomfortable & $\mathbf{0 . 8 9}$ & -0.16 & $\mathbf{0 . 7 4}$ & 0.00 \\
$5 \mathrm{r}$ & satisfying & frustrating & -0.15 & $\mathbf{0 . 6 9}$ & $\mathbf{0 . 8 9}$ & -0.13 \\
$7 \mathrm{r}$ & pleasant & unpleasant & $\mathbf{0 . 7 9}$ & -0.02 & $\mathbf{0 . 7 6}$ & -0.08 \\
2 & chaotic & organized & 0.07 & $\mathbf{0 . 8 8}$ & $\mathbf{0 . 3 9}$ & 0.08 \\
\hline
\end{tabular}

Note: EFA is performed in SPSS 17.0. Strategy $\mathbf{B}$ was used including principal axis factor analysis methods and Promax rotation using the covariance matrix. 2 factors are extracted for comparison. Item loadings on the assumed factors are highlighted in bold. Items not loaded on the assumed factors in the literature are italic.

$r^{a}$ : negatively stated

Factor scores created by summing associated item score are listed in the Table 6.16 for each course level. Life Sciences Calculus II had the lowest factor score of 3.13 for Intellectual accessibility and 3.36 for emotional satisfaction. For the Engineering Calculus course, the higher level course had significantly higher level of positive attitudes towards calculus, (e.g., intellectually Accessibility score was 3.56, 3.79 and 4.33 for level I, II and III respectively) with the median effect size ranging from .2 to .6, which indicates level III students feel that calculus is more intellectually accessible and emotional satisfying. Calculus I had the similar mean scores with the Engineering Calculus I. 
Table 6.16 Factor score for V3.1, calculus sections

\begin{tabular}{llllll}
\hline Level & & Intellectual & Accessibility & Emotion & Satisfaction \\
\hline & $\mathrm{N}$ & Mean & SD & Mean & SD \\
\hline Life Sciences Calculus II & 31 & 3.17 & 1.05 & 3.36 & 1.27 \\
Calculus I & 29 & 3.53 & 1.00 & 3.58 & 1.01 \\
Engineering Calculus I & 16 & 3.56 & 1.03 & 3.56 & 1.36 \\
Engineering Calculus II & 92 & 3.79 & 1.08 & 3.84 & 1.26 \\
Engineering Calculus III & 19 & 4.33 & 1.30 & 4.45 & 1.27 \\
Overall & 187 & 3.68 & 1.12 & 3.76 & 1.26 \\
\hline
\end{tabular}

Although the trend of attitude difference among these levels was observed from Table 6.17 , it is worthwhile to avoid any hasty conclusion, because the student sample here may not represent the whole calculus population, and a lot of factors may exits and affect attitudes. One factor is that, students from different majors may have different attitudes towards chemistry. Non-science major students may hold more negative attitude towards science (Gogolin \& Swartz, 1992). The question arises; did the student sample here represent the students population enrolled in calculus in terms of declared major? It means, if the sample has overrepresented percentage of some specific major, the conclusion could be biased. To get a gross impression of the entire enrollment of the class, the frequency of students' declared major for each calculus course level is listed in Table 6.17. Calculus I has the most diverse students from 40 different majors. Life Calculus II consists of students mostly from Biomedical Sciences, Environmental Science \& Policy and other majors. All the three levels of the Engineering Calculus I have the students dominantly from engineering or pre-engineering, with the percentage greater than $76 \%$. The frequency of those in this study on declared major was compared with all the enrolled students without the survey by Chi-square analysis and Fisher exact test. For Life Calculus, $\chi^{2}(\mathrm{~N}=40, \mathrm{df}=12, \mathrm{p}=.15)=17.1$, Fisher value: .21 ; For the Calculus I, 
$\chi_{2}(\mathrm{~N}=200, \mathrm{df}=39, \mathrm{p}=.91)=27.8$, no Fisher value; For the Engineering Calculus $\mathrm{I}, \chi^{2}$

$(\mathrm{N}=279, \mathrm{df}=24, \mathrm{p}=.97)=12.6$, Fisher value: .64; Engineering Calculus III, $\chi_{2}(\mathrm{~N}=$

$218, \mathrm{df}=20, \mathrm{p}=.45)=20.2$, Fisher value: .42. All above Chi-Square tests and fisher

values were not significant at the .05 level, which means no evidence to conclude that the student sample in our study and those without survey are different in declared majors.

Table 6.17 The frequency of most declared majors for students at each course level

\begin{tabular}{|c|c|c|c|c|}
\hline Course level & Major code & Major of students enrolled & Number & Percent $(\%)$ \\
\hline \multirow[t]{7}{*}{ Calculus I } & BMS & Biomedical Sciences & 31 & 15.5 \\
\hline & PGU & Pre-Engineering & 27 & 13.5 \\
\hline & PBI & Pre-Biology/Microbiology & 23 & 11.5 \\
\hline & ESP & Environmental Science \& Policy & 19 & 9.5 \\
\hline & $\mathrm{CHM}$ & Chemistry & 17 & 8.5 \\
\hline & EGU & Engineering-General & 14 & 7 \\
\hline & Total & & 200 & 100 \\
\hline \multirow[t]{4}{*}{ Life Calculus II } & BMS & Biomedical Sciences & 13 & 32.5 \\
\hline & ESP & Environmental Science \& Policy & 13 & 32.5 \\
\hline & EGU & Engineering-General & 2 & 5 \\
\hline & Total & & 40 & 100 \\
\hline \multirow[t]{6}{*}{ Engineering Calculus I } & PGU & Pre-Engineering & 121 & 43.37 \\
\hline & EGU & Engineering-General & 92 & 32.97 \\
\hline & PAR & Pre-Architecture & 28 & 10.04 \\
\hline & BMS & Biomedical Sciences & 5 & 1.79 \\
\hline & PBA & COB Pre-Business Admin & 5 & 1.79 \\
\hline & Total & & 279 & 100 \\
\hline \multirow[t]{5}{*}{ Engineering Calculus II } & EGU & Engineering-General & 141 & 51.65 \\
\hline & PGU & Pre-Engineering & 95 & 34.8 \\
\hline & $\mathrm{CHM}$ & Chemistry & 9 & 3.3 \\
\hline & PAR & Pre-Architecture & 3 & 1.1 \\
\hline & Total & & 273 & 100 \\
\hline \multirow[t]{6}{*}{ Engineering Calculus III } & EGU & Engineering-General & 109 & 50 \\
\hline & PGU & Pre-Engineering & 69 & 31.65 \\
\hline & BCS & Computer Science & 10 & 4.59 \\
\hline & MTH & Mathematics & 7 & 3.21 \\
\hline & $\mathrm{CHM}$ & Chemistry & 2 & 0.92 \\
\hline & Total & & 218 & 100 \\
\hline
\end{tabular}


For the Engineering Calculus II, $\chi_{2}(\mathrm{~N}=273, \mathrm{df}=20, \mathrm{p}=.09)=8.7$, Fisher value: .03 . Fisher exact test indicated the significant difference at $\mathrm{p}<.05$. When examining the roster, $51.7 \%$ students declared major of Pre-Engineering and $34.8 \%$ declared Engineering-general. For the survey students, 61.5\% declared Pre-Engineering (this is larger than those without survey), 24.2\% declared Engineering-general. According to the admission requirement (USF, 2008), students meeting or exceeding certain criteria (high school GPA, SAT etc) are granted direct entry to the College, and Pre-Engineering students are "fully admitted to the College after satisfactorily completing Calculus I and II and Physics I and II with labs”. The Calculus attitudes score for Engineering Calculus II could be biased using this sample.

CFA was performed to estimate goodness of fit of the 2-factor model. The estimation of the 2-factor model fit for the Calculus class was (Table 6.18): $\chi^{2}(\mathrm{~N}=187, \mathrm{df}=19, \mathrm{p}$ $=.00)=76.2, \mathrm{CFI}=.91, \mathrm{RMSEA}=0.13, \mathrm{SRMR}=.07$. Since $\mathrm{CFI}$ was less than .95 , and RMSEA was greater than .08, the overall model did not fit the data reasonably well. In terms of possible reason for the misfit, the combination of different level courses for different population (environment, life and general calculus I, II, and III) could be a problem. However, factor analysis for the 92 Engineering Calculus II students didn't improve the model fit. Another reason could be that calculus students didn't use the same subjective words to describe their cognitive and affective attitude towards calculus, since words in ASCI were originally constructed specifically for chemistry students. Cognitive interview may reveal possible hints for calculus attitude items but not performed in this study. 
Table 6.18 Fit statistics of V3.1 calculus results from two-factor CFA, along with MW

\begin{tabular}{lll}
\hline Fit Statistic & Calculus, V3.1 & MW, V3 \\
\hline$\chi^{2}$ & 76.2 & 113.2 \\
$\mathrm{df}$ & 19 & 19 \\
$\mathrm{p}$ & .00 & .00 \\
$\mathrm{~N}$ & 187 & 305 \\
$\mathrm{CFI}$ & .91 & .89 \\
RMSEA & .13 & .13 \\
SRMR & .07 & .07 \\
\hline
\end{tabular}

Note: $\chi^{2}=$ Chi-square, $\mathrm{df}=$ degree of freedom, $\mathrm{N}=$ sample size, $\mathrm{CFI}=$ Comparative Fit Index, RMSEA = Root Mean Square Error of Approximation, SRMR = Standardized Root Mean Square Residual

Factor correlation from CFA between the "intellectual accessibility" and "emotional satisfaction" was .86, which suggests the strong correlation for the two components and consistent with previous findings.

Although the above comparison was made for different courses and different populations, similar pattern appeared consistently. For both cases the survey V3 and V3.1 may not be useful to identify the attitude component for college students. The reliability for each scale is acceptable. The construct validity is not completely confirmed. Some items are not loaded on the assumed factor, and measurement error of items 6 and 8 were correlated, which indicated the decrease of $\chi^{2}$ about 34.3 for calculus and 50.5 for MW data by adding this correlation into the model. We can't figure out exactly why the different item order can lead to this different response patterns. One possible theory for the item order effect is that ASCI V2 may trigger students to discriminate the trivial difference among the items. Are the first two items, easy $v s$ hard and complicated $v s$ simple, same or different? Maybe students got the cues to find distinctions for each item, and may pay more attention.

In sum, ASCI V3.1 is not yet done for the calculus course at this point. 


\section{Evaluation of ASCI V2 for Biochemistry Class}

The results of ASCI V3 for MW chemistry students and the V3.1 for the calculus students didn’t exhibit simple and clean internal structure. After examining the source of misfit, the error term of items 6 and 8 was found to covary and harmed the model fit for both situations. Meanwhile, the cleaner 2-factor solution was confirmed by ASCI V2 results. The investigator decided to move back to V2. Hopefully ASCI V2 can reproduce the good model fit result.

ASCI V2 was given to the students enrolled in Biochemistry course at the last 15 minutes of the class on May 18. There were 105 responses returned, 88 with complete data, which were used for the following analysis.

\section{Results and Discussion}

Descriptive statistics were performed for each item score after all 4 negatively stated items were recoded (Table 6.19). The average scores for each item ranged from 2.84 to 4.55, and standard deviation ranged from 1.25 to 1.62 . No item was found to have skewness or kurtosis greater than $\mathbf{9 ,}$, which suggests good normality of the item responses.

Table 6.19 Descriptive statistics of ASCI V2 for Biochemistry class

\begin{tabular}{lllll}
\hline Item \# & \multicolumn{2}{l}{ Biochemistry, N=88 } & Mean & SD \\
\hline $1 \mathrm{r}$ & easy & hard & $\mathbf{3 . 2 5}$ & 1.24 \\
2 & complicated & simple & $\mathbf{3 . 4 3}$ & 1.55 \\
3 & confusing & clear & $\mathbf{3 . 8 9}$ & 1.40 \\
$4 \mathrm{r}$ & comfortable & uncomfortable & $\mathbf{4 . 0 6}$ & 1.38 \\
$5 \mathrm{r}$ & satisfying & frustrating & $\mathbf{3 . 8 4}$ & 1.56 \\
6 & challenging & unchallenging & $\mathbf{2 . 8 4}$ & 1.57 \\
$7 \mathrm{r}$ & pleasant & unpleasant & $\mathbf{3 . 8 2}$ & 1.42 \\
8 & chaotic & organized & $\mathbf{4 . 5 1}$ & 1.46 \\
\hline
\end{tabular}

Note: Item score is reversed before averaging.

Each score should range from 1 to 7 , and 4 is in the middle point. Higher score means students feel chemistry is intellectually accessible, emotional satisfying. Item 2 has the highest mean of 4.55, and item 6 has the lowest mean of 2.84, which indicates they feel chemistry is organized, and is challenging. 
Internal consistencies were calculated for each subscale using the listwise deletion (Table 6.20). For the Biochemistry results, Cranbach's alpha was .78 and .81 for the 2 subscales, which was above satisfactory level .70 , and comparable to the literature results.

An exploratory factor analysis was performed using strategy B (principal axis factor analysis methods and Promax). Two factors were extracted. Item loadings for each item are listed in Table 6.21. All items were loaded well on the assumed factors.

Table 6.20 Internal consistency for V2 in Biochemistry class

\begin{tabular}{llll}
\hline ASCI, V2 & Cronbach's alpha & \\
\hline Scale and item & Biochemistry (N=95) & PL (n=354) & Literature(Bauer, 2008), v1 \\
\hline Intellectual accessibility $(1,2,3,6)$ & .79 & .82 & $.78^{\text {a }}$ \\
Emotional satisfaction $(4,5,7,8)$ & .81 & .79 & .79 \\
\hline
\end{tabular}

${ }^{\mathrm{a}}$ In ASCI V1, Intellectual accessibility has five items.

Table 6.21 The item loadings of V2 for Biochemistry and PL classes

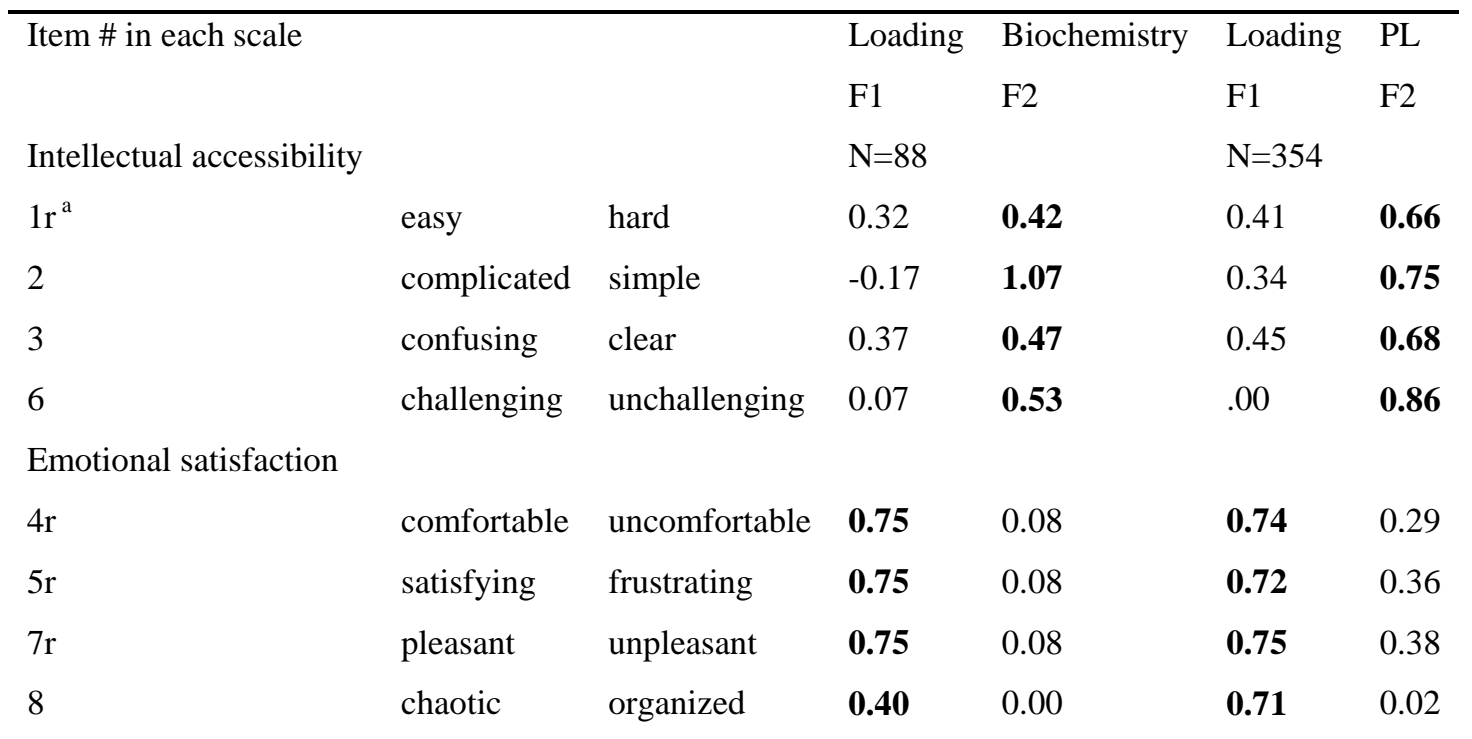

EFA is performed in SPSS 17.0. Strategy $\mathbf{B}$ was used including principal axis factor analysis methods and Promax rotation using the covariance matrix. 2 factors are extracted for comparison. Item loadings on the assumed factors are highlighted in bold.

$\mathrm{r}^{\mathrm{a}}$ : negatively stated

Factor scores created by sum of item score and factor correlations are listed in Table 6.22 
Attitude scores of Biochemistry students were only compared with Peer-led classes and Peer-leaders. Scores on ASCI V3 was not listed because 2-factor structure was not confirmed. Attitude score for Biochemistry students was 3.36 for Intellectual accessibility and 4.09 for emotional satisfaction, with a correlation of .54 between them. Factor correlation was similar with V2 of Peer-led classes, which indicates the factor functions similarly across different populations. Attitude score for Biochemistry students was higher than PL classes in both scales. Because enrollment in the Biochemistry prerequisites the minimum grade of " $\mathrm{C}$ " in General Chemistry I and II, Organic Chemistry I and II, and Biology, the result reflected our expectation that Biochemistry students with more chemistry expertise held a more positive attitude (effect size is about .3). Peer leaders were most satisfied with chemistry, and they scored the highest on both scales.

Table 6.22 Factor score and Pearson correlations for PL and Biochemistry class

\begin{tabular}{|c|c|c|c|c|c|c|}
\hline \multirow[t]{2}{*}{ ASCI, V2 } & Biochemistry & $(n=88)$ & PL student & $(\mathrm{n}=354)$ & Peer leader & $(n=12)$ \\
\hline & Access & Emotion & Access & Emotion & Access & Emotion \\
\hline Mean & 3.36 & 4.06 & 2.91 & 3.62 & 4.27 & 4.58 \\
\hline SD & 1.13 & 1.17 & 1.13 & 1.20 & 1.66 & 2.01 \\
\hline Factor & & & correlation & & & \\
\hline Intellectual access & & 0.54 & & 0.64 & & 0.33 (n.s.) \\
\hline
\end{tabular}

CFA was performed to estimate goodness of fit of the 2-factor model. The items were set to load on its assumed factor only. The estimation of the 2-factor model fit for the Biochemistry class was (Table 6.23): $\chi^{2}(\mathrm{~N}=88, \mathrm{df}=19, \mathrm{p}=.059)=29.5$, which failed to reject the null hypothesis of a good fit. Since CFI was greater than .95 , RMSEA was less than .08 and SRMR was less than .08, the overall model fit the data pretty well. 
Factor correlation from CFA between the "intellectual accessibility" and "emotional satisfaction" was .67 , which suggests the strong correlation for the two components and consistent with previous findings (r: .80).

Table 6.23 Fit statistics of V2 results from two-factor CFA

\begin{tabular}{lll}
\hline Fit Statistic & Value \\
\hline & Biochemistry & PL \\
\hline$\chi^{2}$ & 29.5 & 77.0 \\
$\mathrm{df}$ & 19 & 19 \\
$\mathrm{p}$ & .059 (n.s.) & .00 \\
$\mathrm{~N}$ & 88 & 354 \\
$\mathrm{CFI}$ & .96 & .95 \\
RMSEA & .079 & .093 \\
SRMR & .050 & .042 \\
\hline
\end{tabular}

Note: $\chi^{2}=$ Chi-square, $\mathrm{df}=$ degree of freedom, $\mathrm{N}=$ sample size, $\mathrm{CFI}=$ Comparative Fit Index, RMSEA = Root Mean Square Error of Approximation, SRMR = Standardized Root Mean Square Residual

\section{Summary}

The above results evaluated reliability and construct validity of ASCI V2 data from two groups of students enrolled in PL and Biochemistry classes. For these eight items on the survey, the two factor structure (intellectual accessibility and emotional satisfaction) is supported by CFA for V2 results, but not for V3 and V3.1 results. 


\section{Chapter Seven}

Summary and Concluding Discussion

\section{Summary and Implications for Chemical Education}

Starting with the original ASCI (V1) developed by Bauer, we designed and implemented a process of scale development to refine the instrument for better construct validity.

Better construct validity results in greater ease of interpretation, which we demonstrated via an examination of a nomological network and predictive validity for ASCI V2. The research questions were successfully answered.

Research question one was to evaluate psychometric quality for the responses from ASCI V1 in terms of reliability and validity. ASCI V1 results showed a similar data pattern with the literature, and the construct validity of ASCI V1 scores was not supported by confirmatory factor analysis.

Research question two was to propose modified versions of ASCI based on factor analysis and attitude theoretical framework. Starting from the 20-item ASCI, we deleted redundant items and scales, reconstructed meaningful subscales and estimated the data fit to theoretical models. Several methodological issues were clarified here. For example, confirmatory factor analysis was used as the most rigorous test for whether the internal data structure matches the conceptual framework. Additionally, factor scores were suggested for use when there is more than one factor among the measured data set, with only those items loading on the same construct used to determine the factor score. In general, the investigator has tried to showcase ways in which evidence for reliability and 
validity of instrument scores can be provided so readers can interpret and apply research findings with a certain degree of confidence. This work represents the first time in the area of chemical education that a benchmark for scale development was successfully implemented to reconstruct an existing instrument.

Research question three was to evaluate psychometric quality for the responses from revised ASCI (V2, V3 and V3.1) in terms of reliability and validity. ASCI V2 was designed to measure two subscales of attitude: intellectual accessibility and emotional satisfaction. These two subscales are indicators of cognition and of affect, respectively, and thus make a good connection with the conceptual framework for attitude from psychology. Evidence for construct validity was obtained. The two-factor correlated structure was upheld by confirmatory factor analysis. As regards to correlations among attitude, achievement and ability, attitude correlates with SATM, ACTM, and ACS scores as expected, which provides evidence for a nomological network validity. Finally, once aptitude ability is taken into account, a component of attitude measured by ASCI V2 plays a significant unique part in predicting final achievement in General Chemistry I Peer-led students.

The two-factor correlated structure of ASCI V2 was further replicated for biochemistry students. The score of ASCI could discriminate different student cohorts, as supported by the more positive attitudes held by students in Biochemistry course with more advanced understanding of chemistry than those in General Chemistry I course.

Construct validity of ASCI V3 and V3.1 score was not confirmed by CFA. This study contributes to chemical education research by providing validity evidence for a revised instrument, ASCI V2, for college chemistry students. In addition to showcasing 
a method for examining validity, a second important result of this work is to recommend refinements that lead to greater ease of administration while improving validity: this eight item instrument now takes very little time to administer. Because of its convenience and high psychometric quality, chemistry educators who are interested in determining students' attitudes towards chemistry can easily find time to administer ASCI V2, even to a large class, and can expect the results to be interpretable.

\section{Limitations of the Study and Recommendations for Future Research}

We envision a significant potential use of ASCI V2 will be to identify the effects of curricular reforms, via experimental or quasi-experimental designs. Using ASCI V2 as a pre- and post-test for treatment and comparison groups would allow the effect of course experience on the attitude change of each student to be tracked. In addition, this type of study could provide further evidence for validity which we were not able to provide here, by exploring attitude change directly with the same sample of students on the same measure, and by exploring whether the two factors relate to curricular intentions in an expected way.

It is not the case that ASCI (V2) captures all potential aspects of attitude, nor that a single measure is desirable. Exploration of attitude theory and past research practice involve both a variety of quantitative assessments (Table 6.6 is but a small subset) and of qualitative investigations. Understanding how ASCI V2 fits into this complex set of possibilities can only be accomplished by further examining its relationships with other measures of attitude, achievement, and additional constructs such as learning strategies, motivation, and behavior. 
Ultimately, since we as chemical educators are increasingly asked to utilize assessment within our classrooms, we have a great need for easy-to-use instruments that yield valid, reliable, and readily interpretable scores for constructs of interest. We hope that, in the classes of our collective community, students' attitudes toward chemistry are becoming more rather than less positive, and also that ASCI V2 will help us all to investigate the truth of that proposition.

Since the similar pattern of chemistry and calculus students responded to ASCI V3 and V3.1, it is worthwhile to create the version V2.1 (by changing the word of chemistry into calculus) to calculus classes. If it functions well with calculus, possibly we can give more derivative versions to other science subjects like physics. However, it remains a challenge because people may use different adjectives to describe their attitude towards different subjects, which necessitates the some new items from scratch and cognitive interview. 


\section{References}

American Association for the Advancement of Science. (1989). science for all americans. Project 2061-The American Association for the Advancement of Science: Oxford University Press, Inc.

Aikenhead, G. S. (1973). The measurement of high school students' knowledge about science and scientists. Science Education, 51, 539-549.

Allport, G. W. (1935). Attitudes. In C. M. Murchison (Ed.), Handbook of social psychology (pp. 798-844). London: Oxford University Press.

Angoff, W. H. (1988). Validity: An evolving concept. In H. Wainer \& H. I. Braun (Eds.), Test validity (pp. 19-32). Hillsdale, N J: Lawrence Erlbanm Associates.

Ault, C. R. (1998). Criteria of excellence for geological inquiry: The necessity of ambiguity. Journal of Research in Science Teaching, 35(2), 189-212.

Bagozzi, R. P., \& Burnkrant, R. E. (1979). Attitude organisation and the attitudebehaviour relationship. Journal of Personality and Social Psychology, 37, 913929.

Bandura, A. (1977). Social Learning theory: Oxford, England: Prentice-Hall.

Bandura, A. (1982). Self-Efficacy Mechanism in Human Agency. American Psychologist, $37(2), 122-147$.

Barbera, J., Adams, W. K., Wieman, C. E., \& Perkins, K. K. (2008). Modifying and validating the Colorado Learning Attitudes about Science Survey for use in chemistry. Journal of Chemical Education, 85(10), 1435-1439.

Bauer, C. (2005). Beyond "Student Attitudes": Chemistry Self-Concept Inventory for Assessment of the Affective Component of Student Learning. Journal of Chemical Education, 82(12), 1864-1870.

Bauer, C. (2008). Attitude towards Chemistry: A Semantic Differential Instrument for Assessing Curriculum Impacts. Journal of Chemical Education, 85(10), 14401445 .

Bem, D. J. (1967). Self-Perception: An alternative interpretation of cognitive dissonance phenomena. Psychological Review, 74, 183-200. 
Bem, D. J., \& McConnell, H. K. (1970). Testing Self-Perception Explanation of Dissonance Phenomena - Salience of Premanipulation Attitudes. Journal of Personality and Social Psychology, 14(1), 23-31.

Berg, K. E. (1966). Ethnic attitudes and agreement with a Negro person. Journal of Personality and Social Psychology, 4, 215-220.

Biddle, S. H. J., \& Mutrie, N. (2001). Psychology of physical activity: Determinants, well-being and interventions. New York, NY: Routledge.

Blalock, C. L., Lichtenstein, M. J., Owen, S., Pruski, L., Marshall, C., \& Toepperwein, M. (2008). In Pursuit of Validity: A comprehensive review of science attitude instruments 1935-2005. International Journal of Science Education, 30(7), 961977.

Bong, M. (2001). Between- and within-domain relations of academic motivation among middle and high school students: Self-efficacy, task-value, and achievement goals. Journal of Educational Psychology, 93(1), 23-34.

Bong, M., \& Clark, R. E. (1999). Comparison between self-concept and self-efficacy in academic motivation research. Educational Psychologist, 34(3), 139-153.

Bray, D. W. (1950). The prediction of behavior from two attitude scales. Journal of Abnormal and Social Psychology, 45, 64-84.

Breckler, S. J. (1984). Empirical Validation of Affect, Behavior, and Cognition as Distinct Components of Attitude. Journal of Personality and Social Psychology, 47(6), 1191-1205.

Brophy, B. M. (2004). Motivating students to learn(2nd Edition). Hillsdale: Lawrence Erlbaum Associates.

Brown, A. L. (1987). Metacognition, executive control, self-regulation, and other more mysterious mechanisms. In F. E. Weinert \& R. H. Kluwe (Eds.), Metacognition, motivation, and understanding (pp. 65-116). Hillsdale, New Jersey: Lawrence Erlbaum Associates.

Chatterjee, S., Williamson, V. M., McCann, K., \& Peck, M. L. (2009). Surveying Students' Attitudes and Perceptions toward Guided-Inquiry and Open-Inquiry Laboratories. Journal of Chemical Education, 86(12), 1427.

Cheng, S. T., \& Chan, A. C. M. (2003). The development of a brief measure of school attitude. Educational and Psychological Measurement, 63(6), 1060-1070.

Cohen, J. (1977). Statistical power analysis for the behavioral sciences (revised edition). New York: Academic Press. 
Cohen, J. (1988). Statistical power analysis for the behavioral sciences (2nd edition). Hillsdale, NJ: Erlbaum.

Cooper, M. M., \& Sandi-Urena, S. (2009). Design and Validation of an Instrument To Assess Metacognitive Skillfulness in Chemistry Problem Solving. Journal of Chemical Education, 86(2), 240-245.

Cooper, M. M., \& Sandi-Urena, S. (2009). Design and Validation of an Instrument To Assess Metacognitive Skillfulness in Chemistry Problem Solving J. Chem. Educ., 86(2), 240-245.

Corno, L., \& Mandinach, E. B. (1983). The role of cognitive engagement in classroom learning and motivation. Educational Psychologist, 18, 88-108.

Cronbach, L. J. (1988). Five perspectives on validation argument. In H. Wainer \& H. Braun (Eds.), Test validity (pp. 3-17). Hillsdale, NJ: Erlbaum.

Cronbach, L. J., \& Meehl, P. E. (1955). Construct Validity in Psychological Tests. Psychological Bulletin, 52, 281-302.

Cronkhite, G., \& Liska, J. R. (1980). The judgment of communicant acceptability. In M. R. Roloff \& G. R. Miller (Eds.), Persuasion: New directions in theory and research. Beverly Hills, CA: Sage.

Cunningham, G. B., \& Mahoney, K. (2004). Self-efficacy of part-time employees in university athletics: The influence of organizational commitment, valence of training, and training motivation. Journal of Sport Management, 18(1), 59-73.

Custers, E., \& Ten Cate, O. T. J. (2002). Medical students' attitudes towards and perception of the basic sciences: a comparison between students in the old and the new curriculum at the University Medical Center Utrecht, The Netherlands. Medical Education, 36(12), 1142-1150.

Dahle, L. O., Forsberg, P., Svanberg-Hard, H., Wyon, Y., \& Hammar, M. (1997). Problem-based medical education: development of a theoretical foundation and a science-based professional attitude. Medical Education, 31(6), 416-424.

DeVellis, R. F. (2003). Scale Development: Theory and Applications, Second Edition. Thousand Oaks, CA: Sage Publications.

Doran, R., Lawrenz, F., \& Helgeson, S. (1994). Research on assessment in science. In D. Gabel (Ed.), Handbook of research on science teaching and learning (pp. 388442). New York: Macmillan.

Eagly, A. H., \& Chaiken, S. (1993). The psychology of attitudes. Fort Worth, TX: Harcourt Brace Jovanovich. 
Eagly, A. H., \& Chaiken, S. (2007). The advantages of an inclusive definition of attitude. Social Cognition, 25(5), 582-602.

Fabrigar, L. R., Wegener, D. T., MacCallum, R. C., \& Strahan, E. J. (1999). Evaluating the use of exploratory factor analysis in psychological research. Psychological Methods, 4(3), 272-299.

Festinger, L. (1957). A theory of cognitive dissonance. Stanford, CA: Stanford University Press.

Fishbein, M., \& Ajzen, I. (1975). Beliefs, Attitude, Intention, and Behavior: An Introduction to Theory and Research. Reading, MA: Addison-Wesley.

Fisher, R. A. (1922). On the interpretation of $\chi 2$ from contingency tables, and the calculation of P. Journal of the Royal Statistical Society, 85(1), 87-94.

foundation, W. e. (2002). The testing industry's big four: Profiles of the four companies that dominate the business of making and scoring standardized achievement tests. Retrieved 2/16/2010, from http://www.pbs.org/wgbh/pages/frontline/shows/schools/testing/companies.html

Fowler, L. S. (1980). An Application of Piaget Theory of Cognitive-Development in Teaching Chemistry - the Learning Cycle. Journal of Chemical Education, 57(2), 135-136.

Franko, D. L., Cousineau, T. M., Trant, M., Green, T. C., Rancourt, D., Thompson, D., et al. (2008). Motivation, self-efficacy, physical activity and nutrition in college students: Randomized controlled trial of an internet-based education program. Preventive Medicine, 47(4), 369-377.

Freedman, M. P. (1997). Relationship among laboratory instruction, attitude toward science, and achievement in science knowledge. Journal of Research in Science Teaching, 34(4), 343-357.

Gao, Z., Lee, A. M., \& Harrison, L. (2008). Understanding students' motivation in sport and physical education: From the expectancy-value mode and self-efficacy theory perspectives. Quest, 60(2), 236-254.

Gardner, P. L. (1975). Attitudes to science: A review. Studies in Science Education, 2, 141.

Gardner, P. L. (1995). Measuring Attitudes to Science: Unidimensionality and Internal Consistency Revisited. Research in Science Education, 25(3), 283-289.

Germann, P. J. (1988). Development of the attitude toward science in school assessment and its use to investigate the relationship between science achievement and attitude toward science in school. Journal of Research in Science Teaching, 25(8), 689-703. 
Gogolin, L., \& Swartz, F. (1992). A Quantitative and Qualitative Inquiry into the Attitudes toward Science of Nonscience College-Students. Journal of Research in Science Teaching, 29(5), 487-504.

Gonzàlez, V. E. (1992). On human attitudes: Root metaphors in theoretical conceptions. University of Gothenburg.

Gouveiaoliveira, A., Rodrigues, T., \& Demelo, F. G. (1994). Computer Education Attitudes and Opinions of 1st-Year Medical-Students. Medical Education, 28(6), 501-507.

Greenbaum, P. E., \& Dedrick, R. F. (1998). Hierarchical confirmatory factor analysis of the Child Behavior Checklist/4-18. Psychological Assessment, 10(2), 149-155.

Grove, N., \& Bretz, S. L. (2007). CHEMX: An Instrument to Assess Students' Cognitive Expectations for Learning Chemistry. Journal of Chemical Education, 84(9), 1524-1929.

Gutwill, J. (1998). Cognitive and attitudinal change in a ModularChem/ChemLinks modular chemistry course at the post-secondary level. Abstracts of Papers of the American Chemical Society, 215, 015-SOCED.

Hagger, M. S., Chatzisarantis, N. L., \& Biddle, J. H. (2002). A meta-analytic review of the theories of reasoned action and planned behavior in physical activity: Predictive validity and the contribution of additional variables. Journal of Sport \& Exercise Psychology, 24, 3-32.

Hogarty, K. Y., Hines, C. V., Kromrey, J. D., Ferron, J. M., \& Mumford, K. R. (2005). The quality of factor solutions in exploratory factor analysis: The influence of sample size, communality, and overdetermination. Educational and Psychological Measurement, 65(2), 202-226.

Hren, D., Lukic, I. K., Marusic, A., Vodopivec, I., Vujaklija, A., Hrabak, M., et al. (2004). Teaching research methodology in medical schools: students' attitudes towards and knowledge about science. Medical Education, 38(1), 81-86.

Hsieh, P. H. P., \& Schallert, D. L. (2008). Implications from self-efficacy and attribution theories for an understanding of undergraduates' motivation in a foreign language course. Contemporary Educational Psychology, 33(4), 513-532.

Hu, L., \& Bentler, P. M. (1999). Cutoff criteria for fit indexes in covariance structure analysis: Conventional criteria versus new alternatives. Structural Equation Modeling, 6, 1-55.

Jurisevic, M., Glazar, S. A., Pucko, C. R., \& Devetak, I. (2008). Intrinsic motivation of pre-service primary school teachers for learning chemistry in relation to their academic achievement. International Journal of Science Education, 30(1), 87-107. 
Koballa, T. R. J., \& Crawley, F. E. (1985). The influence of attitude on science teaching and learning. School Science and Mathematics, 85, 222-232.

Kutner, B., Wllkins, C., \& Yarrow, P. R. (1952). Verbal attitudes and overt behavior involving racial prejudice. Journal of Abnormal and Social Psychology, 47, 649652.

Lapiere, R. T. (1934). Attitude vs. actions. Social Farces, 13, 230-237.

Laws, P. W., Rosborough, P. J., \& Poodry, F. J. (1999). Women's responses to an activity-based introductory physics program. American Journal of Physics, 67(7), S32-S37.

Leavers, D. R. (1975). Course Which Changed Attitudes of Students Towards Science. Journal of Chemical Education, 52(12), 804-804.

Lewis, S. E., \& Lewis, J. E. (2007). Predicting at-risk students in general chemistry: comparing formal thought to a general achievement measure. Chemistry Education: Research and Practice, 8(1), 32-51.

Lewis, S. E., Shaw, J. L., Heitz, J. O., \& Webster, G. H. (2009). Attitude Counts: SelfConcept and Success in General Chemistry. Journal of Chemical Education, 86(6), 744-749.

Lichtenstein, M. J., Owen, S. V., Blalock, C. L., Liu, Y., Ramirez, K. A., Pruski, L. A., et al. (2008). Psychometric reevaluation of the scientific attitude inventory-revised (SAI-II). Journal of Research in Science Teaching, 45(5), 600-616.

Likert, R. (1932). A Technique for the Measurement of Attitudes. Archives of Psychology(140), 1-55.

Lindsay, H. A. (2001). Investigation of the relationship between selected cognitive and non-cognitive variables and achievement in sophomore organic chemistry. Abstracts of Papers of the American Chemical Society, 221, 18-CHED.

MacCallum, R. C., Widaman, K. F., Preacher, K. J., \& Hong, S. (2001). Sample size in factor analysis: The role of model error. Multivariate Behavioral Research, 36(4), 611-637.

Margolis, H., \& McCabe, P. P. (2006). Improving self-efficacy and motivation: What to do, what to say. Intervention in School and Clinic, 41(4), 218-227.

Marsh, H. W., \& Balla, J. (1994). Goodness-of-Fit in Confirmatory Factor-Analysis - the Effects of Sample-Size and Model Parsimony. Quality \& Quantity, 28(2), 185217. 
Marsh, H. W., Balla, J. R., \& McDonald, R. P. (1988). Goodness-of-Fit Indexes in Confirmatory Factor-Analysis - the Effect of Sample-Size. Psychological Bulletin, 103(3), 391-410.

Mayer, V. J., \& Richmond, J. M. (1982). An overview of assessment instruments in science. Science Education, 66, 49-66.

McGuire, W. J. (1985). Attitudes and attitude change. In G. Lindzey \& E. Aronson (Eds.), Handbook of Social Psychology. 3rd ed (Vol. 2:233-346). New York: Random House.

Messick, S. (1980). Test Validity and the Ethics of Assessment. American Psychologist, 36(11), 1012-1027.

Messick, S. (1989). Validity. In R. L. Linn (Ed.), Educational measurement (3rd edition) (pp. 13-103). Washington, DC: American Council on Education.

Mills, N., Pajares, F., \& Herron, C. (2007). Self-efficacy of college intermediate french students: Relation to achievement and motivation. Language Learning, 57(3), 417-442.

Mohsin, S. M. (1990). Attitude: Concept, formation and change. New Delhi: Wiley, Darya Ganj.

Moss, P. A. (1994). Can there be validity without reliability? Educational Researcher, 23, 5-12.

Munby, H. (1983). An investigation into the measurement of attitudes in science education. Columbus, OH: SMEAC Information Reference Center.

Muthe'n, L. K., \& Muthe'n, B. O. (2007). Mplus user's guide (5rd ed.): Los Angeles: Muthe'n \& Muthe'n.

Netemeyer, R. G., Bearden, W. O., \& Sharma, S. (2003). Scaling Procedures: Issues and Applications. Thousand Oaks, CA: Sage Publications.

Neuberg, S. L., West, S. G., Judice, T. N., \& Thompson, M. M. (1997). On dimensionality, discriminant validity, and the role of psychometric analyses in personality theory and measurement: Reply to Kruglanski et al.'s (1997) Defense of the Need for Closure Scale. Journal of Personality and Social Psychology, 73, 1017-1029.

Nunnally, J. C. (1978). Psychometric Theory. Second ed. New York: McGraw Hill.

Oppenheim, V. E. (1992). Questionnaire design, interviewing and attitude measurement. New York: St. Martin's Press. 
Osborne, J. W., \& Waters, E. (2002). Four Assumptions Of Multiple Regression That Researchers Should Always Test. Practical Assessment, Research, and Evaluation, 8(2).

Ostrom, T. M. (1969). The relationship between the affective, behavioral, and cognitive components of attitude. Journal of Experimental Social Psychology, 5, 12-30.

Ozmen, H. (2008). The influence of computer-assisted instruction on students' conceptual understanding of chemical bonding and attitude toward chemistry: A case for Turkey. Computers \& Education, 51(1), 423-438.

Pajares, F., \& Graham, L. (1999). Self-efficacy, motivation constructs, and mathematics performance of entering middle school students. Contemporary Educational Psychology, 24(2), 124-139.

Palmer, C. L., Burwitz, L., Dyer, A. N., \& Spray, C. M. (2005). Endurance training adherence in elite junior netball athletes: A test of the theory of planned behaviour and a revised theory of planned behaviour. Journal of Sports Sciences, 23(3), 277288.

Paris, S. G., Yambor, K. M., \& Packard, B. W. L. (1998). Hands-on biology: A museumschool-university partnership for enhancing students' interest and learning in science. Elementary School Journal, 98(3), 267-288.

Park, R. E., \& Burgress, E. W. (1924). Introduction to the science of sociology. Chicago: Univ. Chicago Press.

Parke, H. M., \& Coble, C. R. (1997). Teachers designing curriculum as professional development: A model for transformational science teaching. Journal of Research in Science Teaching, 34(8), 773-789.

Pedhazur, E. J. (1997). Multiple Regression in Behavioral Research (3rd ed.). Orlando, FL: Harcourt Brace.

Perlman, F., Bobak, M., Steptoe, A., Rose, R., \& Marmot, M. (2003). Do health control beliefs predict behaviour in Russians? Preventive Medicine, 37(2), 73-81.

Petty, R. E., Wegener, D. T., \& Fabrigar, L. R. (1997). Attitudes and attitude change. Annual Review of Psychology, 48, 609-647.

Pintrich, P. R., \& Schunk, D. H. (1996). Motivation in Education. Englewood Cliffs, NJ: Prentice-Hall.

Pribyl, J. R., Adams, D., Hoganmiller, E., \& Stevens, M. (1991). A Study of the Relationships between Achievement-Motivation, Coping Skills, Self-Efficacy, Cognitive Level, Health Behavior and Success in Introductory Chemistry Courses. Abstracts of Papers of the American Chemical Society, 201, 216-CHED. 
Randall, D. M., \& Wolff, J. A. (1994). The Time-Interval in the Intention Behavior Relationship - Metaanalysis. British Journal of Social Psychology, 33, 405-418.

Reynolds, A. J., \& Walberg, H. J. (1992). A Structural Model of Science Achievement and Attitude - an Extension to High-School. Journal of Educational Psychology, 84(3), 371-382.

Rivis, A., \& Sheeran, P. (2003). Descriptive norms as an additional predictor in the theory of planned behaviour: A meta-analysis. Current Psychology, 22(3), 218233.

Romance, N. R., \& Vitale, M. R. (1992). A Curriculum Strategy That Expands Time for in-Depth Elementary Science Instruction by Using Science-Based Reading Strategies - Effects of a Year-Long Study in Grade 4. Journal of Research in Science Teaching, 29(6), 545-554.

Rubba, P. A., \& Anderson, H. O. (1978). Development of an instrument to assess secondary students understanding of the nature of scientific knowledge. Science Education, 62(4), 449-458.

Salta, K., \& Tzougraki, C. (2004). Attitudes toward chemistry among 11th grade students in high schools in Greece. Science Education, 88(4), 535-547.

Schunk, D. H. (1991). Self-Efficacy and Academic Motivation. Educational Psychologist, 26(3-4), 207-231.

Sedlacek, W. E. (2004). Beyond the Big Test: Noncognitive Assessment in Higher Education. San Francisco: Jossy-Bass.

Shevlin, M., \& Miles, J. N. V. (1998). Effects of sample size, model specification and factor loadings on the GFI in confirmatory factor analysis. Personality and Individual Differences, 25(1), 85-90.

Shibley, I. A., Milakofsky, L., Bender, D. S., \& Patterson, H. O. (2003). College chemistry and piaget: An analysis of gender difference, cognitive abilities, and achievement measures seventeen years apart. Journal of Chemical Education, 80(5), 569-573.

Shymansky, J. A., Yore, L. D., \& Anderson, J. O. (2004). Impact of a school district's science reform effort on the achievement and attitudes of third- and fourth-grade students. Journal of Research in Science Teaching, 41(8), 771-790.

Sins, P. H. M., van Joolingen, W. R., Savelsbergh, E. R., \& van Hout-Wolters, B. (2008). Motivation and performance within a collaborative computer-based modeling task: Relations between students' achievement goal orientation, self-efficacy, cognitive processing, and achievement. Contemporary Educational Psychology, 33(1), 5877. 
Snider, J. G., \& Osgood, C. E. (1969). Semantic Differential Technique: A Sourcebook. Chicago, IL: Aldine.

Spearman, C. (1904). The proof and measurement of association between two things. American Journal of Psychology, 15, 72-101.

Steele, D. J., Medder, J. D., \& Turner, P. (2000). A comparison of learning outcomes and attitudes in student- versus faculty-led problem-based learning: an experimental study. Medical Education, 34(1), 23-29.

Sternberg, R. J., \& Williams, W. M. (1997). Does the Graduate Record Examination predict meaningful success in the graduate training of psychologists? - A case study. American Psychologist, 52(6), 630-641.

Straus, M. A., \& Wauchope, B. (1992). Measurement Instruments. In E. F. Borgatta \& M. L. Borgatta (Eds.), Encyclopedia of Sociology (Vol. 2, pp. 1236-1240). NY: Macmillian Publishing Co.

Subramaniam, P. R., \& Silverman, S. (2000). Validation of Scores From an Instrument Assessing Student Attitude Toward Physical Education. Measurement in Physical Education and Exercise Science, 4(1), 29-43.

Subramaniam, P. R., \& Silverman, S. (2007). Middle school students' attitudes toward physical education. Teaching and Teacher Education, 23(5), 602-611.

The joint committee on standards for educational evaluation. (2007). The personnel evaluation standards, 2nd edition.

Thompson, B. (2003). Score reliability: Contemporary thinking on reliability issues. Thousand Oaks, CA: Sage Publication, Inc.

Thompson, B., \& Daniel, L. G. (1996). Factor analytic evidence for the construct validity of scores: A historical overview and some guidelines. Educational and Psychological Measurement, 56(2), 197-208.

Thurstone, L. L. (1928). Attitudes Can Be Measured. The American Journal of Sociology, 33(4), 529-554.

Tracey, T. J., \& Sedlacek, W. E. (1984). Noncognitive Variables in Predicting AcademicSuccess by Race. Measurement and Evaluation in Guidance, 16(4), 171-178.

Tracey, T. J., \& Sedlacek, W. E. (1987). A Comparison of White and Black-Student Academic-Success Using Noncognitive Variables - a Lisrel Analysis. Research in Higher Education, 27(4), 333-348.

Tuan, H.-L., Chin, C.-C., \& Shieh, S.-H. (2005). The development of a questionnaire to measure students' motivation towards science learning. International Journal of Science Education, 27(6), 639 - 654. 
Turner, R. C., \& Lindsay, H. A. (2003). Gender differences in cognitive and noncognitive factors related to achievement in organic chemistry. Journal of Chemical Education, 80(5), 563-568.

USF. (2008). USF 2008-2009 Undergraduate Catalog--College of Engineering general acedemic information. Retrieved 10/6, 2009, from http://www.ugs.usf.edu/catalogs/0809/enacainf.htm

Uzuntiryaki, E., \& Aydin, Y. C. (2009). evelopment and validation of chemistry selfefficacy scale for college students. Research in Science Education, 39, 539-551.

Walczak, M. M., \& Walczak, D. E. (2009). Do Student Attitudes toward Science Change during a General Education Chemistry Course? Journal of Chemical Education, 86(8), 985-991.

Walker, C. O., Greene, B. A., \& Mansell, R. A. (2006). Identification with academics, intrinsic/extrinsic motivation, and self-efficacy as predictors of cognitive engagement. Learning and Individual Differences, 16(1), 1-12.

Wicker, A. W. (1969). Attitudes versus actions: The relationship of verbal and overt behavior responses to attitude objects. Journal of Social Issues, 25(4), 41-78.

Wilkinson, L. (1999). Statistical methods in psychology journals: Guidelines and explanations. American Psychologist, 54(8), 594-604.

Zanna, M. P., \& Rempel, J. K. (1988). Attitudes: A new look at an old concept. In D. Bar-Tal \& A. W. Kruglanski (Eds.), The Social Psychology of Knowledge (pp. 315- 334). New York: Cambridge University Press. 
Appendices 


\section{Appendix A: Commonly Used Acronyms}

University MW: a large Middle West Public Research University

University SE: a large Southeastern Public Research University

PL: Peer-Led Guided Inquiry

SAT Math: SATM, math portion of the SAT exam

ACT math: ACTM, math portion of the ACT exam

ACS: American Chemical Society

ACS Exam: American Chemical Society First Semester General Chemistry (Special)

Examination

Sk: Skewness, a measure of symmetry of the probability distribution

$\mathrm{Ku}$ : Kurtosis, a measure of "peakedness" (peaked or flat) of the probability

n: sample size

M: mean

SD: standard deviation

EFA: exploratory factor analysis

CFA: confirmative factor analysis 


\section{Appendix B: ASCI VI}

Name:

$\mathrm{U}^{* *}$-ID

lab section:

A list of opposing words appears below. Rate how well these words describe your feelings about chemistry. Think carefully and try not to include your feelings toward chemistry teachers or chemistry courses. For each line, choose a position between the two words that describes exactly how you feel. Circle that number on this sheet. The middle position is if you are undecided or have no feelings related to the terms on that line. When you are done with all 20 items, also record your responses on the scantron. $(\mathrm{B}=1, \mathrm{C}=2, \mathrm{D}=3, \mathrm{E}=4, \mathrm{~F}=5, \mathrm{G}=6, \mathrm{H}=7$ )

\section{CHEMISTRY IS}

\begin{tabular}{|c|c|c|c|}
\hline 1 & easy & 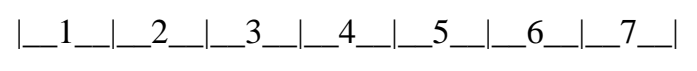 & hard \\
\hline \multicolumn{4}{|c|}{ middle } \\
\hline 2 & worthless & 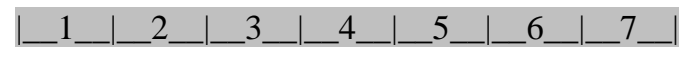 & beneficial \\
\hline 3 & exciting & |-1_|_2_|_3_-| 4_|_5_-_6_|_6_| & boring \\
\hline 4 & complicated & 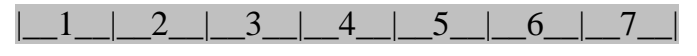 & simple \\
\hline 5 & confusing & 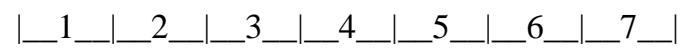 & clear \\
\hline 6 & good & 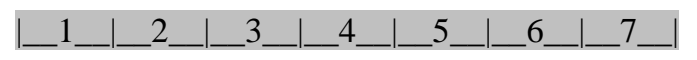 & bad \\
\hline \multicolumn{4}{|c|}{ middle } \\
\hline 7 & satisfying & | 1 1_|_2_|_3_-_4_- & frustrating \\
\hline 8 & scary & 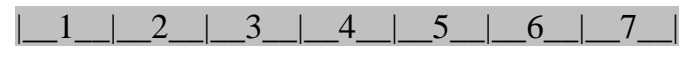 & fun \\
\hline 9 & comprehensible & 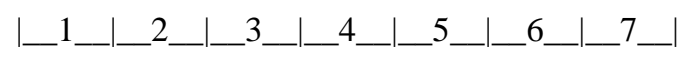 & incomprehensible \\
\hline 10 & challenging & 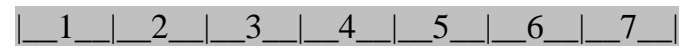 & not challenging \\
\hline 11 & pleasant & 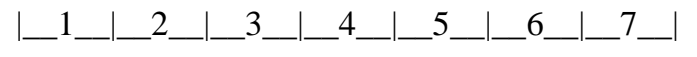 & unpleasant \\
\hline \multicolumn{4}{|c|}{ middle } \\
\hline 12 & interesting & 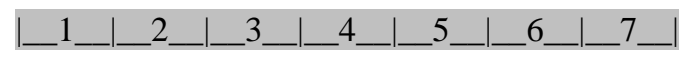 & dull \\
\hline 13 & disgusting & |-1_|_2_|_3_-| 4_|_5_-_6_|_6_| & attractive \\
\hline 14 & comfortable & 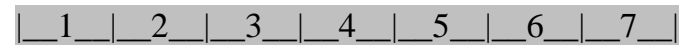 & uncomfortable \\
\hline 15 & worthwhile & |-1_|_2_|_3_-| 4_|_5_-_6_|_6_| & useless \\
\hline 16 & work & 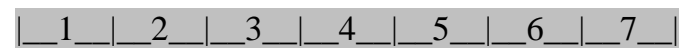 & play \\
\hline \multicolumn{4}{|c|}{ middle } \\
\hline 17 & chaotic & |_1_|_2_|_3_|_4_|_5_-_6_|_7_| & organized \\
\hline 18 & safe & 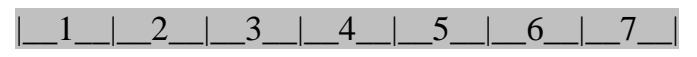 & dangerous \\
\hline 19 & tense & 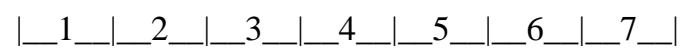 & relaxed \\
\hline 20 & insecure & 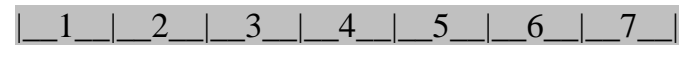 & secure \\
\hline
\end{tabular}




\section{Appendix C: ASCI V2}

Name:

$\mathrm{U}^{* *}$-ID:

Section:

A list of opposing words appears below. Rate how well these words describe your feelings about chemistry. Think carefully and try not to include your feelings toward chemistry teachers or chemistry courses. For each line, choose a position between the two words that describes exactly how you feel. Circle that number on this sheet. The middle position is if you are undecided or have no feelings related to the terms on that line.

When you are done with all 8 items, also record your responses on the scantron $(B=1$, $\mathrm{C}=2, \mathrm{D}=3, \mathrm{E}=4, \mathrm{~F}=5, \mathrm{G}=6, \mathrm{H}=7$ ). Make sure to bubble in your name and $\mathrm{U}^{* *}$-ID.

\section{CHEMISTRY IS}

1 easy

2 complicated

3 confusing

4 comfortable

$5 \quad$ satisfying

6 challenging

7 pleasant

8 chaotic

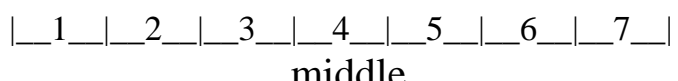

middle

hard

simple

clear

uncomfortable

frustrating

not challenging

unpleasant

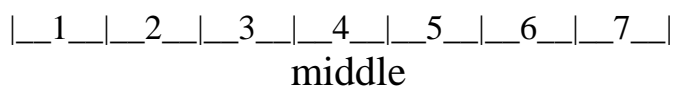

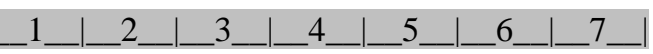

organized 
Name:

$$
\text { U**-ID: }
$$

Peer Leader:

A list of opposing words appears below. Rate how well these words describe your feelings about chemistry. Think carefully and try not to include your feelings toward chemistry teachers or chemistry courses. For each line, choose a position between the two words that describes exactly how you feel. Circle that number on this sheet. The middle position is if you are undecided or have no feelings related to the terms on that line.

When you are done with all 8 items, also record your responses on the scantron $(B=1$, $\mathrm{C}=2, \mathrm{D}=3, \mathrm{E}=4, \mathrm{~F}=5, \mathrm{G}=6, \mathrm{H}=7$ ). Make sure to bubble in your name and $\mathrm{U}^{* *}$-ID.

\section{CHEMISTRY IS}

1 easy

2 chaotic

3 confusing

4 comfortable

$5 \quad$ satisfying

6 challenging

7 pleasant

8 complicated

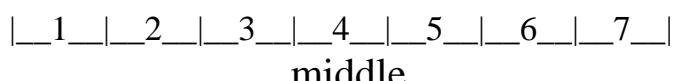

middle

hard

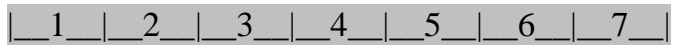

organized

clear

uncomfortable

frustrating

not challenging

unpleasant middle

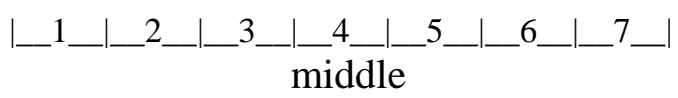

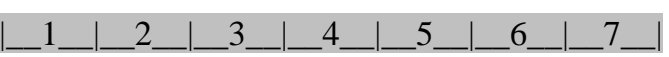

simple 
Name:

$\mathrm{U} * *-\mathrm{ID}:$

Instructor:

A list of opposing words appears below. Rate how well these words describe your feelings about calculus. Think carefully and try not to include your feelings toward calculus teachers or calculus courses. For each line, choose a position between the two words that describes exactly how you feel. Circle that number on this sheet. The middle position is if you are undecided or have no feelings related to the terms on that line.

When you are done with all 8 items, also record your responses on the scantron $(B=1$, $\mathrm{C}=2, \mathrm{D}=3, \mathrm{E}=4, \mathrm{~F}=5, \mathrm{G}=6, \mathrm{H}=7$ ). Make sure to bubble in your name and $\mathrm{U}^{* *}$-ID.

\section{CALCULUS IS}

\begin{tabular}{|c|c|c|}
\hline easy & 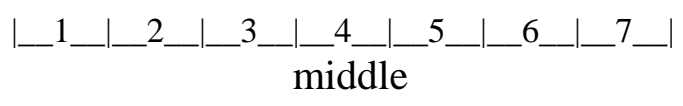 & Hard \\
\hline chaotic & 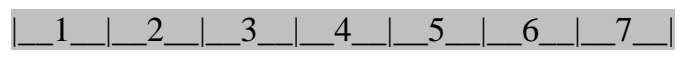 & organized \\
\hline confusing & 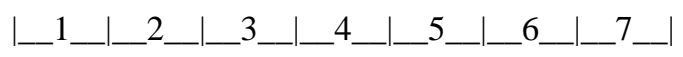 & Clear \\
\hline comfortable & |-1_|_2_|_3_|_4_|_5_|_6_|_7_| & uncomfortable \\
\hline satisfying & |_1_- & frustrating \\
\hline challenging & |-1_|_2_|_3_|_4_|_5_|_6_|_7_| & Not challenging \\
\hline pleasant & 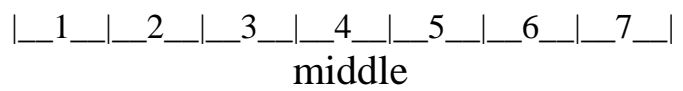 & unpleasant \\
\hline complicated & 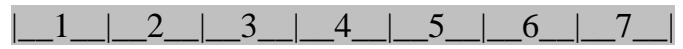 & simple \\
\hline
\end{tabular}

